University of Louisville ThinkIR: The University of Louisville's Institutional Repository

Electronic Theses and Dissertations

$5-2016$

\title{
The influence of nutrition education and self- efficacy on fruit and vegetable consumption for low-income women in rural west Kentucky.
}

Lewatis Darnell McNeal

University of Louisville

Follow this and additional works at: https://ir.library.louisville.edu/etd

Part of the Public Health Education and Promotion Commons

\section{Recommended Citation}

McNeal, Lewatis Darnell, "The influence of nutrition education and self-efficacy on fruit and vegetable consumption for low-income women in rural west Kentucky." (2016). Electronic Theses and Dissertations. Paper 2411.

https://doi.org/10.18297/etd/2411

This Doctoral Dissertation is brought to you for free and open access by ThinkIR: The University of Louisville's Institutional Repository. It has been accepted for inclusion in Electronic Theses and Dissertations by an authorized administrator of ThinkIR: The University of Louisville's Institutional Repository. This title appears here courtesy of the author, who has retained all other copyrights. For more information, please contact thinkir@louisville.edu. 
THE INFLUENCE OF NUTRITION EDUCATION AND SELF-EFFICACY ON FRUIT AND VEGETABLE CONSUMPTION FOR LOW-INCOME WOMEN IN RURAL WEST KENTUCKY

\author{
By \\ Lewatis Darnell McNeal \\ B.S. University of Arkansas at Pine Bluff, 2003 \\ M.P.H. Western Kentucky University, 2005

\begin{abstract}
A Dissertation
Submitted to the Faculty of the

School of Public Health and Information Sciences at the University of Louisville

In Partial Fulfillment of the Requirements

for the Degree of

Doctor of Philosophy in Public Health Sciences

University of Louisville

Louisville, Kentucky
\end{abstract} \\ Department of Health Promotion and Behavioral Sciences
}

May 2016 



\title{
THE INFLUENCE OF NUTRITION EDUCATION AND SELF-EFFICACY ON FRUIT AND VEGETABLE CONSUMPTION FOR LOW-INCOME WOMEN IN RURAL WEST KENTUCKY
}

\author{
By \\ Lewatis Darnell McNeal \\ B.S. University of Arkansas at Pine Bluff, 2003 \\ M.P.H. Western Kentucky University, 2005
}

Dissertation Approved on

March 18, 2016

by the following Dissertation Committee

Dissertation Chair: Muriel J. Harris, PhD

Richard Wilson, DHSc, MPH

Barbara Head, PhD

Shesh N. Rai, PhD 


\section{DEDICATION}

I dedicate this to my father, Odell McNeal, and my mother, Annie L. McNeal. Dad, thank you for the wisdom, discipline, knowledge, and leadership you provided in preparing me to be the leader and man I am today. I am proud to carry on your name and legacy of being a positive force within my family and my community. I love you and miss you. Mom, I miss you daily, your smile and words of encouragement continue to serve as my motivation. I've lived my life trying positive influence the lives of others as you so graciously modeled for us as children.

To my wife Kim, I thank you for being my rock and my support. I love you very much.

To my kids Raven and Kylan, I hope that I can provide you with the inspiration to be whatever you want to be and accomplish anything in this world that you seek out. I love you both!

To my brothers Ronald and Konrad, I owe you guys more than you ever know. Thank you for your love and support. To my other siblings, I appreciate all the love and support you have shown me throughout this journey.

To Chris and JoAnn Gwynn, I can't find the words to describe the significant impact you guys have made on my life. I thank you for believing in me, investing in me, and opening my eyes to endless possibilities. I love you both.

To my uncle Luther Moore, thanks for your guidance and your wisdom through the years. I appreciate the love and support you have given to me and my brothers from day one. 
To my other family and friends who have provided me words of encouragement and support through the years, I love you and thank you! 


\section{ACKNOWLEDGEMENTS}

First, I would like to acknowledge my dissertation chair Dr. Muriel Harris. Thank you for the mentorship, patience, and support you have given me during this process. I would also like to acknowledge my dissertation committee members, Dr. Richard Wilson, Dr. Barbara Head, and Dr. Shesh Rai. I would also like to thank my former academic advisor and mentor Dr. Thomas Nicholson. I would like to thank my supervisors, Dr. Gene Tice, Dr. Scott Williams, Dr. Jim Klauber, and Mr. Kevin Beardmore. I would also like to acknowledge two special advisors Dr. Joe Yazvac of Owensboro Community and Technical College and Mr. Robert Cobb of Western Kentucky University. To Debbie Fillman, Linda Hughes, and the entire Green River District Health Department, I thank you for your support. Thank you to the H. L. Neblett Community Center, Owensboro Community and Technical College, The Learning Villa, Girls Inc., and The Daniel Pitino Shelter. 


\begin{abstract}
THE INFLUENCE OF NUTRITION EDUCATION AND SELF-EFFICACY ON FRUIT AND VEGETABLE CONSUMPTION FOR LOW-INCOME WOMEN IN RURAL WEST KENTUCKY. Lewatis Darnell McNeal
\end{abstract}

March 18, 2016

Objective: To examine how participation in nutrition education programs, self-efficacy to consume fruit and vegetables and predictor of behavior to eat health foods (POB) influences the consumption of fruit and vegetables for low-income women in west Kentucky eligible or participating in federal supplemental nutrition assistance programs.

Methods: A comparative study was conducted between low-income women participating in Special Supplemental Nutrition Assistant Program for Women and Children (WIC) and those eligible for SNAP but were not participating. The study examined consumption in six categories of fruit and vegetables, self-efficacy to consume fruit and vegetables, predictor of behavior to eat healthy foods (POB).

Participants: Three hundred and twenty low-income women eligible for SNAP benefits participated in the study in two groups, WIC participants $(n=160)$ and non-WIC $(n=160)$.

Dependent Variables: Dependent Variable: Fruit and Vegetable Consumption (fruit juice, fruit, dark green vegetables, beans, orange vegetables, and other vegetables). 
Independent Variables: Self-Efficacy to consume fruit and vegetables, Predictor of Behavior (POB) and Nutrition Education.

Analysis: Correlational analyses determined the relationship between variables. Independent sample t-tests examined differences between WIC and Non-WIC groups in six categories of fruit and vegetable consumption, Predictor of Behavior, and selfefficacy to consume fruit and vegetables.

Results: Bivariate correlations indicated a positive relationship between self-efficacy to consume fruit and vegetables with each of the six consumption categories for fruit and vegetables (fruit juice, fruit, dark green vegetables, beans, orange colored vegetables and other vegetables). Although all of the correlations were positive (fruit juice $p=.0003$, fruit, $p=.0001$, beans, $p=.0047$, dark green vegetables, $p=.0007$, orange vegetables, $\mathrm{p}=.0001$, and other vegetables, $\mathrm{p}=.0001)$, none were strong correlations. Predictor of behavior to eat healthy foods (POB) also had significant correlations in five of the six consumption categories (fruit juice, $p=.0003$, fruit, $p=.0001$, dark green vegetables, $\mathrm{p}=.032$, orange vegetables, $\mathrm{p}=.0001$, and other vegetables, $\mathrm{p}=.0001$ ), but these positive correlations were weak to moderate. Total nutrition education participation which measured participation in one or more nutrition education programs (WIC, SNAP-Ed, EFNEP, or other nutrition education) produced only one positive significant correlation with fruit juice $(p=.006)$.

T-tests on differences in fruit and vegetable consumption between WIC participants and non-WIC participants indicated only two of the six consumption categories reported significant differences (fruit juice, $p=.0008$ and fruit, $p=.0001$ ). 
Additional t-tests reported differences in mean scores to consume fruit and vegetables in difficult situations between WIC and non-WIC groups in POB to eat healthy foods $(p=.0005)$ and self-efficacy $(p=.001)$.

\section{Conclusions and Implications:}

Participation in the WIC program is associated with higher consumption amounts of fruit juice and fruit. This conclusion could be attributed to the nutrition education that participants receive from participating in the program. This conclusion could also be attributed to the assistance received, which includes vouchers used to purchase fruit juice, fruit, and vegetables. Additional research should focus on usage of vouchers related to fruit and vegetable consumption. Future research of nutrition education within the WIC program could provide a better understanding of the relationship between fruit and vegetable consumption and nutrition education by the WIC program. Self-efficacy to consume fruit and vegetables in difficult situations proved to be more likely for individuals who participated in WIC. These results could impact future implications with interventions aimed at improving fruit and vegetable consumption for low-income populations, by developing nutrition education interventions aimed at improving selfefficacy to consume fruit and vegetables in difficult situations. Predictor of Behavior toward attitudes and beliefs about eating healthy proved to be significantly different with WIC participants. WIC participants were more likely to have positive attitudes and beliefs toward eating healthy foods. Future research on the WIC program should further examine the components of WIC Nutrition education and specific WIC services and the influence of those services on actual consumption. This study's results suggest that participating in the WIC program is associated with higher consumption amounts of fruit 
juice and fruit, a higher self-efficacy to consume in difficult situations and stronger beliefs and attitudes toward eating healthy foods. 


\section{TABLE OF CONTENTS}

DEDICATION

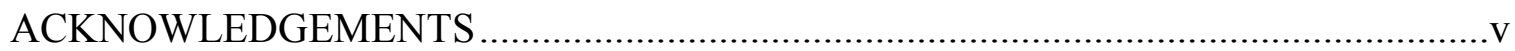

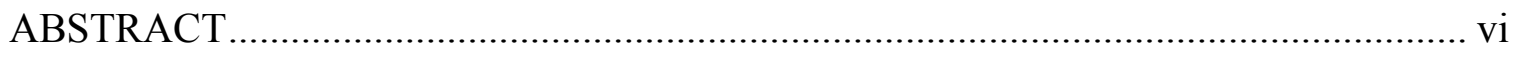

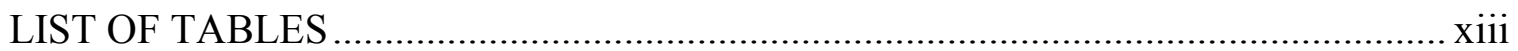

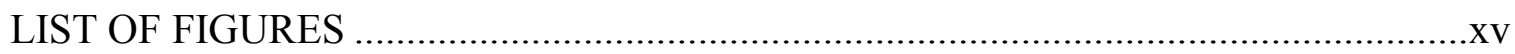

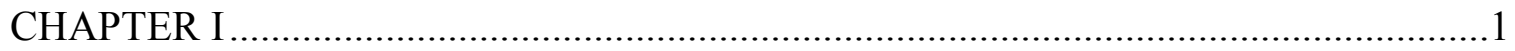

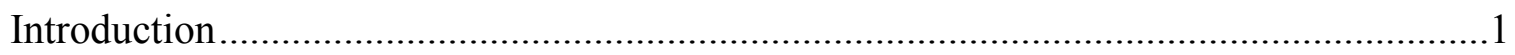

The Problem of Obesity ........................................................................................... 1

Low-Income Households and Consumption .............................................................. 2

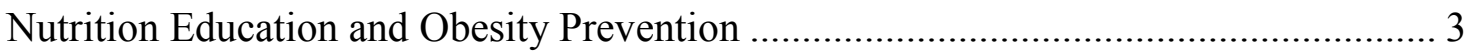

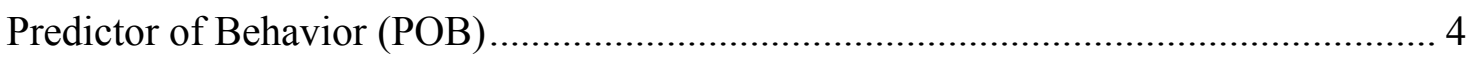

Self-efficacy to Consume Fruit and Vegetables............................................................ 4

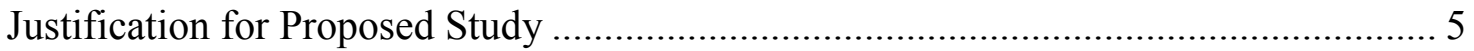

Research Hypotheses........................................................................................... 7

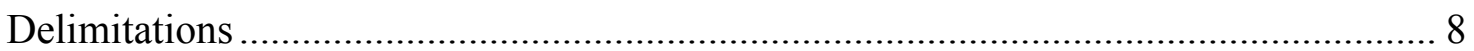

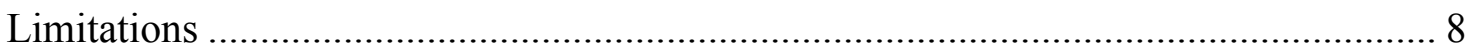

CONCEPTUAL MODEL FOR FRUIT AND VEGETABLE CONSUMPTION........ 11

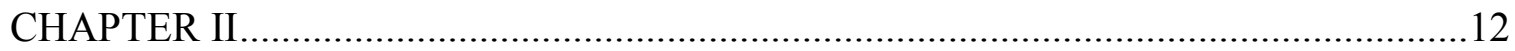

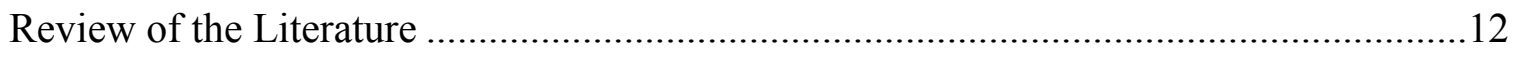

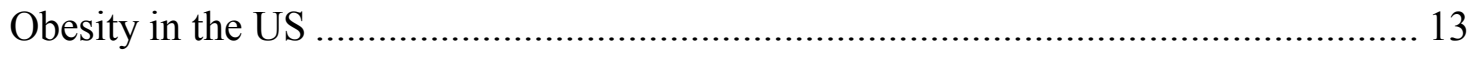

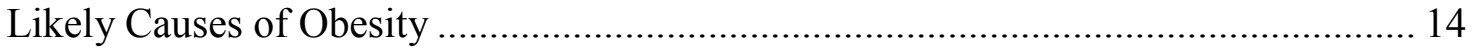




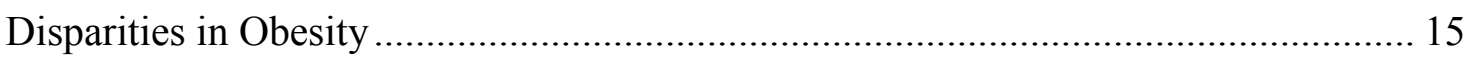

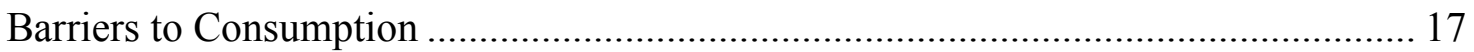

Efforts to Reduce Obesity ………….................................................................... 19

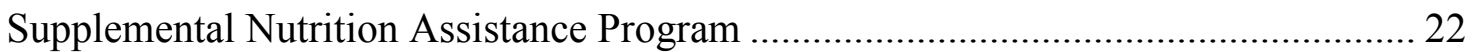

The Special Supplemental Nutrition Program for Women Infant and Children........... 22

Supplemental Nutrition Education Program- Educational (SNAP-Ed) ......................... 24

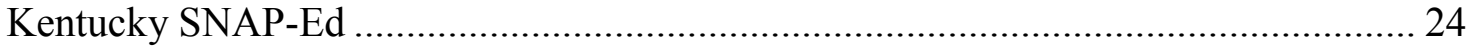

Expanded Food and Nutrition Education Program (EFNEP) ........................................ 26

(WIC) Nutrition Education Program .................................................................. 28

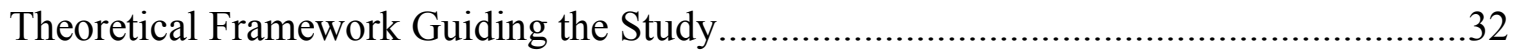

The Health Belief Model........................................................................................ 32

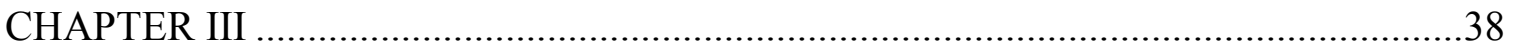

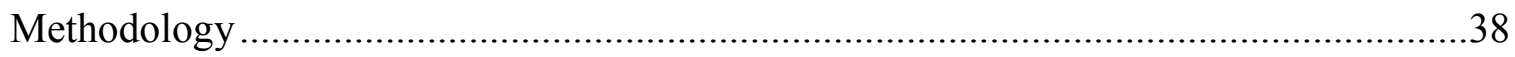

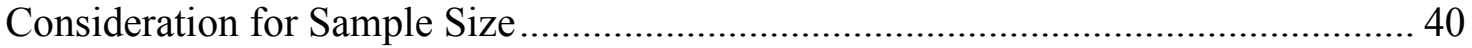

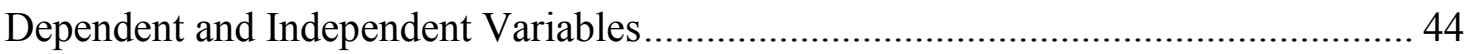

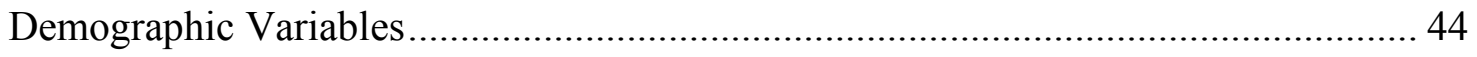

Self-Efficacy to Consume Fruit and Vegetables Measure ............................................... 44

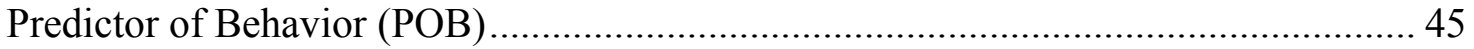

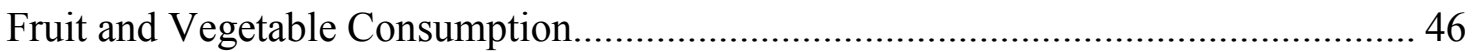

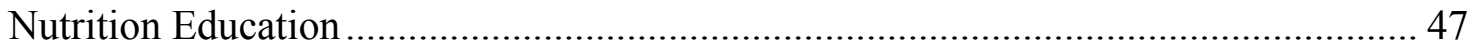




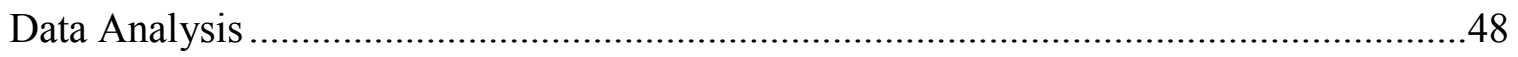

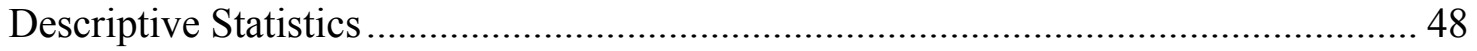

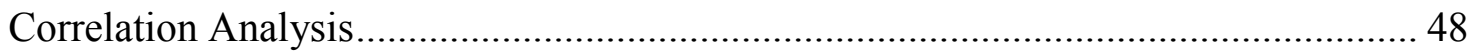

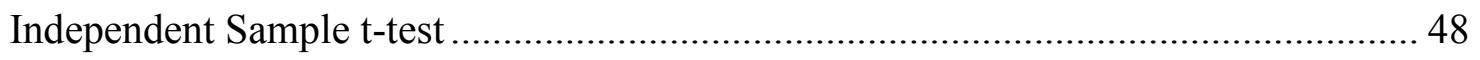

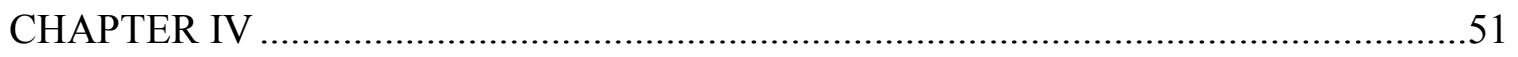

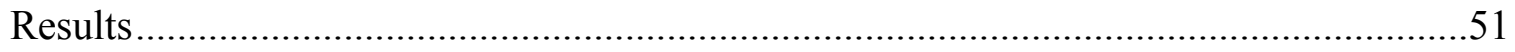

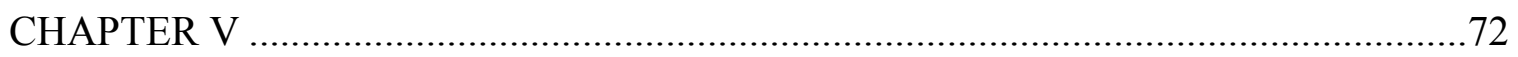

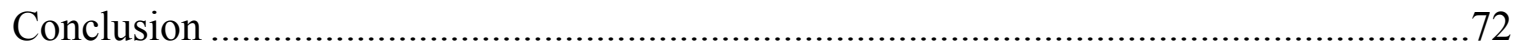

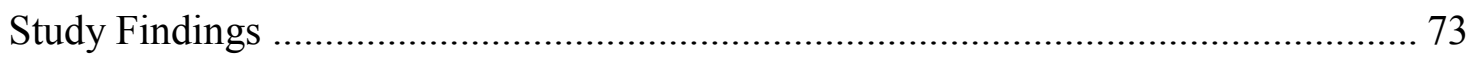

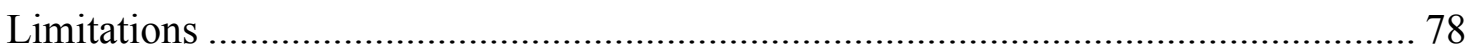

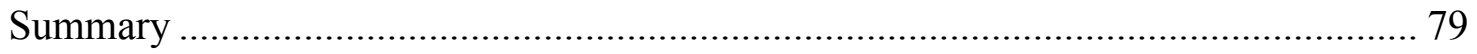

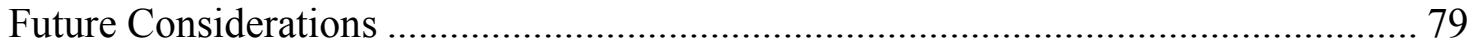

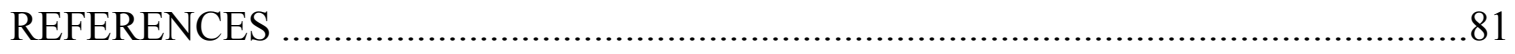

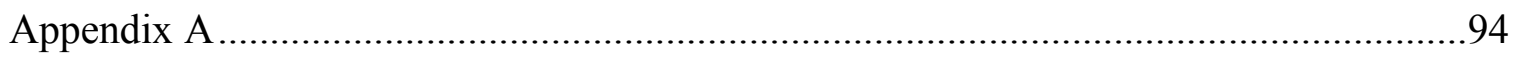

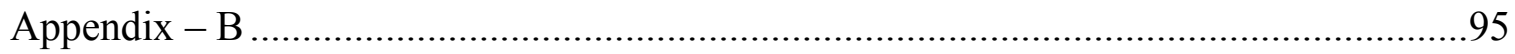

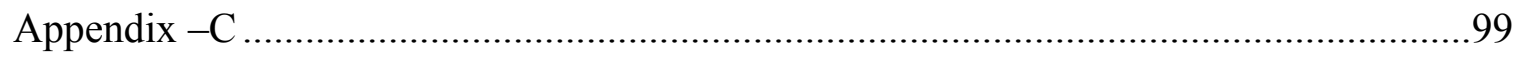

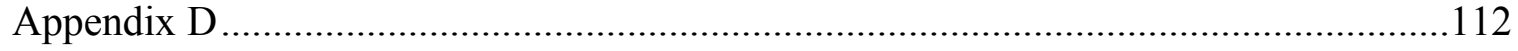

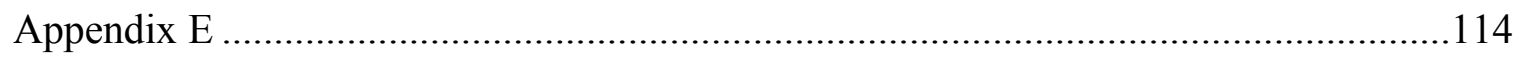

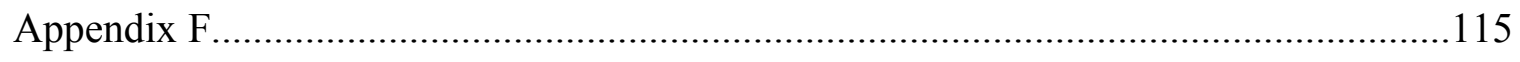

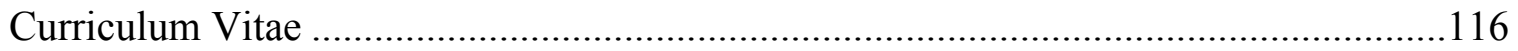




\section{LIST OF TABLES}

TABLE

PAGE

1. Federal Nutrition Assistance Programs under FNS ........................................ 21

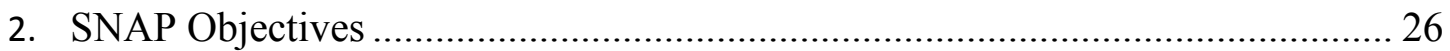

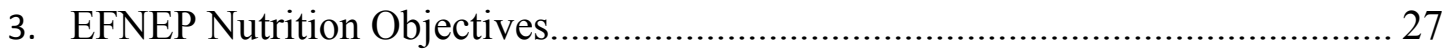

4. Objectives for WIC Education Intervention ................................................. 29

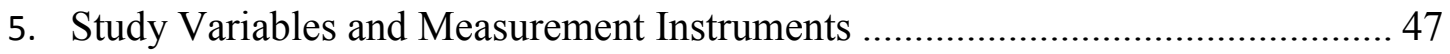

6. Age, Race, Household Size and Children in Household Characteristics for Study

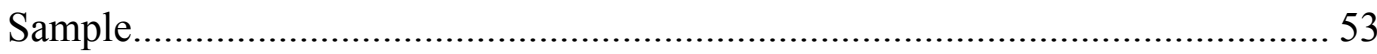

7. Income, Relationship Status and Employment Status Characteristics for Study

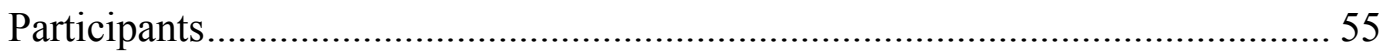

8. Participation in Federal Nutrition Education by Program ................................ 56

9. Average Weekly Consumption of Fruit and Vegetables for Study Sample ......... 57

10. Variables for Predictor of Behavior Score (POB) ......................................... 58

11. Self-Efficacy to Consume Fruit and Vegetables for Study Population ................. 60

12. Characteristics of Fruit and Vegetable Consumption (WIC vs Non-WIC) .......... 62

13. Bivariate Correlation Results for POB, Self-efficacy and Education with Fruit and

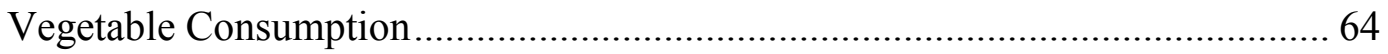


14. Summary of T-Tests Analyzing Fruit and Vegetable Consumption between WIC

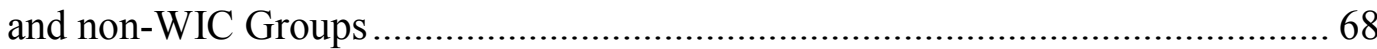

15. T-Tests Analyzing Self-Efficacy to Consume Fruit and Vegetables between WIC

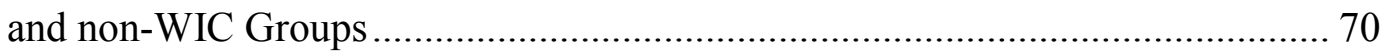

16. T-Test Analyzing the Predictor of Behavior to Eat Healthy Foods (POB) between

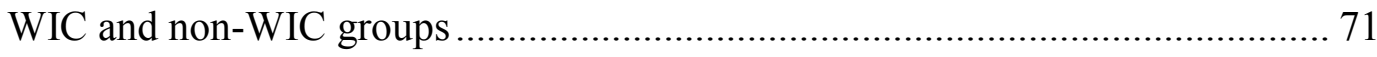




\section{LIST OF FIGURES}

FIGURE

PAGE

1. Conceptual Model for Fruit and Vegetable Consumption ................................. 11

2. Conceptual Model for Selecting Population Sample .......................................... 43 


\section{CHAPTER I}

\section{INTRODUCTION}

\section{The Problem of Obesity}

Almost two thirds of the United States adult population is considered overweight or obese. In 2009-10, 36\% of adults in the United States were overweight or obese (Ogden, Carroll, Kit, \& Flegal, 2012). Obesity increases one's risk of experiencing adverse health conditions such as diabetes, cardiovascular disease, and stroke (CDC, 2012a; NCHS, 2010) and disproportionately affects low-income women, racial and ethnic minorities, and rural populations (CDC, 2012b; Patterson, Moore, Probst, \& Shinogle, 2004). Kentucky has consistently ranked high in poor outcome indicators regarding obesity. In 2012, according to a report from the Center for Disease Control's Behavioral Risk Surveillance System, the obesity prevalence was 31.3\% in Kentucky Commonwealth (CDC, 2012a). In a report by the Kentucky Institute of Medicine (KIOM), Daviess County, Kentucky, reported that 23\% were obese (Medicine, 2007).

Although Daviess County, Kentucky, ranked $8^{\text {th }}$ in the state in a comparative assessment of health risk, data from the KIOM report on health outcome indicators for cancer deaths, prevalence of diabetes, and cardiovascular disease deaths in Daviess County all show rates above the national average (Medicine, 2007). 


\section{Low-Income Households and Consumption}

Dietary behavior is a critical component of obesity management and prevention. The Dietary Guidelines for Americans recommend increasing fruit and vegetable consumption by filling half the plate with fruit and vegetables while consuming fewer foods that are high in sodium, saturated fat, trans fat, sugar, and refined grains (USDA, 2010a). Low-income households maintain a higher risk of obesity and are more likely to have suboptimal diets due to the lack of availability or accessibility to healthy foods (Lucan, Barg, \& Long, 2010; Nord, Coleman-Jensen, Andrews, \& Carlson, 2010).

Due to this lack of availability of food and the consumption of an inadequate diet, low-income households are more likely to be obese (Dubois, Farmer, Girard, \& Porcherie, 2006; Lorson, Melgar-Quinonez, \& Taylor, 2009). Households in poverty are less likely to purchase and consume fruits and vegetables compared to households with higher incomes (Do et al., 2008; Greene et al., 2004; Webber, 2009). An analysis of food consumption in low-income U.S. households revealed that households consuming fewer fruit and vegetables have suboptimal nutritional intake and higher risks of poor nutritional practices and diet- related diseases compared to high-income households (Larson, Perry, Story, \& Neumark-Sztainer, 2006; McLaughlin, Tarasuk, \& Kreiger, 2003). In addition, the dietary portfolios of many low-income families consistently fall short of recommended daily intake or dietary guidelines (King, Kavanagh, Jolley, Turrell, \& Crawford, 2006). Efforts to promote fruit and vegetable consumption consist of public health programs that enhance nutrition education, promote healthy dietary practices, promote physical activity, and reduce rates of obesity among individuals with an increased risk of being overweight or obese. 


\section{Nutrition Education and Obesity Prevention}

Many education programs seek to reduce obesity, improve dietary habits, and promote a healthier lifestyle. Increasing knowledge through nutrition education has been linked to reducing obesity and improving fruit and vegetable consumption (Dollahite, 2003; Shankar et al., 2007). Nutrition education programs funded by the United States federal government play an important role in these intervention efforts. Many of the federally funded programs promote increasing intake of fruit and vegetables and reducing the amount of sugars and fats consumed by providing information and teaching skill building activities that promote adopting healthier behaviors. Low-income individuals who are eligible to receive federally funded nutrition assistance programs such as the Supplemental Nutrition Assistance Program (SNAP) are also eligible to participate in complementary nutrition education programs that aim to improve an individual's nutrition-related health status. Several nutrition education programs have been implemented to help to reduce or prevent increasing rates of obesity, particularly those programs developed for participants of supplemental nutrition assistance programs. Participants of the SNAP program may participate in nutrition education programs or services, but participation in these programs is voluntary. Other nutrition education programs like the Special Supplemental Nutrition Assistance Program for Women, Infants, and Children (WIC) provides nutrition education to program participants during the time they receive services. This study compares recipients of WIC services who access nutrition education services to other low-income individuals who may or may not participate in other federal nutrition education programs such as Expanded Food 
Nutrition Education program (EFNEP) and the Supplemental Nutrition Assistance Program Education programs (SNAP-ED).

\section{Predictor of Behavior (POB)}

The predictor of behavior to eat healthy foods is a variable created from constructs of the health belief model. This study adapts the constructs from that model to form the "predictor to eat healthy foods variable" (POB) from a previous study that assessed how nutritional beliefs influenced health behavioral intention for college students, using components of the health belief model (Kim, Ahn, \& No, 2012). In this study, the "Predictor to Eat Healthy Foods "(POB) is assessed for low-income women participating in the federal nutrition education program WIC compared to those who were not participants in the WIC program.

\section{Self-efficacy to Consume Fruit and Vegetables}

In an effort to reduce the mortality rates related to poor health outcomes and poor dietary habits, more attention has been placed on improving the consumption of fruits and vegetables (Bazzano et al., 2002; He, Nowson, Lucas, \& MacGregor, 2007; Hung et al., 2004). Self-efficacy has been strongly associated with the increased intake of fruit and vegetables for adults (AbuSabha \& Achterberg, 1997; Brug, Lechner, \& De Vries, 1995). For this study, self-efficacy is measured as one's own belief in his/her ability to consume fruit and vegetables in difficult situations. Additionally, this study is examining selfefficacy between WIC and Non-WIC participants, using a self-efficacy scale (Mainvil, Lawson, Horwath, McKenzie, \& Reeder, 2009), with consumption of fruit and vegetables as the outcome. 


\section{Purpose Statement}

This study has two purposes. The first purpose is to examine whether relationships exist between (1) participating in nutrition education programs, (2) selfefficacy to consume fruit and vegetables, (3) the predictor of behavior to eat healthy foods (POB), and the consumption of fruit and vegetables.

Second, this study seeks to assess how (1) the consumption of fruit and vegetables, (2) the self-efficacy mean to consume fruit and vegetables in difficult situations, and (3) the predictor of behavior to eat healthy foods (POB) differ based on participation in the WIC program.

Results from this study seek to provide insight to whether nutrition education participation is associated with higher fruit and vegetable consumption for low-income individuals. Additionally, this study seeks to explore how self-efficacy to consume fruit and vegetables in difficult situations and whether having a predictor of behavior to eat healthy foods influence fruit and vegetable consumption based on participating in the WIC program.

\section{Justification for Proposed Study}

Millions of dollars and other resources are spent on nutrition education programs for low-income households eligible to participate in the federal nutrition assistance programs. Goals outlined in Healthy People 2020 point to efforts addressing the problem of obesity through improving nutrition and dietary status.

The nutrition and weight status objectives of the Healthy People 2020 identify nutrient consumption as a key area to promote health and reduce chronic disease such as obesity (DHHS, 2012). The Healthy People 2020 objective for improving food nutrient 
content and consumption seeks to reduce saturated fats and sodium intake while increasing the consumption of whole grains, fruits, and vegetables (DHHS, 2013). These nutrition education programs are provided to improve the dietary habits of lowincome individuals participating in the supplemental nutrition assistance programs. Individuals with low socioeconomic status and lower educational attainment are more likely to experience low fruit and vegetable intake because of their limited access to food, low-income level, and low level of self-efficacy (Guillaumie, Godin, \& Vezina-Im, 2010; Landers, 2007; Webber, 2009). In addition, studies examining obesity have shown a strong association between improved dietary habits and reducing obesity (Jackson, Doescher, Jerant, \& Hart, 2005; Jilcott, Keyserling, Crawford, McGuirt, \& Ammerman, 2011; Paeratakul, Lovejoy, Ryan, \& Bray, 2002).

Studies have shown nutrition education programs improve dietary consumption (Campbell et al., 1994; Dickin, 2005; Dollahite, 2003; Landers, 2007). The proposed study looks specifically at the Special Supplemental Nutrition Assistance Program for Women and Children (WIC). Many of the federal nutrition assistance programs provide optional nutrition education for program participants. With nutrition education being optional, program participants may or may not receive nutrition education. The WIC program, however, provides nutrition education to program participants while they receive WIC services. Additionally, the research literature identifies constructs of the health belief model as important factors in influencing the consumption of fruits and vegetables (Guillaumie et al., 2010; Kim et al., 2012; Maclellan, Gottschall-Pass, \& Larsen, 2004). The predictor of behavior to eat healthy foods (POB) uses the constructs from the Health Belief Model to examine whether significant differences exist among 
participants. Previous studies using Health Belief Model constructs to examine fruit and vegetable consumption indicated the importance of self-efficacy, social support, positive attitudes and beliefs toward consumption as important factors in improving fruit and vegetable consumption (Brug et al., 1995; Cullen et al., 2010; Havas, Treiman, et al., 1998; Krebs-Smith et al., 1995). Figure 1 in Chapter One illustrates a conceptual model that hypothesizes the influence of the variables federal nutrition education programs, selfefficacy and predictor of behavior (POB) on fruit and vegetable consumption.

\section{Research Hypotheses}

\section{Null Hypotheses:}

$\mathrm{H}_{0}$ : There is no relationship between the predictor variables total education, SelfEfficacy to consume fruit and vegetables, and POB and fruit and vegetable consumption for study participants.

$\mathrm{H} 2_{0}$ : There is no difference in the consumption of fruit and vegetables between the WIC and non-WIC groups.

$\mathrm{H} 3_{0}$ : There is no difference in the Self-Efficacy to consume fruit and vegetables between the WIC and non-WIC groups.

$\mathrm{H}_{4}$ : There is no difference in POB between the WIC and non-WIC groups. 


\section{Alternative Hypotheses:}

$\mathrm{H} 1_{1}$ : There is a relationship between the predictor variables total education, Self-Efficacy to consume fruit and vegetables, and POB and fruit and vegetable consumption for study participants.

$\mathrm{H} 2{ }_{1}$ : There is a difference in the consumption of fruit and vegetables between the WIC and non-WIC groups.

$\mathrm{H} 3_{1}$ : There is a difference in the Self-Efficacy to consume fruit and vegetables between the WIC and non-WIC groups.

$\mathrm{H} 4_{1}$ : There is a difference in POB between the WIC and non-WIC groups.

\section{Delimitations}

Delimitations for the proposed study include geographical residence to Daviess County, Kentucky, individuals eligible for the Supplemental Nutrition Assistance Program (SNAP) and the Special Supplemental Nutrition Program for Women, Infants, and Children (WIC) within the last six months.

\section{Limitations}

This cross-sectional study only captures a snapshot of the participant's dietary behavior and fruit and vegetable consumption, unlike a dietary food log which more accurately accounts for the level of consumption. In measuring POB, the instrument is

designed to assess beliefs toward behavioral intention to consume healthy foods, which include fruits and vegetables but is not exclusively limited to fruit and vegetables. Since 
conceptually healthy foods may encompass other foods in addition to fruits and vegetables, an error in the measurements may have affected study results.

\section{Summary}

Many of the federally funded nutrition education programs do not require participation of individuals receiving supplemental nutrition assistance. The WIC program is different; program participants receive nutrition education as part of the services. Although a number of studies evaluated the short-term outcomes of respective programs on fruit and vegetable consumption, few studies compare the effect of required and voluntary federal nutrition education programs on fruit and vegetable consumption. This study examines the relationship between participation in the federal nutrition education program WIC and fruit and vegetable consumption for low-income women. Additionally, the study examines whether a difference exists in the average consumption rate of fruit and vegetables for individuals participating in nutrition education programs compared to non-participants. Using the Predictor of Behavior, this study compares beliefs about behavioral intent to eat healthy foods between participants of nutrition education programs and non-participants. Perceived Self-Efficacy has been identified as a strong predictor of fruit and vegetable consumption for adults. This study takes a closer look at how self-efficacy to consume fruit and vegetables in difficult situations differs for low-income women, based on their participation in federal nutrition education program WIC. 
In this chapter, discussions on the scope of the problem with obesity, the purpose of the study and hypothesis for the study were presented. The next chapter presents an in depth view of fruit and vegetable consumption in low-income households, federal nutrition assistance programs, federal nutrition education programs, and self-efficacy and fruit and vegetable consumption. 


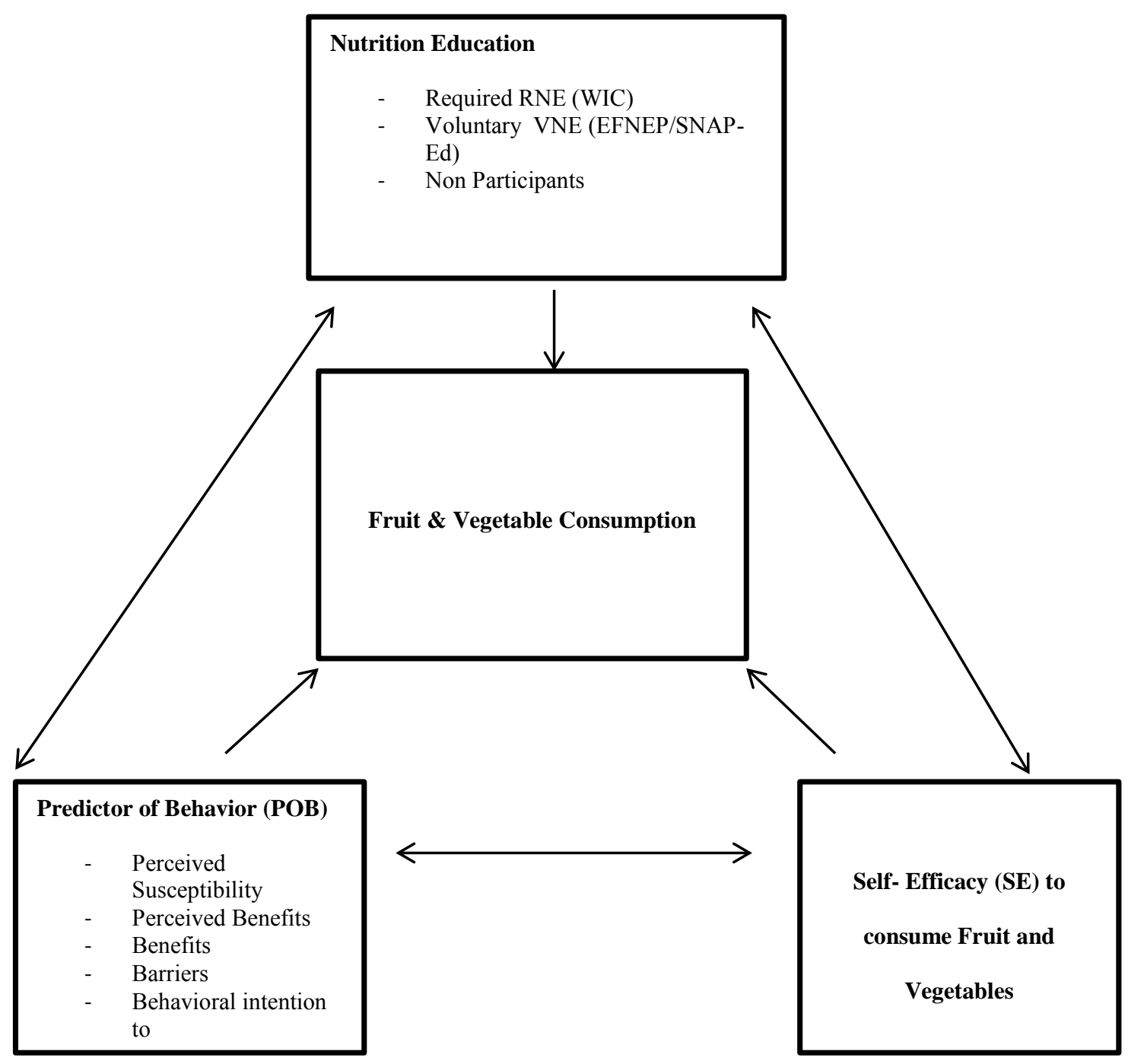

Figure 1: Conceptual Model for Fruit and Vegetable Consumption 


\section{CHAPTER II}

\section{REVIEW OF THE LITERATURE}

\section{Introduction}

The review of literature for this study begins with an introduction to the problem of obesity and factors that increase the risk of obesity for low-income populations. Next, the literature review provides an overview of fruit and vegetable consumption in lowincome populations and the psychosocial and socioeconomic factors that affect consumption. The review also looks at the federal nutrition assistance programs and their nutrition education component. Next, the review examines the federal nutrition education programs' relationship with fruit and vegetable consumption. Additionally, the literature review examines the relationship between self-efficacy and fruit and vegetable consumption. Lastly, it examines the theoretical application of the Health Belief Model in studies related to fruit and vegetable consumption for rural low-income participants. 


\title{
The Problem of Obesity
}

\author{
Obesity in the US
}

The prevalence of obesity has increased throughout the world, particularly in the United States, where current obesity trends estimate $41.8 \%$ of Americans will become obese by the year 2020 (Ruhm \& Walsh, 2007). A person considered to be overweight has a Body Mass Index ${ }^{1}(\mathrm{BMI})$ between $25.0-29.9 \mathrm{~kg} / \mathrm{m}^{2}$, and a person considered to be obese has a BMI greater than $30.0 \mathrm{~kg} / \mathrm{m}^{2}$ (CDC, 2015a). According to a report by the Economic Research Service of the United States Department of Agriculture (USDA), over a 15 year period (1985-2000) the U.S. population experienced a large increase in the average caloric intake with no increase in physical activity. The inability of individuals to increase the expenditure of calories at the same rate of their caloric intake has played a major role in the growth of obesity rates (Putnam, 2002). Kentucky remains one of several Southern states grappling with a high percentage of citizens living with obesity (CDC, 2015b).

\section{Obesity in Kentucky}

Increasing rates of obesity have placed Kentucky among a group of states with high rates of health issues such as diabetes, cardiovascular disease and stroke (CDC, 2015b). According to a 2012 report on obesity in Kentucky, $66.2 \%$ of Kentuckians were overweight with a Body Mass Index of $25 \mathrm{~kg} / \mathrm{m}^{2}$ or greater, $31.3 \%$ who reported a Body

\footnotetext{
${ }^{1}$ Body Mass Index (BMI) is defined by Center for Disease Control and Prevention as a calculated reliable indicator of body fatness and use to screen into weight categories that may lead to health problems.
} 
Mass Index of $30 \mathrm{~kg} / \mathrm{m}^{2}$ or greater (Division of Nutrition, 2012). Kentucky remains part of a cluster of states with an obesity prevalence rate higher than $30 \%$, with little evidence of slowing the trend in the short-term. Poor dietary habits as well as low physical activity levels both contribute to the increased percentage of overweight and obese adults. Dietary behavior assessment for adults in Kentucky revealed only $24 \%$ of adults reported eating the recommended servings of two or more fruit each day, with only $29 \%$ of Kentucky adults reporting eating the recommended three or more vegetable servings a day (Division of Nutrition, 2012).

\section{Likely Causes of Obesity}

Poor dietary habits and lack of physical activity are major contributors to increased rates of obesity. Several factors such as increased consumption of energydense foods, increased consumption of sugars, fats and fast food, as well as the lack of physical activity, have been linked to the obesity epidemic (Binkley \& Golub, 2007; Drewnowski \& Specter, 2004; Harnack, Stang, \& Story, 1999; Kant, 2000; Wardle, Waller, \& Jarvis, 2002; Zizza, Siega-Riz, \& Popkin, 2001).

Increased consumption of fast food, and large portion sizes of food away from home are all seen as factors that influence dietary behavior along with lack of opportunities for increased physical activity (Binkley \& Golub, 2007; French, Story, \& Jeffery, 2001; Harnack et al., 1999). Examination of physical activity habits for Kentucky adults revealed $41 \%$ achieved at least 300 minutes of moderate-intense physical activity a week, with $29 \%$ of Kentucky adults reporting no physical activity within the past month (Division of Nutrition, 2012). 
Other studies focusing on obesity showed a strong association between lowincome households and being overweight (Drewnowski \& Specter, 2004; Grutzmacher \& Gross, 2011; Kropf, Holben, Holcomb, \& Anderson, 2007; Oberholser \& Tuttle, 2004). Additionally, low-income individuals often experience suboptimal nutritional intake and higher risk of poor nutritional practices (Larson et al., 2006; McLaughlin et al., 2003). Non elderly adults and children who experienced problems with food availability were more likely to be overweight and obese compared to their counterparts living in food secure households (Dinour, Bergen, \& Yeh, 2007). The rates of obesity are disproportionately higher for some groups than others. This troubling pattern of disparities in obesity specifically affects certain disadvantaged groups.

\section{Disparities in Obesity}

Obesity rates are disproportionately higher among certain ethnic minority groups. Some minorities groups tend to have a higher prevalence of being overweight or obese compared to their white counterparts (Dharod, Drewette-Card, \& Crawford, 2011; Drewnowski \& Specter, 2004; Flegal, Carroll, Kit, \& Ogden, 2012; Flegal, Carroll, Ogden, \& Curtin, 2010; Paeratakul et al., 2002). According to the data from the Centers for Disease Control and Prevention, the white non-Hispanic population reported the lowest percentage (34\%) of obesity, for adults ages 20 years and over (age adjusted) in 2009-10 whereas the adult black non-Hispanic and Hispanic populations had rates of 49\% and 39\% (age adjusted), respectively (CDC, 2012b).

Data trends across the United States also reveal an increased risk of obesity in rural areas compared to urban areas. Adults living in rural areas reported higher levels of obesity than adults living in urban areas (Jackson et al., 2005; Patterson et al., 2004). 
Additionally, minorities who live in rural areas reported a higher prevalence of obesity compared to minorities in urban areas (Patterson et al., 2004). Between the periods of 1994-96 and 2000-01, Kentucky ranked among the states with the highest percentage of rural obesity and was identified as one of nine states that reported the highest percentage increase of obesity (Jackson et al., 2005). Given the high rates of obesity, nutrition education programs to modify dietary habits have been among the strategies used to reduce obesity.

\section{Factors that Influence Fruit and Vegetable Consumption}

A high dietary consumption of fruit and vegetables is associated with a reduced risk of obesity and other chronic diseases (Do et al., 2008; Erinosho, 2012). Consuming fruits and vegetables as a regular part of one's dietary intake is essential in protecting against diseases such as obesity, cardiovascular disease, diabetes, and cancer (USDA, 2010a, 2011b). The USDA's “Choose My Plate" recommends a larger intake of fruits and vegetables compared to its outdated predecessor, the food guide pyramid (USDA, 2010a). The latest dietary guidelines recommend 2-3 servings of fruit and 3-5 servings of vegetables daily (USDA, 2010b). Levels of fruit and vegetable consumption in the United States have generally fallen below suggested recommendations. Only $40 \%$ of Americans consumed more than five half-cup servings of fruits and vegetables per day (Guenther, Dodd, Reedy, \& Krebs-Smith, 2006). Americans who live in poverty are more likely to consume even less of the recommended amounts of fruit and vegetables (Havas et al., 2003; Havas, Treiman, et al., 1998; Maclellan et al., 2004; USDA, 2011a). 


\section{Barriers to Consumption}

For low-income households, addressing the problems associated with fruit and vegetable consumption is imperative. Environmental barriers to fruit and vegetable consumption were among the key factors influencing when individuals shopped and what they purchased (Lucan et al., 2010; Wiig \& Smith, 2009; Yeh et al., 2008).

Socioeconomic status, limited nutrition knowledge, shopping practices, food cost, selfefficacy and environmental factors are identified as significant barriers to fruit and vegetable consumption. These barriers also influence the consumption of fruit and vegetables for rural low-income individuals (Havas, Treiman, et al., 1998; Hersey et al., 2001; Maclellan et al., 2004).

Socio-economic status has been linked to dietary behavior in low-income households, and these households tend to have higher rates of obesity and lower ability to secure healthy foods compared to higher earning households. Low-income households consume less grains, poultry, fish, and lean meat compared to individuals from higher income households (Stewart, Hyman, Frazao, Buzby, Carlson, 2011; Tarasuk, McIntyre, \& Li, 2007). An analysis of Thrifty Food Plan, a cost analysis designed to determine minimal cost to prepare a nutritious meal found that low-income households in the United States allocated fewer monetary resources to healthy food choices than other households and spend the least amount of resources on the fruit and vegetable food group (Stewart \& Blisard, 2006).

Limited nutrition education is also a barrier to fruit and vegetable consumption. Recent studies indicate that individuals who increase their level of knowledge in nutrition education are more likely to purchase healthy food options, including fruits and 
vegetables (Blitstein, 2006; Herman, Harrison, Afifi, \& Jenks, 2008; Wiig \& Smith, 2009). Increasing knowledge in nutrition has been associated with increases in fruit and vegetable consumption and improved overall dietary behavior (Ball, Crawford, \& Mishra, 2006; Guillaumie et al., 2010; Maclellan et al., 2004; L. Williams, Ball, \& Crawford, 2010).

Food availability influences purchasing of fruit and vegetables for low income individuals (Hersey et al., 2001; Turrell, Hewitt, Patterson, \& Oldenburg, 2003). The lack of availability of healthy food choices has been linked to the consumption of foods that contribute to obesity (Lucan et al., 2010; Moore, Diez Roux, Nettleton, Jacobs, \& Franco, 2009; Powell, 2010). Evidence from other studies also suggests food availability directly influences purchasing for low-income individuals, many times impacting the quality of food purchased (Lucan et al., 2010; Wiig \& Smith, 2009).

Regarding fruit and vegetable consumption outside the home, perceived availability was positively correlated with greater self-efficacy for fruit and vegetable consumption (Erinosho, 2012). An additional factor influencing purchasing is cost. Studies analyzing barriers to fruit and vegetable consumption among low-income individuals identify cost as a common barrier associated with low fruit and vegetable consumption across ethnicities, with high cost of fruit and vegetables being identified as the most prevalent concern for low income participants among all ethnicities in the study (Lucan et al., 2010; Maclellan et al., 2004; Peterson et al., 2002).

Poor shopping practices for low-income populations have been linked to their low level of formal education, knowledge of nutrition education, and availability of full service grocery stores (Hersey et al., 2001; Lucan et al., 2010; Wiig \& Smith, 2009). 
Individuals with less motivation and fewer skills to prepare healthy foods are less likely to adopt healthy behaviors in unsupportive environments (Brug, Kremers, Lenthe, Ball, \& Crawford, 2008; Dubowitz et al., 2008; Williams, Thornton, \& Crawford, 2012). Wiig and Smith (2009) found that many low-income families considered meat the most important purchase, allocating almost $50 \%$ of their food budget to meat purchases (Wiig \& Smith, 2009) leaving little in the family budget for fruits and vegetables. Additionally, household shopping practices are strongly associated with the quality of foods selected (Havas, Treiman, et al., 1998; Hersey et al., 2001; Lucan et al., 2010). Many low-income women have to prioritize their food choices based on what they perceive as most important for their families (Drewnowski \& Specter, 2004).

Physical environments either promote or impede healthy behaviors based on the access and the ability to increase fruit and vegetable intake. Additionally, the socioeconomic status of communities has been associated with fruit and vegetable consumption (Dubowitz et al., 2008; Inglis, Ball, \& Crawford, 2008). Other studies argue that social environmental determinants such as availability and affordability are just as important if not more so to improving consumption of fruit and vegetables (Inglis et al., 2008; Williams et al., 2010). Intervention efforts to reduce obesity through nutrition education programs must better understand factors that influence behavior and provide a foundation for developing interventions.

\section{Efforts to Reduce Obesity}

Low-income individuals struggle with maintaining an adequate consumption of fruit and vegetables as recommended by dietary guidelines (USDA, 2010a). Nutrition education programs for low-income individuals have focused on increasing knowledge, 
skills, and resources that improve dietary habits (Guthrie, Stommes, \& Voichick, 2006; Havens, Martin, Yan, Dauser-Forrest, \& Ferris, 2012; Peterson et al., 2002). Changes to dietary habits include increasing fruit, vegetables, and whole grains and reducing sugar and saturated fat intake generally associated with less healthy foods (Guillaumie et al., 2010; Havas, Treiman, et al., 1998; USDA, 2010a, 2010b). Food resource management is another strategy used to reduce obesity. Food resource management teaches program participants to maximize resources and make healthy choices in food purchasing. Federal nutrition programs have been developed to provide nutrition assistance as well as nutrition education to low-income individuals to assist with improving dietary habits and reducing obesity.

\section{Overview of Federal Nutrition Programs}

The Food and Nutrition Service (FNS), a division of the United States Department of Agriculture (USDA) is responsible for overseeing all government nutrition assistance programs that provide foods supplements to individuals and families who are at risk of experiencing poor nutrition. The mission of the FNS is to end hunger and obesity by providing food assistance and comprehensive nutritional programs that ensure children and needy families have access to a more healthy diet (FNS, 2013a). The federal nutrition assistance programs provide to needy families vouchers, food stamps, food commodities, and nutrition education programs. These programs are under the food distribution and supplemental nutrition assistance programs of the Federal Nutrition Service (Table 1). A complete overview of federal nutritional assistance programs is provided at the end of the document. 
Table 1: Federal Nutrition Assistance Programs and Food Distribution programs under FNS

\begin{tabular}{ll}
\hline Food Distribution Programs & $\begin{array}{l}\text { Supplemental Nutrition Assistance } \\
\text { Programs (SNAP) }\end{array}$ \\
\hline $\begin{array}{l}\text { Commodity Supplemental Food } \\
\text { Program(CSFP) }\end{array}$ & SNAP(Former Food Stamps Program) \\
& Women Infant and Children (WIC) \\
$\begin{array}{l}\text { The Emergency Food Assistance Program } \\
\text { (TEFAP) }\end{array}$ & $\begin{array}{l}\text { Senior Farmers' Market Nutrition } \\
\text { Program (SFMNP) }\end{array}$ \\
& $\begin{array}{l}\text { Farmers' Market Nutrition Program } \\
\text { (FMNP) }\end{array}$ \\
\hline Source: http://www.fns.usda.gov/programs-and-services & \\
\hline
\end{tabular}

\section{Food Distribution}

The Commodity Supplemental Food Program (CSFP) aims to improve the nutrition status of low-income women who are pregnant or breastfeeding, new mothers, children up to age six and elderly people age 60 and over (USDA, 2011b). The program provides food supplements and administers funds to individual states to supplement diets of people eligible for the program. This program is similar to the Women, Infants, and Children (WIC) program, which provides actual food, rather than vouchers to its recipients. Women who are eligible for CSFP can also receive WIC, but not concurrently.

The Emergency Food Assistance Program (TEFAP) provides emergency food supplements and assistance to low-income families (USDA, 2011b). It distributes funds at the state level to provide emergency food assistance for those in need at no cost. Assistance through TEFAP is distributed through individual states to local soup kitchens 
and food banks. Households may also receive assistance through this program if they meet the requirements set by each individual state.

\section{Supplemental Nutrition Assistance Program}

The Supplemental Nutrition Assistance Program (SNAP), formerly known as the Food Stamp program, has been in existence since 1949 and is an important component of the nation's mission to improve nutrition and eliminate hunger for low-income families (Landers, 2007). SNAP is the nation's largest nutrition assistance program, providing nutrition assistance to an estimated 46 million low-income individuals per month. Eligibility for the SNAP program is based on household income and expenses as established by federal income guidelines and regulations.

\section{The Special Supplemental Nutrition Program for Women Infant and Children}

The Special Supplemental Nutrition Program for Women, Infants, and Children (WIC) is for low-income women who are pregnant or breastfeeding and infants and children up to age 5 who need adequate nutrition (USDA, 2011b). WIC eligibility is based on income and level of nutritional risk; persons participating in WIC are eligible to participate in other federal nutrition assistance programs if they meet the income eligibility requirements. WIC provides nutrition education and nutrition assistance through vouchers for healthy foods, including fruits and vegetables, to program participants at no cost.

The WIC Farmers' Market Nutrition Program (FMNP) is associated with the WIC program. The FMNP provides access to fresh fruits and vegetables through local farmers' markets and roadside stands that accept its vouchers and Electronic Benefit Transfer (EBT). In addition to the FMNP, the federal government supports Federal Nutrition 
Education Programs for low-income families in federal nutrition assistance programs as well as those who are eligible to participate in FMNP.

\section{Federal Nutrition Education Programs}

Federal Nutrition Education programs provide nutrition education to improve dietary behaviors and overall nutrition status of low-income families. Studies examining nutrition education and dietary behavior for low-income women indicate positive dietary changes and reduction in fat consumption (Campbell, Honess-Morreale, Farrell, Carbone, \& Brasure, 1999; Eicher-Miller, Mason, Abbott, McCabe, \& Boushey, 2009).

Additionally, low-income individuals who participated in nutrition education programs reported higher levels of fruit and vegetable consumption (Ball et al., 2006; Guillaumie et al., 2010; Maclellan et al., 2004; L. Williams et al., 2010). Many of the nutrition assistance programs in FNS provide Supplemental Nutrition Assistance Program Educational (SNAP-Ed) and the Expanded Food Nutrition Education Program for those eligible for food assistance. The WIC program, also housed in the FNS, has a nutrition education component built into its food supplement program. In the state of Kentucky, programs from FNS provide nutrition education to eligible low-income households. These are the Expanded Food Nutrition Education Program (EFNEP), The Special Supplemental Nutrition Assistance Program (WIC), and the Special Nutrition Assistance Program Educational Programs (SNAP-Ed). These programs provide federally funded nutrition education serving low-income individuals who are at or above $185 \%$ of the federal poverty level. 
These education programs improve food choices by helping participants increase their nutritional knowledge and gain dietary skills that promote healthy dietary behaviors. The goal of these educational programs is to improve the consumption of healthy and nutritious foods for individuals who participate in the programs. Individuals who participate in nutrition education programs are more likely to incorporate healthy dietary practices into their food preparation (Larson et al., 2006; McLaughlin et al., 2003).

\section{Supplemental Nutrition Education Program- Educational (SNAP-Ed)}

With an estimated 33 million people per month participating in SNAP (USDA, 2010b), SNAP-Ed's focus is improving the health status of low income individuals by providing nutrition education resources for programs and activities to improve knowledge and skill sets associated with healthy living. States must apply to the USDA for matching funds to provide nutrition education programs for populations eligible for USDA programs. SNAP-Ed has developed key behavioral outcomes for program participants. This evidence-based program seeks to increase physical activity; promote a caloric balance; and increase consumption of whole grains, fruits, and vegetables (FNS, 2012). SNAP-Ed programs vary based on the targeted population and the type of nutrition assistance provided. The Food Nutrition Service provides agencies applying for funding specific guidelines regarding how to meet eligibility guidelines to be considered for SNAP-Ed program.

\section{Kentucky SNAP-Ed}

Funding for SNAP Education programs grew quickly between 2004 and 2009. A USDA (2009) report indicated over 33 million people in the United States received SNAP benefits, with the largest percentage being households with children. In 2004, the 
funding budget for SNAP-Ed programs in the United States totaled $\$ 222,435,638.00$, with $\$ 678,920.00$ being allocated to Kentucky. In 2009 , the funding for SNAP-Ed programs increased to $\$ 343,189,406.00$, with the Kentucky portion of the budget increasing to $\$ 9,865,128.00$ (USDA, 2010b). In 2007, Kentucky reported 778,114 persons on annual average who participated in the SNAP program (USDA, 2007).

The SNAP-Ed initiative for Kentucky is coordinated by The Kentucky Cabinet for Families and Children. This state-run agency is responsible for managing SNAP-Ed proposals for Kentucky, oversees SNAP-Ed funds, and contracts with organizations to implement SNAP-Ed programs across the commonwealth. It has developed several SNAP-Ed programs that meet the approval of the USDA's SNAP Education Guidance. The flexibility of having a variety of SNAP-Ed programs provides opportunity to be creative and specific in addressing program participants. The challenge this variety presents is being able to effectively evaluate them (Townsend, Johns, Shilts, \& FarfanRamirez, 2006). Many of the nutrition education programs within the FNS lack a common measure for evaluation, have large variations in program components and implementation, and many times offer no credible way to ensure adequate data collection (Guthrie et al., 2006; Taylor-Powell, 2006; Townsend et al., 2006). According to requirements developed by the USDA, all SNAP-Ed programs must meet the goals and behavioral outcomes outlined in Table 2 . 
Table 2: SNAP Objectives

\begin{tabular}{|l|l|}
\hline SNAP-Ed Goal requirements & SNAP-Ed Key Behavioral Outcomes \\
\hline $\begin{array}{l}\text { Health Promotion to assist SNAP eligible citizens } \\
\text { to establish healthy eating habits and lead a } \\
\text { physically active lifestyle }\end{array}$ & $\begin{array}{l}\text { Make half of your plate fruits and vegetables, at least } \\
\text { half of your grains whole grains, and switch to fat- } \\
\text { free or low-fat milk and milk products }\end{array}$ \\
\hline $\begin{array}{l}\text { Primary prevention of diseases to help residents } \\
\text { eligible for SNAP that have risk factors for } \\
\text { chronic disease prevent or postpone the onset of } \\
\text { disease by establishing healthier eating habits and } \\
\text { being more physically active }\end{array}$ & $\begin{array}{l}\text { Increase physical activity and reduce time spent in } \\
\text { sedentary behaviors as part of a healthy lifestyle }\end{array}$ \\
\hline & $\begin{array}{l}\text { Maintain appropriate calorie balance during each } \\
\text { stage of life- childhood, adolescence, adulthood, } \\
\text { pregnancy and breastfeeding, and older age. }\end{array}$ \\
\hline \multicolumn{2}{|l}{} \\
\hline Source: http://www.nal.usda.gov/fsn/Guidance/FY2013SNAP-EdPlanGuidance.pdf
\end{tabular}

Expanded Food and Nutrition Education Program (EFNEP)

The Expanded Food Nutrition Education Program (EFNEP) has become one of the primary interventions for health promotion focusing on low income, food insecure households in the United States (Townsend et al., 2006). This community-based nutrition education program is funded by the USDA to promote behavior change among lowincome men, women, and children who meet the federal poverty guidelines (Dollahite, 2003). The EFNEP Program consists of a series of nutrition education sessions that aim to increase knowledge of (1) basic human nutrition, (2) improving diet, (3) nutritional welfare of families, (4) improving food purchasing, (5) food preparation, (6) and food safety practices of families (Dickin, 2005; USDA, 1983). The EFNEP program provides specific lessons to participants focusing on improving fruit and vegetable consumption. (Table 3). 
Table 3: EFNEP Nutrition Objectives

Expanded Food and Nutrition Education Program Objectives

Improve diets and nutritional welfare for the total family

Increase knowledge of the essentials of human nutrition

Increase ability to select and buy food that satisfies nutritional needs

Improve practices in food production, preparation, storage, safety and sanitation

Increased ability to manage food budgets and resources such as food stamps

Source: US Department of Agriculture Extension Service: Expanded Food Nutrition Education Program Policies:

http://www.nifa.usda.gov/nea/food/efnep/pdf/program-policy.pdf

As of 2011, EFNEP served 134,446 adults and over 500,000 children and indirectly reached over 400,000 households with nutrition education programs across the United States (USDA, 2012). Of those participating in the program, the $87 \%$ who disclosed their income earned at or less than $\$ 22,050$ for a family of four, which is at $100 \%$ of the poverty level. In 2012 , over 4,000 individuals and families participated in EFNEP programs through the University of Kentucky Cooperative Extension Service. In follow up, about 3,971 families reported making healthier food choices because of EFNEP lessons (Vail, 2012).

Evaluation of the EFNEP program has focused primarily on improving dietary quality and less on food resource management and food safety. Research focused on the impact of nutrition education on food security status of low-income individuals has shown individuals who participate in EFNEP programs experience significant improvement in their food security status (Dollahite, 2003; Townsend et al., 2006). Although most studies evaluate the EFNEP program's effect on food security status, a 
few studies have examined the program's effectiveness with fruit and vegetable consumption (Dickin, 2005; Dollahite, 2003; Nord, Andrews, \& Carlson, 2009; Townsend et al., 2006). A study of the Texas EFNEP program found that the program was able to positively influence behavior change regarding fruit and vegetable consumption for program participants (Cullen et al., 2010). Participants who reported attaining goals for fruit and vegetable consumption reported a higher self-efficacy in their ability to consume fruits and vegetables as well as improved food preparation skills and improved availability of fruits and vegetables in the household. An EFNEP report released by the USDA showed $94 \%$ of adults participating in the program improved their diet quality and increased their fruit and vegetable consumption (USDA, 2012). Many of the individuals who participate in EFNEP are also eligible for other federally funded nutrition education programs such as SNAP-Ed and WIC programs.

\section{(WIC) Nutrition Education Program}

The Special Supplemental Nutrition Program for Women, Infants, and Children is a federally funded supplemental nutrition program that serves as a safety net for lowincome women and children at risk of being nutrition insufficient. This program provides nutrient-dense food subsidies and nutrition education programs for its participants. The WIC program serves low-income pregnant women and low-income children ages birth to five years old. The current WIC programs serves an estimated half of all mothers and their infants born in the United States and about $25 \%$ of preschool children (Herman et al., 2008).

The WIC nutrition education program provides participants with a basic understanding of the relationship between nutrition, physical activity, health and 
nutritional needs during pregnancy, postpartum, and breastfeeding, and for children up to the age of five. The WIC nutrition education program is unique compared to SNAP-Ed and EFNEP nutrition education programs. Unlike SNAP-Ed or EFNEP, participants complete a nutritional assessment that determines eligibility and provides an opportunity to tailor the nutrition education intervention based on the nutritional assessment (FNS, 2013d). The WIC program incorporates six objectives into its intervention efforts to improve the dietary behavior of individuals participating in the program (See Table 4).

Table 4: Objectives for WIC Education Intervention

1. Review of the WIC nutrition assessment to identify the participant's nutritional risk factors, needs, and concerns.

2. Provide messages that engage the participant in setting individual, simple and attainable goals and provide clear and relevant "how to" actions to accomplish those goals.

3. Present counseling methods/teaching strategies that are relevant to the participant's nutritional risk and are easily understood by the participant.

4. Provide a delivery medium that creates opportunities for participant interaction and feedback.

5. Provide continuous support through informational/environmental reinforcements

6. Initiate follow-up to assess for behavior change and determine intervention effectiveness

Source: WIC Nutrition Education Program Guidance.

http://www.nal.usda.gov/wicworks/Learning_Center/ntredguidance.pdf

In 2011, WIC reached a participation level of nearly 8.9 million. A total of 6.8 million dollars was spent on the WIC program, with $\$ 4.9$ million on food and \$1.9 million on nutritional services and administrative costs (FNS, 2013c). In the same year, 
Kentucky reported 132,698 participated in the WIC program (FNS, 2013b) and Daviess County saw an average monthly participation of 2,302 (A. C. Foundation, 2011).

Studies examining the diets of WIC families revealed an improvement of overall diets as a result of changes to the WIC food package guidelines in 2007. WIC program participants showed increases in consumption of whole grains, fruit and vegetables, and low-fat milk (Havens et al., 2012; Kropf et al., 2007; Whaley, Ritchie, Spector, \& Gomez, 2012).

\section{Comparison of Nutrition Education Programs}

Research on the effectiveness of the EFNEP and WIC programs has shown increases in fruit and vegetable consumption for each of the respective programs (Dharod et al., 2011; Guthrie et al., 2006; Taylor-Powell, 2006; Townsend et al., 2006). Very little research has been published to provide evidence of the influence of SNAP-Ed, EFNEP, and WIC programs together. In one particular study (Peterson et al., 2002) addressing dietary intervention efforts, low-income postpartum women who participated in both WIC and EFNEP programs were the study subjects. The comprehensive ecological model was used to test the efficacy of the WIC and EFNEP programs in improving nutritional behaviors of low-income women following the birth of a child. The assessment of the effectiveness of the WIC and EFNEP interventions was based on the intrapersonal, interpersonal, and organizational levels of the social ecological model. The study concluded that a comprehensive model that included federal nutrition education programs, such as WIC and EFNEP, incorporating multiple behavior change strategies would be beneficial in enabling low-income mothers to overcome a constellation of 
barriers that contributed to their low intake of fruit and vegetables, high intake of sugar and fats, and low level of physical activity (Peterson et al., 2002).

The three federal nutrition education programs for the proposed study, WIC, SNAP-ED, and EFNEP, all have similar goals and behavioral outcomes for individuals who participate in the respective programs. Beyond these similarities, each program has characteristics that make it unique in regard to providing nutrition education. (1) The SNAP-Ed program provides a number of curriculum program opportunities to educate program participants. (2)The EFNEP program provides nutrition education through lessons individuals receive while in the program. These lessons promote nutrition education and provide opportunity to build skills in dietary and resource management to improve consumption. (3) WIC programs provide a series of lessons on nutrition education programs and nutrition assessments so that a more tailored intervention can be prepared for the participant.

The common objectives across the WIC, SNAP-Ed, and EFNEP nutrition education programs include

- Increasing knowledge and education on benefits of eating fruit and vegetables and developing healthy dietary behaviors

- Implementing behavioral outcomes that lead to consumption of more fruits and vegetables

- Reducing consumption of unhealthy foods, including foods high in fat

- Promoting improved physical activity habits as a strategy to improving nutritional status. 
Studies have begun to focus on health promotion and health behavior theories to gain a better understanding about behavioral factors that influence fruit and vegetable consumption.

In studies examining psychosocial and socio-demographic factors associated with fruit and vegetable consumption for WIC participants, self-efficacy, attitudes, and perceived barriers emerge as significant predictors of fruit and vegetable consumption (Chen \& Gazmararian, 2014; Havas, Anliker, et al., 1998; Havas et al., 2003; Herman et al., 2008; Kropf et al., 2007). Results from nutrition education evaluations of the Maryland WIC program listed the number of nutrition education sessions attended, education self-efficacy, and ethnicity as strong predictors of increased fruit and vegetable consumption (Havas, Anliker, et al., 1998; Havas et al., 2003). Another study comparing WIC participants by geographic classification and ethnicity found higher fruit and vegetable consumption for urban black WIC participants compared to rural WIC participants who were also black (Ettienne-Gittens et al., 2013).

\section{THEORETICAL FRAMEWORK GUIDING THE STUDY}

\section{The Health Belief Model}

The Health Belief Model (HBM) is a theoretical framework used in understanding the influence of social, economic, and environmental factors on health behavior (Glanz, 2002). For the proposed study, the constructs will be defined in the context of behaviors of fruit and vegetable consumption. The constructs of the HBM consist of perceived seriousness, perceived susceptibility, perceived benefits, perceived barriers, cues to action and self-efficacy (Bensley, 2009). The perceived seriousness refers to how serious 
an individual perceives the problem of obesity. Perceived susceptibility refers to an individual's perception of actually being affected by obesity and health issues related to being obese. Cues to action is a construct that looks at the factors that lead to individuals improving their fruit and vegetable consumption; the self-efficacy construct in this study deals with an individual's belief in their ability to consume fruit and vegetables.

Perceived benefits is a construct where an individual is convinced there is a benefit to the health intervention or prevention efforts. Perceived barriers look at actions or barriers that would prevent the individual from achieving the desired health outcome. Identifying and understanding the psychosocial determinants to fruit and vegetable consumption is important in developing an effective intervention that addresses specific behavioral intentions.

Studies assessing fruit and vegetable consumption using the HBM as a theoretical framework assess attitudes and behaviors toward fruit and vegetable consumption. A number of social and psychological variables surfaced as correlates of fruit and vegetable intake (Steptoe, Perkins-Porras, Rink, Hilton, \& Cappuccio, 2004). In a specific study examining psychosocial variables influence on fruit and vegetable consumption for lowincome women performed a regression analysis to test the influence of selected sociodemographic and psychosocial variables. Higher self-efficacy (.76), current knowledge of nutrition (.52), higher attitude scores (.27), and lower perceived barriers (.80) were psychosocial variables that proved to be influential in improving fruit and vegetable consumption (Havas, Anliker, et al., 1998). Not all social demographic variables in this particular study were statistically significant, and those that proved to be significant did not have a higher level of significance compared to the psychosocial variables. Studies 
measuring perceived benefits of fruit and vegetables, revealed a positive association with fruit and vegetable consumption for study participants (Krebs-Smith et al., 1995; Steptoe et al., 2003; Steptoe et al., 2004; L. K. Williams et al., 2012).

Other studies addressing barriers to fruit and vegetable consumption provide evidence that psychosocial variables such as knowledge, level of self-efficacy, and attitudes and beliefs are significant factors that influence fruit and vegetable consumption (Hildebrand \& Betts, 2009; Shaikh, Yaroch, Nebeling, Yeh, \& Resnicow, 2008; Steptoe et al., 2004)

\section{Self-Efficacy}

Researchers have begun to examine the relationship between self-efficacy and fruit and vegetable consumption. In studies focused on improving dietary behavior, conclusions indicated a positive correlation between fruit and vegetable consumption and self-efficacy (Campbell et al., 1998; Steptoe et al., 2004). Interventions yielding positive changes in self-efficacy were also shown to lead to increased fruit and vegetable consumption (Campbell et al., 1994; Campbell et al., 2008; Campbell et al., 1998; Greene et al., 2004; Steptoe et al., 2004).

Self-efficacy is defined as the conviction that one can successfully execute the behavior required to produce the outcome (Bandura, Adams, \& Beyer, 1977). In a microanalysis of self-efficacy and behavioral change, Bandura's experiment provided evidence that the stronger the self-efficacy expectations, the higher likelihood that a particular task would be completed (Bandura et al., 1977). 
Higher levels of self-efficacy to consume fruit and vegetables lead to higher intake of fruit and vegetables. Variables such as perceived barriers and self-efficacy have been linked as correlates of fruit and vegetable intake. An analysis performed on the influence of selected socio-demographic and psychosocial variables on fruit and vegetable consumption among low-income women found higher self-efficacy was statistically significant in improving fruit and vegetable consumption (Campbell et al., 1998; Greene et al., 2004; Guillaumie et al., 2010; Havas, Anliker, et al., 1998;

Hildebrand \& Betts, 2009; Steptoe et al., 2004).

Although different studies have examined fruit and vegetable consumption among certain age demographics, specifically children, adolescents, college students, adults, and older adults, (Ettienne-Gittens et al., 2013; Hersey et al., 2001; Webber, 2009) the literature reporting self-efficacy and fruit and vegetable consumption among rural lowincome populations is limited.

Studies used varying definitions of self-efficacy based on the specifics of the respective studies. One particular study assessed the participants' belief in their ability to eat fruit and vegetables during challenging situations (Greene et al., 2004) while another study's definition was centered on the ability to consume fruit and vegetables away from the home (Havas, Anliker, et al., 1998). Despite variations in the operating definitions of self-efficacy, those individuals who reported higher levels of self-efficacy were likely to consume more fruits and vegetables and were more likely to maintain the behavior.

As more individuals fall below the poverty line and receive federal nutrition assistance, more families will have access to nutrition assistance programs to assist with 
access to foods. The nutrition education programs will be essential for providing lowincome families with the education and skills needed to eat and live in a healthy way.

\section{Summary}

Literature synthesized in this chapter examined low-income individuals and their relationship to the risk of being overweight and obese. Low-income individuals, rural households and ethnic minorities all have higher risk of being obese and consuming less fruits and vegetables as part of their daily diet (Dharod et al., 2011; Drewnowski \& Specter, 2004; Patterson et al., 2004; Stewart, Hyman, Frazao, Buzby, \& Carlson, 2011). Additionally, the literature presented in this chapter examined how the various federal nutrition education programs and self-efficacy influenced fruit and vegetable consumption. Federal nutrition assistance programs provide food supplements as well as nutrition education and other information for program participants. The literature revealed three major programs under the FNS umbrella: food distribution, child nutrition, and supplemental food assistance. The objectives of these programs are similar, but characteristics of the programs may possibly influence fruit and vegetable consumption. Lastly, the literature in this chapter supports self-efficacy as a predictor for fruit and vegetable consumption.

As communities across the United States continue working on the challenging issues of obesity, nutrition education programs that promote adopting a healthy diet have been implemented and expanded to improve health behavior and reduce individual risk. Although improved levels of fruit and vegetable consumption would be an indicator of improved health behavior, little research has assessed the influence of nutrition education 
programs and perceived self-efficacy on the consumption of fruits and vegetables among low-income individuals. This study examined whether participation in federal nutrition education programs, the predictor of behavior to eat healthy foods, or the self-efficacy to consume fruit and vegetables influence the consumption rate of fruit and vegetables for low-income rural women. Although few studies compare the listed federal nutrition education programs, the current research specifically looks at the comparison of fruit and vegetable consumption as influenced by participation in federal nutrition education programs.

This chapter provided a synthesis of the literature related to fruit and vegetable consumption, self-efficacy and consumption, federal nutrition assistance programs, and nutrition education programs. The next chapter will discuss the methodology of this study. 


\section{CHAPTER III}

\section{METHODOLOGY}

\section{Introduction}

This chapter provides information about the study design, recruitment methodology, data collection, and data analyses for the current study. First, the study examines the relationship between the variables nutrition education, self-efficacy to consume fruit and vegetables, and predictor of behavior (POB) to eat healthy foods with the dependent variable fruit and vegetable consumption. Next, the study used a comparison design that aimed to examine how the consumption of fruit and vegetables differed between WIC and non-WIC groups. Lastly, it looked at how the variables predictor to eat healthy foods (POB), self-efficacy to consume fruit and vegetables and nutrition education differed between individuals who participated in the WIC program compared to those who did not.

\section{Recruitment}

Low-income women of Daviess County, Kentucky, were recruited for this study at three community locations. Two of these locations, (1) the Green River District Health Department and (2) the H.L. Neblett Community Center, are community organizations that provide services to low-income residents eligible to receive SNAP benefits. The third location was (3) Owensboro Community and Technical College. The community college serves a large section of the community through its ready to work programs for low- 
income students. Additionally, a large section of the student population and the community college received Federal Pell assistance and fit the participation criteria for study. An informational flyer (appendix A) about the study was posted at community locations. Informational flyers posted at each of the sites instructed interested persons to contact the co-investigator to set up an appointment to participate in the study. Walk-ins were also welcome to participate in the study, the investigator designated time at each of the four locations for walk-ins.

Eligible participants had to meet the following criteria: (1) able to respond to questions written in English, (2) resident of Daviess County, Kentucky, (3) 18 years of age or older, and (4) eligible to receive Supplemental Nutrition Assistance (SNAP). Individuals interested in participating in the study completed the pre-screening questionnaire. Upon demonstrating their eligibility, participants were contacted to schedule an appointment to complete the survey. All individuals who consented to participate in the study completed and submitted the survey to the co-investigator. The signed consent forms and completed surveys were placed in a locked filing cabinet at Owensboro Community and Technical College. The questionnaires were completed either through interviews or self-completion by the participants. All of the self-completed surveys were checked by the investigator to ensure completeness. Data was collected until sufficient samples based on the required sample size were collected representing individuals who had participated in WIC in the last six months and those who did not. As an incentive, eligible individuals who completed the survey had their name entered in a drawing for a $\$ 25$ gift card. Ten gift cards totaling $\$ 250$ were distributed in drawings at the conclusion of the data collection process. Drawings took place from June 
to October of 2015, and winners were notified by phone. Upon completion of the drawings, all entry slips were destroyed.

\section{Population and Sample Size}

Daviess County is located in rural northwestern Kentucky. The largest city in Daviess County is Owensboro, with a population of 57,618 (Census, 2010). The study population consisted of low-income residents of the county who were eligible for Supplemental Nutrition Assistance programs based on federal guidelines. In 2010, there were 16,811 (29\%) men and women in Daviess County who lived at or below the federal poverty level and 13,360 (79\%) received SNAP benefits (Center, 2010).

\section{Consideration for Sample Size}

Of 16,811 low income individuals, the U.S. census estimated 4,835 belong to households headed by women (Census, 2008-2012). Kentucky WIC data recorded that a monthly average of 2,166 low-income participants in Daviess County, Kentucky, utilized services in 2012 (A. E. C. Foundation, 2012). This left an estimated 2,669 (4,835 minus 2,166 ) women in Daviess County who were low income, but not utilizing WIC services.

The minimum sample size necessary for this study was determined to be 320 participants. An alpha $=.055 \%$ and power $=.80 \%$ were set with the sample groups WIC (n $=160)$ and non-WIC $(\mathrm{n}=160)$. Using a two-tailed, two-sample binomial test for proportions, we determined that the differences between the groups were at least $14 \%$. Using a two-tailed, two-sample t-test for comparing means, study results determined that the difference in the means was at least $0.28 \mathrm{SD}$ (Cohen, 1998). However, we expect 
about $15 \%$ missing data. After adjusting for missing data and multiple covariates, which account for at least an additional $15 \%$ in the group indicator variable, the study would still be able to detect moderate effect sizes (Hsieh, Bloch, \& Larsen, 1998). The 320 study participants were divided into two groups, 160 who participated in WIC in the past six months and another 160 who did not participate in the WIC program.

The WIC program was used as a comparison point because of the educational component within the services. All of the federal nutrition education programs in this study, with the exception of WIC-Ed are optional programs individuals can participate in if they so choose. Participants in the WIC program receive WIC-Education as a part of the services. The justification to separate the group by WIC and non-WIC participants is based on the WIC compulsory nutrition education as part of WIC services compared to optional participation of SNAP-Ed and EFNEP participants in nutrition education programs. Although analyses were conducted to test the relationship between any nutrition education and fruit and vegetable consumption, the majority of the analyses focus on comparing the differences of the selected variables between the WIC and nonWIC group.

Due to the difficulties in determining eligible program participants from the population subset being measured, a purposive sampling method was used to recruit study participants. This method was used to recruit participants at the local community college and two community service locations that provide services to low-income individuals. Those locations were the H.L. Neblett Community Center and The Green River District Health Department. One hundred and thirty five study participants were recruited from the Green River District Health Department, 121 from Owensboro 
Community and Technical College, 49 from The H.L. Neblett Community Center, and 15 who were referred by a participant from the other sites. The participants of this study were recruited from September 2014 to March 2015. All study participants completed the survey with the principal investigator present. Participants either were read survey questions or provided instructions for completing the survey. The researcher checked all completed surveys to ensure any missing information was intentionally left blank and not mistakenly omitted. Figure 2 diagrams the study population and sample groups design. 
Figure 2: Conceptual Model for Selecting Population Sample

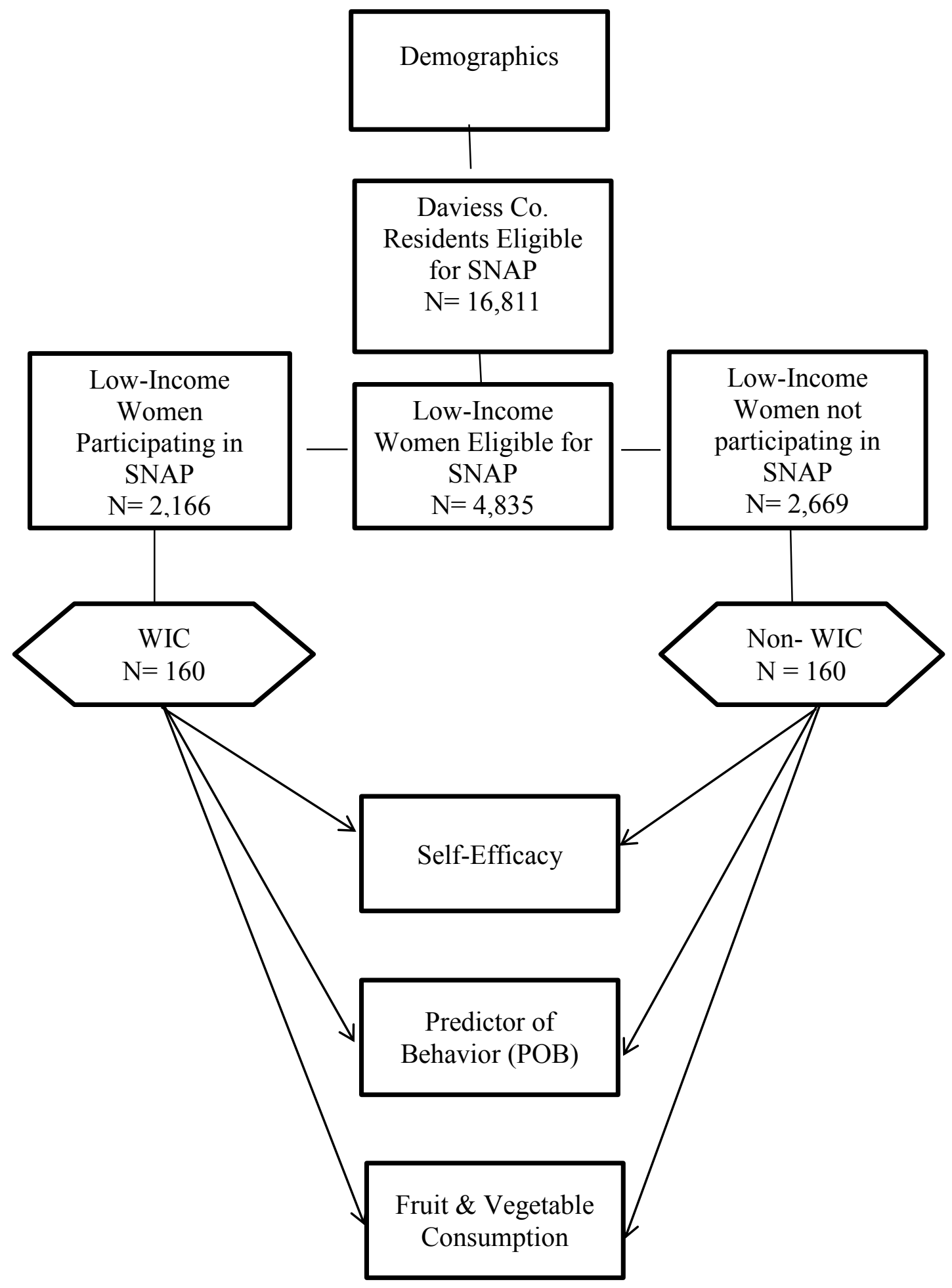




\section{Data Collection}

\section{Instrumentation}

\section{Dependent and Independent Variables}

The dependent variable, average weekly fruit and vegetable consumption, was measured using selected questions from the Behavioral Risk Factor Surveillance System (BRFSS) survey (CDC, 2012c). The survey gathered responses to the six questions measuring the quantity and type of fruits, fruit juices, and vegetable products consumed. The independent variables were Predictor of Behavior (POB), participation or nonparticipation in the WIC federal nutrition education program, and self-efficacy to consume fruit and vegetables.

\section{Demographic Variables}

The questions elected to describe the demographic profile of respondents were adopted from the BRFSS survey (BRFSS, 2012). Fourteen questions were used to gain information from study participants related to their education attainment, age, gender, race, marital status, household income, household size, county residence, zip code, height, weight, employment status, and geographical residency.

\section{Self-Efficacy to Consume Fruit and Vegetables Measure}

Self-efficacy in this study as described by Bandura's concept of self-efficacy is a person's belief about their capabilities to produce designated levels of performance that exercise influences over events that affect their lives (Bandura, 1994). For this study, self-efficacy is operationally defined as a person's belief in their capability to consume 
fruit and vegetables, as measured by the self-efficacy fruit and vegetable assessment scale (Mainvil et al., 2009). The assessment consisted of eighteen questions on a five point Likert scale ranging from " 1 ", not at all confident, to "5", totally confident. The internal consistency of the fruit and vegetable self-efficacy scale proved to be higher when fruit and vegetables consumed were assessed separately (yielding a Cronbach $\alpha=.80$ for vegetables and .85 fruit). When fruit and vegetables were combined and assessed together, the Cronbach $\alpha$ was .70 (Mainvil et al., 2009).

\section{Predictor of Behavior (POB)}

Kim et al. (2012) used variables from the Health Belief Model (HBM) to assess attitudes and beliefs toward eating healthy for college students. The predictor of behavior to eat healthy foods (POB) using a 29 item index developed from HBM model variables, a mean score was produced to assess participant's value and beliefs about eating healthy by examining perceived susceptibility, severity, benefits, and barriers to eating healthy foods (Kim et al., 2012). All POB variables tested met the minimum Cronbach's coefficient of reliability (0.832); susceptibility (0.779), severity (0.829), barrier (0.827), benefit (0.827), and behavioral intention to eat healthy food (0.829). All of the variables were assessed on the Likert Scale. Perceived susceptibility was measured with the response ranging from 1, "Not at all Concerned", to 5, "Very Concerned". For the

remaining variables, the responses ranged from 1, "Strongly Disagree" to 5, "Strongly Agree. Six of the questions (Q 35-40) were reverse coded to account for negatively-keyed questions. 


\section{Fruit and Vegetable Consumption}

To assess fruit and vegetable intake, this study used questions from the Behavioral Risk Factor Surveillance System (BRFSS). Six questions provided information on the consumption of fruit juice, fruit, green vegetables, beans, orange colored vegetables, and other vegetables. The frequency of consumption of fruit and vegetables was assessed by measuring the number of times per day, per week, or per month (BRFSS, 2012) they were consumed. (Each of the six questions provided the dependent variable for the consumption of fruit and vegetables types in separate analyses.) An average consumption rate was calculated for the week for each item. Table 5 shows the formula for the calculations.

Table 5: Conversion Formula for Average Weekly Fruit and Vegetable Consumption

\begin{tabular}{lll}
\hline $\begin{array}{l}\text { Consumption Amount by } \\
\text { Frequency }\end{array}$ & Conversion formula & $\begin{array}{l}\text { Average } \\
\text { Consumption Rate }\end{array}$ \\
\hline Times per Day & $\begin{array}{l}\text { Multiplied answer by } \\
\text { seven }\end{array}$ & Per Week \\
Times Per Week & No conversion necessary & Per Week \\
Times Per Month & $\begin{array}{l}\text { Divided answer by four } \\
\text { (average weeks per } \\
\text { month) }\end{array}$ & Per Week \\
\hline & & \\
\hline
\end{tabular}




\section{Nutrition Education}

All participants were questioned about their participation in federal nutrition education programs such as WIC, as well as their participation in the Expanded Food and Nutrition Education Program (EFNEP) and Supplemental Nutrition Assistance ProgramEducation (SNAP-Ed). Items on the questionnaire assessed participation in these programs during the six months prior to completing the survey. Respondents were categorized based on their participation in the WIC program. Participants were categorize as WIC participants if they reported receiving WIC services within the past six months, and those who did not receive WIC services or received services longer than six months prior to the study were categorized as non- WIC participants. Table 6 provides a list of the study variables and their measurement instruments.

Table 6: Study Variables and Measurement Instruments

\begin{tabular}{|c|c|c|}
\hline Variable & Instrument(s) & $\begin{array}{l}\text { Number of } \\
\text { Items }\end{array}$ \\
\hline Self-Efficacy & $\begin{array}{l}\text { Mainvil's Self-efficacy scale }{ }^{1} \text { assesses one's belief in } \\
\text { their capability to consume the recommended amount } \\
\text { fruit and vegetables }\end{array}$ & 24 \\
\hline $\begin{array}{l}\text { Nutrition } \\
\text { Education }\end{array}$ & $\begin{array}{l}\text { Assesses participation in federal nutrition education } \\
\text { programs } \\
\text { (Yes /No Questions) }\end{array}$ & 7 \\
\hline $\begin{array}{l}\text { Fruit and } \\
\text { Vegetable } \\
\text { Consumption }\end{array}$ & $\begin{array}{l}\text { Behavioral Risk Factor Surveillance System (BRFSS) } \\
\text { will measure fruit \& vegetable intake }\end{array}$ & 6 \\
\hline $\begin{array}{l}\text { Predictor of } \\
\text { Behavior } \\
\text { (POB) } \\
\end{array}$ & $\begin{array}{l}\text { Questions from } \mathrm{Kim}^{3} \text { to measure HBM constructs } \\
\text { susceptibility, barriers, benefits and perceived severity } \\
\text { and behavioral intent to consume healthy foods. }\end{array}$ & 20 \\
\hline $\begin{array}{l}\text { Demographic } \\
\text { Information }\end{array}$ & $\begin{array}{l}\text { Demographic Questionnaire: Adapted from the } \\
\text { Demographic sections of BRFSS }{ }^{2}\end{array}$ & 14 \\
\hline Total & & 71 \\
\hline
\end{tabular}

${ }^{1}$ (Mainvil et al., 2009) ${ }^{2}(C D C, 2010)^{3}$ (Kim et al., 2012) 


\section{DATA ANALYSIS}

Descriptive Statistics

Mean, median, minimum, maximum and standard deviation were reported for the continuous variables POB, Self-efficacy and nutrition education participation of this study. The categorical variables measured in this study include age, income, educational level, and marital status.

\section{Correlation Analysis}

Correlation analyses were used to examine bivariate associations between variables in the study. The bivariate correlates were estimated using Pearson's correlation coefficient. Relationships were assessed between the variables self-efficacy to consume fruit and vegetables, predictor of behavior to eat healthy foods (POB), and total nutrition education with the consumption of fruits and vegetables. The measurement of consumption assessed each of the six dependent variables separately, providing analyses for consumption of fruit juice, fruit, beans, dark green vegetables, orange colored vegetables, and other vegetables.

\section{Independent Sample t-test}

This study used the t-test and assessed the significance of those differences between WIC and Non-WIC groups related to fruit and vegetable consumption, selfefficacy to consume fruit and vegetables and the predictor to eat healthy foods (POB). When testing fruit and vegetables, the tests were conducted assessing each question separately. The t-test examined differences between the two groups in consumption of fruit juice, fruit, beans, dark green vegetables, orange colored vegetables and other vegetables between WIC and non-WIC participants. 


\section{Research Questions}

These are the research questions being considered for this study:

First, what are the relationships between federal nutrition education program (participation in at least one or more nutrition education programs, WIC, SNAP-Ed, EFNEP) self-efficacy to consume fruit and vegetables, and predictor to consume healthy foods (POB)?

Second, is there a significant difference between the two groups in the consumption of fruit and vegetables, the self-efficacy to consume fruit and vegetables and the predictor of behavior (POB) to eat healthy foods for WIC and Non-WIC groups?

\section{Null Hypotheses:}

$\mathrm{H} 1_{0}$ : There is no significant relationship between the predictor variables total nutrition education, self-efficacy to consume fruit and vegetables and the predictor to eat healthy foods (POB) on fruit and vegetable consumption for study participants.

$\mathrm{H} 2_{0}$ : There is no significant difference in the consumption of fruit and vegetables between the WIC and non-WIC groups.

$\mathrm{H} 3_{0}$ : There is no significant difference in the self-efficacy to consume fruit and vegetables between the WIC and non-WIC groups.

$\mathrm{H} 4_{0}$ : There is no significant difference in the predictor to eat healthy foods (POB) between the WIC and non-WIC groups. 


\section{Alternative Hypotheses:}

$\mathrm{H} 1_{1}$ : There is a significant relationship between the predictor variables total nutrition education, self-efficacy to consume fruit and vegetables and the predictor to eat healthy foods (POB) on fruit and vegetable consumption for study participants.

$\mathrm{H} 2_{1}$ : There is a significant difference in the consumption of fruit and vegetables between the WIC and non-WIC groups.

$\mathrm{H} 3_{1}$ : There is a significant difference in the self-efficacy to consume fruit and vegetables between the WIC and non-WIC groups.

$\mathrm{H} 4_{1}$ : There is a significant difference in the predictor to eat healthy foods (POB) between the WIC and non-WIC groups.

This chapter provided a guide to the methodology and population sample for the proposed study. Chapter four focuses on reporting the results of the analyses conducted. 


\section{CHAPTER IV}

\section{RESULTS}

\section{Introduction}

Chapter four discusses the results of this study. The chapter starts with a discussion of the results of the analyses of the demographic data. The next section presents the results from the research hypotheses tested in the study. The chapter concludes with a summary of the findings.

\section{Descriptive Analysis}

The final study sample consisted of 320 eligible low-income women from Daviess County, Kentucky. This sample included low-income women who had participated in the Special Supplemental Nutrition Assistance Program (WIC) within the last six months $(\mathrm{N}=160)$ and low-income women who had not participated in WIC in the last six months $(\mathrm{N}=160)$ but who were eligible for federal assistance. The women for this study were recruited from three locations; The Green River District Health Department (135), Owensboro Community \& Technical College (121), H.L. Neblett Community Center (49), and 15 were referrals from other participants.

The demographic profile of the sample was determined using basic descriptive statistics. All 320 participants of the study were female participants' ages 18-45 years from Daviess County, Kentucky. The sample was made up predominately of women aged 18-35 years with the single largest age group being women ages 18-25 (44\%). Nineteen percent of study participants represented ethnic minorities, with $12 \%$ being African 
American. Most (84\%) of the study participants reported having at least one child in the household and only $17 \%$ of participants reported having no children living in the household. Of the participants in this study reporting children in the household, the largest group had only one child (38\%) followed by two children $(24 \%)$ and three $(15 \%)$. Table 7 summarizes the age, race, household size, and children in household demographic variables. 
Table 7: Age, Race, Household Size and Children in Household Characteristics for Study Sample

\begin{tabular}{|c|c|c|c|c|c|c|}
\hline \multirow{2}{*}{$\begin{array}{l}\text { Demographic } \\
\text { Variable } \\
\end{array}$} & \multicolumn{2}{|c|}{ Non WIC } & \multicolumn{2}{|c|}{ WIC } & \multicolumn{2}{|c|}{ Total } \\
\hline & $\underline{\mathbf{N}}$ & $\underline{\%}$ & $\underline{\mathbf{N}}$ & $\underline{\%}$ & $\underline{\mathbf{N}}$ & $\underline{\%}$ \\
\hline \multicolumn{7}{|l|}{ Age Group } \\
\hline $18-25$ & 68 & 21.3 & 72 & 22.5 & 140 & 43.8 \\
\hline $26-30$ & 28 & 8.8 & 50 & 15.6 & 78 & 24.4 \\
\hline $31-35$ & 25 & 7.8 & 24 & 7.5 & 49 & 15.3 \\
\hline $36-40$ & 16 & 5.0 & 11 & 3.4 & 27 & 8.4 \\
\hline $41-45$ & 9 & 2.8 & 2 & 0.6 & 11 & 3.4 \\
\hline Over 45 & 14 & 4.4 & 1 & 0.3 & 15 & 4.7 \\
\hline Total & 160 & 50 & 160 & 50 & 320 & 100 \\
\hline \multicolumn{7}{|l|}{ Race } \\
\hline White & 133 & 41.6 & 125 & 39.1 & 258 & 80.6 \\
\hline African American & 25 & 7.8 & 15 & 4.7 & 40 & 12.5 \\
\hline Non-White & 2 & 0.6 & 20 & 6.3 & 22 & 6.9 \\
\hline Total & 160 & 50 & 160 & 50 & 320 & 100 \\
\hline \multicolumn{7}{|l|}{ Household Size } \\
\hline One & 8 & 2.5 & 0 & 0 & 8 & 2.5 \\
\hline Two & 49 & 15.3 & 34 & 10.6 & 83 & 25.9 \\
\hline Three & 38 & 11.9 & 53 & 16.6 & 91 & 28.4 \\
\hline Four & 30 & 9.4 & 37 & 11.6 & 67 & 20.9 \\
\hline Five & 24 & 7.5 & 19 & 5.9 & 43 & 13.4 \\
\hline Six & 8 & 2.5 & 10 & 3.1 & 18 & 5.6 \\
\hline Seven & 3 & 0.9 & 4 & 1.3 & 7 & 2.2 \\
\hline Eight & 0 & 0 & 2 & 0.6 & 2 & 0.6 \\
\hline Nine & 0 & 0 & 1 & 0.3 & 1 & 0.3 \\
\hline Total & 160 & 50 & 160 & 50 & 320 & 100 \\
\hline \multicolumn{7}{|l|}{$\begin{array}{l}\text { Children in } \\
\text { Household }\end{array}$} \\
\hline None & 51 & 15.9 & 1 & 0.3 & 52 & 16.3 \\
\hline One & 51 & 15.9 & 70 & 21.9 & 121 & 37.8 \\
\hline Two & 32 & 10.0 & 47 & 14.7 & 79 & 24.7 \\
\hline Three & 17 & 5.3 & 32 & 10.0 & 49 & 15.3 \\
\hline Four or More & 9 & 2.8 & 10 & 3.1 & 19 & 5.9 \\
\hline Total & 160 & 50 & 160 & 50 & 320 & 100 \\
\hline
\end{tabular}


Relationship status, education level, income, and employment status were also examined in this study. More participants in the study (33\%) reported being single than any other relationship status. Of women participating in this study, $62 \%$ reported being employed for wages, $14 \%$ of study participants indicated they were college students. Over half of the study participants reported having some experience taking college classes (57\%), yet they were considered low-income and eligible for federal nutrition assistance programs. The second highest number was study participants having earned a high school diploma or a GED (26\%). Four percent of study participants were college graduates who also were considered low-income and were eligible for federal nutrition assistance programs. Results of household income revealed that $33 \%$ of the respondents earned less than $\$ 10,000$ per year while another 33\% reported making between $\$ 10,000$ and $\$ 20,000$ per year. However, $14 \%$ reported earning $\$ 30,000$ per year. Table 8 summarizes the income, relationship, employment, and education variables. 
Table 8: Income, Relationship Status and Employment Status Characteristics for Study Participants

\begin{tabular}{|c|c|c|c|c|c|c|}
\hline \multirow{2}{*}{$\begin{array}{l}\text { Demographic } \\
\text { Variable } \\
\end{array}$} & \multicolumn{2}{|c|}{ Non-WIC } & \multicolumn{2}{|c|}{ WIC } & \multicolumn{2}{|c|}{ Total } \\
\hline & $\underline{\mathrm{N}}$ & $\underline{\%}$ & $\underline{\mathrm{N}}$ & $\underline{\%}$ & $\underline{\mathrm{N}}$ & $\underline{\%}$ \\
\hline \multicolumn{7}{|l|}{ Income } \\
\hline$<\$ 10,000$ & 43 & 13.4 & 64 & 20.0 & 107 & 33.4 \\
\hline$\$ 10-\$ 20 \mathrm{~K}$ & 42 & 13.1 & 65 & 20.3 & 107 & 33.4 \\
\hline$\$ 20 \mathrm{~K}-\$ 30 \mathrm{~K}$ & 37 & 11.6 & 18 & 5.6 & 55 & 17.2 \\
\hline$>\$ 30 \mathrm{~K}$ & 34 & 10.6 & 12 & 3.8 & 46 & 14.4 \\
\hline Total & 156 & 48.7 & 159 & 49.7 & 315 & 98.4 \\
\hline \multicolumn{7}{|l|}{ Relationship Status } \\
\hline Married & 26 & 8.1 & 39 & 12.2 & 65 & 20.3 \\
\hline Divorced & 24 & 7.5 & 9 & 2.8 & 33 & 10.3 \\
\hline Widowed & 5 & 1.6 & 0 & 0.0 & 5 & 1.6 \\
\hline Separated & 5 & 1.6 & 3 & 0.9 & 8 & 2.5 \\
\hline Never Married & 2 & 0.6 & 3 & 0.9 & 5 & 1.6 \\
\hline Single & 54 & 16.9 & 54 & 16.9 & 108 & 33.8 \\
\hline In a relationship & 44 & 13.8 & 52 & 16.3 & 96 & 30.0 \\
\hline Total & 160 & 50 & 160 & 50 & 320 & 100 \\
\hline \multicolumn{7}{|l|}{ Employment Status } \\
\hline Employed & 107 & 33.4 & 92 & 28.7 & 199 & 62.2 \\
\hline Self-employed & 1 & 0.3 & 0 & 0.0 & 1 & 0.3 \\
\hline Unemployed $<6$ mos & 8 & 2.5 & 9 & 2.8 & 17 & 5.3 \\
\hline Unemployed 6 mo-1 yr & 0 & 0.0 & 3 & 0.9 & 3 & 0.9 \\
\hline Unemployed $>1 \mathrm{yr}$ & 4 & 1.3 & 11 & 3.4 & 15 & 4.7 \\
\hline Homemaker & 1 & 0.3 & 21 & 6.6 & 22 & 6.9 \\
\hline Student & 30 & 9.4 & 15 & 4.7 & 45 & 14.1 \\
\hline Disabled & 9 & 2.8 & 8 & 2.5 & 17 & 5.3 \\
\hline Unknown & 0 & 0 & 1 & 0.4 & 1 & 0.3 \\
\hline Total & 160 & 50 & 160 & 50 & 320 & 100 \\
\hline \multicolumn{7}{|l|}{ Education } \\
\hline $8^{\text {th }}$ grade or less & 1 & 0.3 & 5 & 1.6 & 6 & 1.9 \\
\hline Some High School & 7 & 2.2 & 21 & 6.6 & 28 & 8.8 \\
\hline HS Grad/ GED & 31 & 9.7 & 55 & 17.2 & 86 & 26.9 \\
\hline Some College & 113 & 35.3 & 70 & 21.9 & 183 & 57.2 \\
\hline College Graduate (4yr) & 6 & 1.9 & 8 & 2.5 & 14 & 4.4 \\
\hline Graduate Degree & 2 & 0.6 & 1 & 0.3 & 3 & 0.9 \\
\hline Total & 160 & 50 & 160 & 50 & 320 & 100 \\
\hline
\end{tabular}


Additional analyses were conducted to measure participation in federal nutrition assistance programs, 160 study subjects reported participating in WIC, 34\% of those WIC participants also indicated they were receiving SNAP benefits. Only $11 \%$ of those receiving SNAP benefits indicated they also participated in SNAP-Ed programs within the last year. Eight percent of WIC participants received specific nutrition education information on fruit and vegetables from SNAP-Ed programs. Ten percent of WIC participants reported receiving nutrition education information from different sources other than SNAP-Ed, WIC, or the EFNEP program. Thirteen percent of study participants who received SNAP benefits indicated receiving specific nutrition education information from SNAP-Ed programs about fruit and vegetable consumption. Eleven percent of SNAP recipients indicated receiving nutrition education information from other sources that do not include WIC, SNAP-Ed, or EFNEP. Table 9 shows the study populations participation in nutrition education programs.

Table 9: Participation in Federal Nutrition Education by Program

\begin{tabular}{lll}
\hline & N & $\%$ \\
\hline WIC * & 160 & 46.6 \\
SNAP-Ed* & 21 & 6.6 \\
EFNEP* & 6 & 1.9 \\
Other SNAP* & 56 & 17.5 \\
Other Ed* & 61 & 19.1 \\
\hline
\end{tabular}

*Participants could be enrolled into multiple programs.

Survey questions in this study asked women about the average weekly consumption of fruit and vegetables. Respondents answered six questions about their consumption of fruit and vegetables. They were asked to recall their consumption of 
fruits and vegetables within the past thirty days of completing the survey. The survey provided the option for respondents to report their consumption as per day, per week, or per month. Consumptions reported by times per day and per month were converted to weekly averages.

Study results indicated the mean for the weekly consumption of fruit and other vegetables. For categories of fruit, the mean consumption was 5.78 and for other vegetables consumed, the mean consumption was 5.52. The lowest average weekly consumption was for the consumption of beans 1.73 and orange colored vegetables 1.93 . A more detailed list of average weekly consumption results is listed in Table 10.

Table 10: Weekly Consumption of Fruit and Vegetables for Study Sample $\begin{array}{llll}\text { Weekly Consumption } & \text { N } & \text { M } & \text { SD }\end{array}$

\begin{tabular}{llll}
\hline $100 \%$ fruit juice & 320 & 3.70 & 5.85
\end{tabular}

\begin{tabular}{llll}
\hline Fruit & 320 & 5.78 & 7.35
\end{tabular}

$\begin{array}{llll}\text { Beans } & 320 & 1.73 & 2.85\end{array}$

$\begin{array}{llll}\text { Dark leafy green vegetables } & 320 & 3.24 & 4.44\end{array}$

$\begin{array}{llll}\text { Orange colored vegetables } & 320 & 1.93 & 3.15\end{array}$

$\begin{array}{llll}\text { Other vegetables consumed } & 320 & 5.52 & 5.29\end{array}$

Fourteen questions were used to measure the predictor of behavior (POB) score to assess participant's value and beliefs of their intention to eat healthy foods. Questions 29-43 produced a mean score for each question for the study participants. POB for participants in both groups produced a mean of 57.50, $\mathrm{SD}=8.35$. Reporting POB between groups, WIC participants reported a mean score of 59.11 for their POB score, compared 
to 55.88 for non-WIC participants. The difference in POB between groups proved to be significantly different $(\mathrm{p}>.05)$. Table 11 provides a detailed list of the variables that make up the POB variable, along with the mean score and standard deviation for each of the questions. The total POB score for both WIC and non-WIC groups is available in Table 11.

Table 11: Variables for Predictor of Behavior Score (POB)

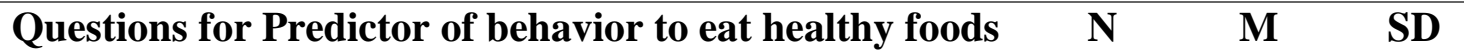
(POB)

\begin{tabular}{|c|c|c|c|}
\hline I believe supplements are good for my health. & 320 & 4.28 & 0.870 \\
\hline I believe that healthy foods can prevent disease. & 320 & 4.32 & 0.882 \\
\hline $\begin{array}{l}\text { I believe the "My Plate Food Guide" helps me make } \\
\text { healthy choices }\end{array}$ & 320 & 3.63 & 0.988 \\
\hline $\begin{array}{l}\text { I believe that nutrition facts food labels help me make } \\
\text { healthy choices }\end{array}$ & 320 & 3.88 & 1.05 \\
\hline I believe that eating breakfast is important for my health & 320 & 4.42 & 0.811 \\
\hline $\begin{array}{l}\text { What I eat is one of the most important things for my } \\
\text { health. }\end{array}$ & 320 & 4.38 & 0.799 \\
\hline I have no control over the foods available at my home & 320 & 4.38 & 1.10 \\
\hline I have trouble knowing how much I should eat & 320 & 3.80 & 1.28 \\
\hline $\begin{array}{l}\text { I know I should reduce fat and sugar in my diet but I don't } \\
\text { know which foods are best to do this. }\end{array}$ & 320 & 3.16 & 1.37 \\
\hline It is difficult to plan healthy meals & 320 & 2.86 & 1.39 \\
\hline $\begin{array}{l}\text { I don't see any benefits from my efforts to eat a healthier } \\
\text { diet }\end{array}$ & 320 & 4.17 & 1.06 \\
\hline $\begin{array}{l}\text { I have trouble choosing healthy foods when I am out with } \\
\text { my family and friends }\end{array}$ & 320 & 3.23 & 1.41 \\
\hline The chance I will eat healthy foods is high & 320 & 3.67 & 1.11 \\
\hline $\begin{array}{l}\text { The likelihood that I would recommend healthy food to a } \\
\text { friend is high }\end{array}$ & 320 & 3.85 & 1.05 \\
\hline $\begin{array}{l}\text { If I had to eat any type of meal I would choose a healthy } \\
\text { food. }\end{array}$ & 320 & 3.39 & 1.14 \\
\hline
\end{tabular}


Self- efficacy to consume fruit and vegetables was assessed to determine participant's belief in their ability to consume fruit and vegetables. Questions 44-67 on the survey were used to produce a mean score for self-efficacy to consume fruit and vegetables. The mean self-efficacy score for all study participants was $95.78, \mathrm{SD}=17.37$. Reporting self-efficacy to consume fruit and vegetables between groups, WIC participants demonstrated a self-efficacy mean of 98.91 compared to 92.64 for non-WIC participants (range 36-120). The differences of the mean (6.27) proved to be significantly different between the two groups. A summary of the variables for self-efficacy to consume fruit and vegetables is listed in Table 12. 
Table 12: S-E to Consume Fruit and Vegetables for Study Participants $(n=320)$

M SD

\begin{tabular}{|c|c|c|}
\hline I can eat vegetables even when I have to prepare them myself & 4.46 & 0.888 \\
\hline I can eat at least two different vegetables during my main meal on most days & 4.17 & 1.10 \\
\hline I can eat vegetables even on days when I am in a rush & 3.63 & 1.24 \\
\hline I can eat vegetables when I am tired and have to prepare them myself & 3.70 & 1.18 \\
\hline $\begin{array}{l}\text { I can eat vegetables when they are mixed with other foods, such as stir fry, casserole, } \\
\text { or stew }\end{array}$ & 4.46 & 0.898 \\
\hline I can eat vegetables as part of my lunch most days & 3.80 & 1.22 \\
\hline I can eat vegetables as a snack at least once a day & 3.57 & 1.25 \\
\hline I can eat fruit as a snack at least once a day & 4.15 & 1.04 \\
\hline I can eat fruit in the winter & 3.85 & 1.21 \\
\hline I can eat fruit as part of my lunch on most days & 3.89 & 1.15 \\
\hline I can eat fruit even on days when I'm in a rush & 3.94 & 1.17 \\
\hline I can eat fruit even when it has to be peeled and cut & 3.95 & 1.13 \\
\hline I can eat fruit in the morning & 4.08 & 1.19 \\
\hline I can eat fruit and vegetables even when my favorite ones are of poor quality & 3.27 & 1.25 \\
\hline I can eat fruit and vegetables at least once a day & 4.32 & 0.944 \\
\hline I can eat fruit and vegetables when no one else is eating them & 4.36 & 0.920 \\
\hline I can eat fruit and vegetables when I am unsure as to how they are grown & 3.84 & 1.10 \\
\hline I can eat fruit and vegetables when I am outside the home & 4.30 & 0.919 \\
\hline I can eat fruit and vegetables when I am eating out & 4.23 & 0.979 \\
\hline I can eat fruit and vegetables when I do not have much money & 3.78 & 1.24 \\
\hline I can eat fruit and vegetables when I am down or depressed. & 3.96 & 1.12 \\
\hline I can eat other fruit and vegetables when my favorite ones are expensive & 3.70 & 1.26 \\
\hline I can eat fruit and vegetables when I am feeling unwell & 3.83 & 1.14 \\
\hline I can eat fruit and vegetables when they are homegrown & 4.50 & 0.787 \\
\hline
\end{tabular}


There were 160 participants each for the WIC and non-WIC groups. Results from each of the six questions measuring fruit and vegetable consumption for both groups are listed below in Table 13. With the exception of the consumption of beans, participants in the study who participated in the WIC program reported higher levels of average weekly consumption of all categories of fruits and vegetables compared to non-WIC participants. Study participants who participated in the WIC program also reported a higher mean of self-efficacy to consume fruits and vegetables compared to non-WIC participants. The POB to eat healthy foods only varied slightly between the two groups, WIC participants' POB to eat healthy foods was slightly higher compared to non-WIC participants. Table 13 provides a summary of the characteristics of fruit and vegetable consumption between the WIC and non-WIC groups. 
Table 13: Characteristics of Fruit and Vegetable Consumption (WIC vs Non-WIC)

\begin{tabular}{|c|c|c|c|c|c|c|}
\hline $\begin{array}{l}\text { Fruit and Vegetable } \\
\text { Consumption }\end{array}$ & $\mathbf{N}$ & Mean & $S D$ & Min & $\operatorname{Max}$ & $P$ \\
\hline \multicolumn{7}{|l|}{ Fruit Juice } \\
\hline WIC & 160 & $4.79 * *$ & 7.12 & 0 & 42.00 & $\mathrm{P}=.0008$ \\
\hline Non-WIC & 160 & 2.61 & 3.96 & 0 & 21.00 & \\
\hline \multicolumn{7}{|l|}{ Fruit } \\
\hline WIC & 160 & $7.34 * *$ & 8.88 & 0 & 70.00 & $\mathrm{P}=.0001$ \\
\hline Non-WIC & 160 & 4.22 & 4.97 & 0 & 28.00 & \\
\hline \multicolumn{7}{|l|}{ Beans } \\
\hline WIC & 160 & 1.49 & 2.24 & 0 & 14.00 & $\mathrm{P}=.141$ \\
\hline Non-WIC & 160 & 1.96 & 3.35 & 0 & 28.00 & \\
\hline \multicolumn{7}{|l|}{ Dark Green Vegs } \\
\hline WIC & 160 & 3.02 & 3.40 & 0 & 21.00 & $\mathrm{P}=.382$ \\
\hline Non-WIC & 160 & 3.45 & 5.27 & 0 & 46.00 & \\
\hline \multicolumn{7}{|l|}{ Orange Colored } \\
\hline Vegs & & & & & & $\mathrm{P}=.780$ \\
\hline WIC & 160 & 1.98 & 3.21 & 0 & 21.00 & \\
\hline Non-WIC & 160 & 1.88 & 3.10 & 0 & 21.00 & \\
\hline \multicolumn{7}{|l|}{ Other Vegetables } \\
\hline WIC & 160 & 5.77 & 5.03 & 0 & 28.00 & $\mathrm{P}=.398$ \\
\hline Non-WIC & 160 & 5.27 & 5.54 & 0 & 35.00 & \\
\hline \multicolumn{7}{|l|}{ Self-Efficacy Mean } \\
\hline WIC & 160 & $98.91 * *$ & 17.12 & 36.00 & 120.00 & $\mathrm{P}=.0012$ \\
\hline Non-WIC & 160 & 92.64 & 17.11 & 52.00 & 120.00 & \\
\hline \multicolumn{7}{|l|}{ (POB) Mean } \\
\hline WIC & 160 & $59.11 * *$ & 8.67 & 37.00 & 75.00 & $\mathrm{P}=.0005$ \\
\hline Non-WIC & 160 & 55.88 & 7.70 & 37.00 & 75.00 & \\
\hline
\end{tabular}

** Indicates the differences between the mean was statistically significant $\mathrm{p}<.05$. 


\section{Hypothesis I}

Hypothesis one tested the bivariate relationship between the predictor variables of total nutrition education, self-efficacy to consume fruit and vegetables, and the predictor to eat healthy foods (POB) to the dependent variables of fruit and vegetable consumption.

Participants in this study were asked six questions about their consumption: two questions about their average fruit consumption and four questions about their vegetable consumption. Study participants' answers ranged from times per day, week, or month; these responses were calculated to provide the weekly average consumption. Study participants were asked about fruit and vegetable consumption in six areas: consumption

of fruit, $100 \%$ fruit juices, dark leafy greens, beans and lentils, orange colored vegetables, and other vegetables.

This hypothesis was evaluated using data from 320 study participants. Bivariate correlations were conducted to assess the relationship and direction between the average weekly consumption rate of fruit and vegetables and self-efficacy, nutrition education programs, and POB. The correlation assessments were conducted using Pearson's correlation coefficient (r). The results of the correlations are summarized in table 14. 
Table 14: Bivariate Correlation Results for POB, Self-efficacy and Education with Fruit and Vegetable Consumption

\begin{tabular}{ccccccc}
\hline Variable & $\begin{array}{l}\text { (Q22) } \\
\text { Fruit } \\
\text { Juice }\end{array}$ & $\begin{array}{l}(\mathbf{Q} 23) \\
\text { Fruit }\end{array}$ & $\begin{array}{l}(\mathbf{Q 2 4}) \\
\text { Beans }\end{array}$ & $\begin{array}{l}\mathbf{( Q 2 5 )} \\
\text { Dark } \\
\text { Greens }\end{array}$ & $\begin{array}{l}\text { (Q26) } \\
\text { Orange } \\
\text { Vegetables }\end{array}$ & $\begin{array}{l}\text { (Q27) Other } \\
\text { Vegetables }\end{array}$ \\
\hline POB Mean & $.199^{*}$ & $.228^{*}$ & -0.005 & $.119^{*}$ & $.173^{*}$ & $.175^{*}$ \\
$\begin{array}{c}\text { Self- } \\
\text { Efficacy } \\
\text { Mean }\end{array}$ & $.151^{*}$ & $.312^{*}$ & $.157^{*}$ & $.189^{*}$ & $.226^{*}$ & $.223^{*}$ \\
$\begin{array}{c}\text { Total } \\
\text { Education }\end{array}$ & .080 & $.152^{*}$ & 0.0195 & -0.034 & .042 & .071 \\
\end{tabular}

*Correlation significant levels set at $\mathrm{p}<.05$

To test the hypothesis that there is no relationship between the predictor variables total nutrition education, self-efficacy to consume fruit and vegetables, and the predictor to eat healthy foods (POB) and fruit and vegetable consumption, a Pearson's correlation coefficient was performed producing the following results: predictor of behavior to eat healthy foods (POB) proved to have significant but small correlations with all of the questions about fruit and vegetable consumption, fruit juice $(r=.199, \mathrm{p}=.0003)$, fruits $(\mathrm{r}$ $=.228, \mathrm{p}=<.0001)$, dark green vegetables $(\mathrm{r}=.119, \mathrm{p}=.032)$, orange vegetables $(\mathrm{r}=$ $.173, \mathrm{p}=.001)$ and other vegetables $(\mathrm{r}=.175, \mathrm{p}=.001)$. This would suggest that the level of self-efficacy to consume fruit and vegetables is positively related to the amount of consumption for fruit, fruit juice, dark green vegetables, orange colored vegetables, and other vegetables for study participants. Although these relationships with POB and consumption of these fruit and vegetables are significant, the correlations for predictor of behavior to eat healthy foods with fruit and vegetable consumption present a weak to 
moderate relationship. The positive correlations between the variables only accounts for a small percentage of the relationship between the variables. There was no significant relationship between the predictor of behavior to eat healthy foods (POB) and the consumption of beans.

The next variable, self-efficacy to consume fruit and vegetables, was assessed against fruit and vegetable consumption. Results of the correlation indicated a significant relationship between the self-efficacy to consume fruit and vegetables with all questions related to fruit and vegetable consumption. Self-efficacy to consume fruit and vegetables had a significant relationship with consumption of $100 \%$ fruit juice $(r=.151, p=.006)$, consumption of fruit $(\mathrm{r}=.312, \mathrm{p}<.0001)$, consumption of beans $(\mathrm{r}=.157, \mathrm{p}=.004)$, dark leafy greens $(r=.189, p=.0007)$, orange colored vegetables $(r=.226, p=<.0001)$, and other vegetables $(\mathrm{r}=.223, \mathrm{p}=<.0001)$. Consumption of fruit had the highest correlation with self-efficacy to consume fruit and vegetables $(r=.312)$, as well as one of the stronger relationships $(\mathrm{p}=.0001)$.

The final correlation measured was total nutrition education with fruit and vegetable consumption. Those respondents who participated in one or more nutrition education program (WIC, EFNEP, SNAP-Ed, other Nutrition Ed) were categorized as having nutrition education, those who participated in no nutrition education programs were categorized as not having nutrition education. Results of the correlation produced only one significant correlation between fruit and vegetable consumption and participation in nutrition education. Results of the analyses produced a significant relationship between total nutrition education and consumption of fruit $(n=320, r=.152$, $\mathrm{p}=.0006)$. There were no other significant relationships between total nutrition education 
and consumption of $100 \%$ fruit juice, beans, dark green vegetables, orange colored vegetables, or other vegetables consumed.

\section{Hypothesis II}

The second Null Hypothesis tested whether a significant difference existed in fruit and vegetable consumption between the WIC and non-WIC participants. This hypothesis evaluated 320 participants, half of which were WIC participants $(n=160)$ and half were non-WIC participants $(\mathrm{n}=160)$. Six separate $\mathrm{t}$-tests were performed to test this hypothesis; the results are summarized in Table 15.

The first t-test compared WIC and non-WIC groups with regards to fruit juice consumption. There was a higher mean consumption of $100 \%$ fruit juice for the WIC group compared to the non-WIC group (4.79 vs. 2.61). The results of the tests reported a $\mathrm{df}=318, \mathrm{t}=3.39, \mathrm{p}=.0008$. Based on the results of the $\mathrm{t}$-test, there was a significant difference in the consumption of $100 \%$ fruit juice between the WIC and non-WIC groups.

The second t-test compared the consumption for fruit between WIC and non-WIC participants in the study. There was a higher mean consumption of fruit for the WIC group compared to the non-WIC group (7.34 vs. 4.22). The results of the tests reported a $\mathrm{df}=318, \mathrm{t}=3.87, \mathrm{p}=.0001$. Based on the results of the t-test, there was a significant difference in the consumption of fruit between the WIC and non-WIC groups.

The third t-test compared the consumption of beans between WIC and non-WIC participants in the study. There was a lower mean consumption of beans in the WIC group compared to the non-WIC group (1.49 vs. 1.96). The results of the test reported a 
$\mathrm{df}=318, \mathrm{t}=-1.47, \mathrm{p}=.141$. Based on the results of the $\mathrm{t}$-test, there is no significant difference in the consumption of beans between the WIC and non-WIC groups.

The fourth t-test compared the dark green vegetables between WIC and non-WIC participants in the study. There was a lower mean consumption of dark green vegetables for WIC group compared to the non-WIC group (3.02 vs. 3.45). The results of the test reported a df $=318, \mathrm{t}=-.87, \mathrm{p}=.382$. Based on the results of the $\mathrm{t}$-test, there was no significant difference in the consumption of dark green vegetables between the WIC and non-WIC groups.

The fifth t-test compared the consumption of orange colored vegetables between WIC and non-WIC participants in the study. There was a higher mean consumption of orange colored vegetables for the WIC group compared to the non-WIC group (1.98 vs. 1.88). The results of the test reported a df $=318, \mathrm{t}=.28, \mathrm{p}=.780$. Based on the results of the t-test, there was no significant difference in the consumption of orange colored vegetables between the WIC and non-WIC groups.

The sixth t-test compared the consumption of other vegetables consumed between WIC and non-WIC participants in the study. There was a higher mean consumption of other vegetables consumed for the WIC group compared to the non-WIC group (5.77 vs. 5.27). The results of the test reported a df $=318, \mathrm{t}=.84, \mathrm{p}=.398$. Based on the results of the t-test, there was no significant difference in the consumption of other vegetables consumed between the WIC and non-WIC groups. Table 15 provides a summary of the results from the t-tests. 
Table 15: Summary of T-Tests Analyzing Fruit and Vegetable Consumption between WIC and non-WIC Groups

$\begin{array}{lllll}\begin{array}{l}\text { Fruit and Vegetable } \\ \text { Consumption }\end{array} & \text { M } & \text { SD } & \text { T } & \text { P }\end{array}$

\begin{tabular}{lllll}
\hline (Q22) 100\% Fruit Juice & & & 3.39 & $.0008^{*}$ \\
WIC & 4.79 & 7.12 & & \\
Non-WIC & 2.61 & 3.96 & & \\
\hline (Q23) Fruit & & & 3.87 & $.0001^{*}$ \\
WIC & 7.34 & 8.88 & & \\
Non-WIC & 4.22 & 4.97 & & \\
\hline (Q24) Beans & & & -1.47 & .141 \\
WIC & 1.49 & 2.24 & & \\
Non-WIC & 1.96 & 3.35 & & .382 \\
\hline (Q25) Dark Green & & & & \\
\hline
\end{tabular}

Vegetables

\begin{tabular}{lcccc} 
WIC & 3.02 & 3.40 & & \\
Non-WIC & 3.45 & 5.27 & & \\
\hline $\begin{array}{l}\text { (Q26) Orange Colored } \\
\text { Vegetables }\end{array}$ & & & .28 & .780 \\
WIC & 1.98 & 3.21 & & \\
$\quad$ Non-WIC & 1.88 & .310 & & \\
\hline (Q27) Other Vegetables & & & .84 & .398 \\
WIC & 5.77 & 5.03 & & \\
Non-WIC & 5.27 & 5.54 & & \\
\hline
\end{tabular}

*Significant levels set at $\mathrm{p}<.05$ 
The table above shows that for the six questions analyzing fruit and vegetable consumption between WIC and non-WIC groups, two of the six reported significant differences (fruit juice and fruit) in consumption between the two groups. The remaining four groups (beans, dark green vegetables, orange colored vegetables and other vegetables) reported no significant difference in consumption between the WIC and nonWIC groups. Given these results and the inability to combine the fruit and vegetable consumption into one score, the null hypothesis is rejected that there is no difference in the consumption of fruit and vegetables between WIC and non-WIC participants. The significant difference between two variables (fruit juice and fruit) allows the alternative hypothesis to be accepted.

\section{Hypothesis III}

The third null hypothesis stated there is no significant difference in the selfefficacy to consume fruit and vegetables between WIC and Non-WIC groups. This hypothesis was evaluated using data from 320 survey participants.

Results of the analysis indicated a higher mean for self-efficacy to consume fruit and vegetables for the WIC group compared to the non-WIC group (98.91 vs. 92.64). The results of the tests reported a $\mathrm{df}=318, \mathrm{t}=3.38, \mathrm{p}=.0012$ (Table 16). Based on the results of the t-test, there is a significant difference in the self-efficacy to consume fruit and vegetables between WIC and non-WIC groups; therefore, the null hypothesis is rejected and the alternative hypothesis is accepted. Individuals who participate in WIC are more 
like to have a higher self-efficacy to consume fruit and vegetables in a difficult situation compared to those individuals who are not WIC participants.

Table 16: T-Tests Analyzing Self-Efficacy to Consume Fruit and Vegetables between WIC and non-WIC Groups

$\begin{array}{lllll}\text { Self-Efficacy To Consume } & \text { N } & \text { M } & \text { SD } & \text { P-Value }\end{array}$
Fruit and Vegetables

\begin{tabular}{lllll}
\hline WIC & 160 & 98.91 & 17.12 & $.0012^{*}$
\end{tabular}

$\begin{array}{llll}\text { Non-WIC } & 160 & 92.64 & 17.11\end{array}$

*Significant levels set at $\mathrm{p}<.05$

\section{Hypothesis IV}

The fourth null hypothesis tested that there was no significant difference in the predictor to eat healthy foods (POB) between WIC and non-WIC groups. This hypothesis was evaluated using data from 320 survey participants.

Results of the analysis indicated a higher POB mean for WIC compared to nonWIC participants in the study (59.11 vs. 55.88). The results of the study reported a $\mathrm{df}=$ $318, \mathrm{t}=3.52, \mathrm{p}=.0005$. Based on the results of the $\mathrm{t}$-test, there was a significant difference in the predictor to eat healthy foods (POB) between WIC and non-WIC groups, and the alternative hypothesis is accepted. Table 17 provides a summary of the analyses of the predictor to eat healthy foods (POB) between WIC and non-WIC groups. 
Table 17: T-Test Analyzing the Predictor of Behavior to Eat Healthy Foods (POB) between WIC and non-WIC groups

$\begin{array}{lllll}\text { Predictor of Behavior to } & \text { N } & \text { M } & \text { SD } & \text { P-Value } \\ \text { Consume Healthy Foods }(\mathrm{POB}) & & & \end{array}$

Consume Healthy Foods (POB)

$.0005^{*}$

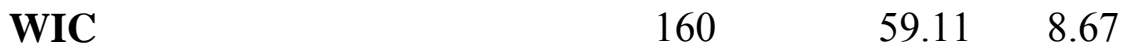

\begin{tabular}{llll}
\hline Non-WIC & 160 & 55.88 & 7.70
\end{tabular}

*Significant levels set at $\mathrm{p}<.05$

In this chapter, a summary of the results of the study analyses was provided. The next chapter discusses the conclusions of the study and the implications the study findings may offer for public health practice. 


\section{CHAPTER V}

\section{CONCLUSION}

\section{Introduction}

Chapter Five presents a discussion about the results from the study. This chapter provides an overview of the study findings and how they may influence future public health practice.

First, the chapter discusses the findings of the descriptive statistics. A discussion of the quantitative results will highlight the study findings, particularly those focusing on the research questions: (1)What is the relationship of federal nutrition education programs (one or more nutrition education programs versus no education programs), selfefficacy to consume fruit and vegetables, and predictor to eat healthy foods with the consumption of fruit and vegetables; (2) Is there a difference in the consumption of fruit and vegetables, the self-efficacy to consume fruit and vegetables, and the predictor to eat healthy foods based on participation in the WIC program? Next, the findings of the study are discussed in relation to the findings in the literature review and theoretical frameworks used in the study. Following this, the study limitations of the study are discussed followed by the study conclusions. This chapter concluded with a discussion of the implications the current study may have on public health practice of the future directions related to this study. 


\section{Study Findings}

\section{Research Question 1:}

What is the relationship of federal nutrition education programs (total nutrition education versus no education), self-efficacy to consume fruit and vegetables, and the predictor to consume healthy foods?

As previously stated, low-income women who participated in nutrition education programs reported higher levels of consumption and had a higher positive association with the consumption of fruits and vegetables compared to those who did not (Ball et al., 2006; Campbell et al., 1999; Eicher-Miller et al., 2009; Guillaumie et al., 2010; Maclellan et al., 2004; L. Williams et al., 2010). This particular question looked at nutrition education as those participating in any of the following programs, WIC, SNAPEd, EFNEP, and other nutrition education. Those who were non-participants of nutrition education did not participate in any of the listed nutrition education programs.

A correlation analysis revealed that participating in one or more of the nutrition education programs in this study (WIC, SNAP-Ed, EFNEP, and other nutrition education) was positively associated with the consumption of fruit for study participants. Although previous research indicate that low-income individuals who participated in nutrition education programs reported higher levels of fruit and vegetable consumption (Ball et al., 2006; Guillaumie et al., 2010; Maclellan et al., 2004; Williams et al., 2010), participation in nutrition education for this particular study was not an important factor in influencing fruit and vegetable consumption for low-income women when examining participation in one or more nutrition education programs compared to not participating 
in any programs. There was only one positive correlation with total nutrition education out of the six fruit and vegetable categories. This correlation was viewed as weak to moderate and just does not support the research literature.

Study findings examining the relationship between predictor of behavior (POB), self-efficacy to consume fruit and vegetables and nutrition education reveal significant relationships. The predictor of behavior to eat healthy food (POB) displayed a significant relationship with the consumption of fruit juice, fruit, dark green vegetables, orange vegetables, and other vegetables (Table 14). Although the POB correlations with fruit and vegetable consumption are significant, they proved to be weak to moderate. The results of this study support the research literature examining constructs of Health Belief Model (components of $\mathrm{POB}$ ) as it relates to attitudes and beliefs about fruit and vegetable consumption. There is a positive association between perceived seriousness, perceived susceptibility, perceived benefits, perceived barriers, cues to action and fruit and vegetable consumption (Guillaumie et al., 2010; Kim et al., 2012; Steptoe et al., 2003; Steptoe et al., 2004). More research would be needed to further examine what type of relationship exists between the POB constructs and fruit and vegetable consumption.

The research examining the relationship between self-efficacy and fruit and vegetable consumption showed positive correlations between fruit and vegetable consumption and self-efficacy. Self-efficacy to consume fruit and vegetables had a significant relationship with all consumption variables: fruit juice, fruit, beans, dark green vegetables, orange colored vegetables, and other vegetables. Study participants who were WIC participants reported higher levels of self-efficacy than non-WIC participants. These results suggest that participating in WIC brings a strong relationship with increased 
consumption of fruit and vegetables for low-income women. Although the results of this hypothesis indicated those with higher levels of self-efficacy are more likely to consume higher amounts of fruits and vegetables, the strength of the significant correlations is weak to moderate at best (Table 14). Results of this study indicated that a significant positive relationship exists between the self-efficacy to consume fruit and vegetables and the predictor of behavior to eat healthy foods (POB). However, the results of the current study does not present a strong argument that self-efficacy to consume fruits and vegetables or individuals with a higher predictor to eat healthy foods (POB) score are more likely to report higher levels of fruit and vegetable consumption, specifically consumption of fruit juice, fruit, beans, dark green vegetables, orange colored vegetables, or other vegetables (Table 14). Results from this study did not support previous research indicating that individuals with a higher self-efficacy to consume fruit and vegetables would be more likely to consume fruit and vegetables (Campbell et al., 1999; Steptoe et al., 2003; Steptoe et al., 2004).

\section{Research Question 2:}

Is there a difference in the consumption of fruit and vegetables, self-efficacy to consume fruit and vegetables, and the predictor of behavior to eat healthy foods (POB) based on participation in the federal Special Supplemental Nutrition Assistance Program for Women and Children (WIC)?

The current WIC program serves an estimated half of all mothers and their infants born in the United States and about $25 \%$ of preschool children (Herman, Harrison, Afifi, \& Jenks, 2008). Based on the results of the study, low-income women who participated 
in WIC consumed a higher weekly average of fruit and vegetables compared to those low-income women who did not participate in WIC.

Women participating in WIC recorded a higher mean of consumption in all of the measured categories. The mean consumption of women participating in the WIC program was higher with fruit juice, fruit, dark green vegetables, orange colored vegetables, and other vegetables. The only category where the mean consumption was lower for WIC participants was with the consumption of beans. The results of the study indicated that only two categories of consumption were significantly different between the groups; those categories were fruit juice and fruit. With this conclusion, women who participated in WIC were more likely to consume higher amounts of fruit juice and fruits compared to those women who were not WIC participants. This conclusion could be attributed to the supplemental services WIC participants receive. WIC participants receive electronic vouchers for food supplements, which include fruit juice, fruit and vegetables.

Future research examining this topic should look closer at the fruit supplements and nutrition education information provided to WIC participants. In this study, all WIC participants receiving services through the Green River District Health Department received nutrition education information along with their WIC vouchers.

The second part of this research question examined whether a difference existed in the self-efficacy to consume fruit and vegetables between low-income women who participated in WIC compared to those who did not. Previous studies have shown that individuals who have a higher self-efficacy to consume fruit and vegetables are more likely to consume higher amounts of fruit and vegetables compared to individuals who report lower levels of self-efficacy (Steptoe et al., 2003; Steptoe et al., 2004; Williams et 
al., 2010). This study concluded that WIC participants had a higher mean in self-efficacy to consume fruit and vegetables compared to the non-WIC participants. The differences in the self-efficacy mean proved to be significant. Individuals who participated in WIC were more likely to have a higher self-efficacy to consume fruit and vegetables in difficult situations. This research does support previous literature stating that participants of WIC programs showed increased consumption of fruit compared to non-WIC participants (Havens et al., 2012; Kropf et al., 2007; Whaley et al., 2012).

The final part of this research question addressed whether a significant difference existed in the predictor to eat healthy foods (POB) between low-income women who participated in WIC compared to those who did not. The predictor of behavior to eat healthy foods (POB) used constructs of the health belief model to assess behavioral intention toward eating healthy foods (Kim et al., 2012). POB assessed perceived susceptibility to nutrition related diseases, perceived benefits of eating healthy foods, benefits and barriers to eating healthy foods and future behavioral intent to consume healthy foods.

Study results indicated that individuals who participated in WIC reported a higher POB mean compared to those individuals who were non-WIC participants. This difference in the mean POB score between groups was significant. The conclusion of the study indicated that individuals who participated in WIC were more likely to have positive values and beliefs and intent to eat healthy foods compared to those individuals who were non-WIC participants. Although this evidence supports other findings showing a relationship between WIC participation and the consumption of fruit, these do not imply causation based on participation in the WIC program. Future research should 
examine the relationship of WIC participation and consumption of fruit and fruit juice with the predictor of behavior to eat healthy foods.

\section{Limitations}

One limitation of this study is that it captures a snapshot of the participants' dietary behavior and fruit and vegetable consumption. Another limitation of this study is only federal nutrition education programs are being examined. The federal nutrition education programs WIC, EFNEP, and SNAP-Ed all have similar goals and objectives, but variability in the program options and delivery modes could limit potential validity of program comparisons. In measuring the predictor of behavior (POB), the instrument includes healthy foods and not just fruits and vegetables. Because conceptually healthy foods may encompass other foods in addition to fruits and vegetables, there may be an error in the measurements, which may affect study results.

Additionally, this study focused on fruit and vegetable consumption but did not include on food availability and access although these two variables influence consumption.

Another limitation of this study was how the fruit and vegetable consumption rate data was collected. The method used in collecting these data did not allow for a combined consumption score to be calculated. Due to this limitation, performing an interaction between total fruit and vegetable consumption and other variables was not feasible. Additionally, this study lack an assessment of the current health status of the study participants; their consumption of alcohol, smoking habits, and their intake of illegal drugs. 


\section{Summary}

Current findings of this study conclude that WIC participation does influence the consumption of fruit. Low income women participating in WIC are more likely to consume fruit and fruit juice and are more likely to report higher levels of self-efficacy to consume fruit and vegetables and report a higher predictor of behavior score to eat healthy foods (POB) compared to those low-income women who are non-WIC participants.

Additionally, the study indicated that individuals who have higher values and beliefs about their ability to eat healthy foods and have a have higher self-efficacy to eat fruit and vegetables during difficult situations are more likely to have higher consumption rates of fruit and vegetables intake compared to individuals who do not. Specifically, this study revealed a significant relationship between self-efficacy to consume fruit and vegetables and predictor of behavior to consume fruit and vegetables with the consumption of fruit and vegetables for low-income women in west Kentucky.

\section{Future Considerations}

Research from the current study has multiple implications for improving fruit and vegetable consumption for low-income women participating in supplemental nutrition assistance programs. Results of this research concluded that low-income women who were WIC participants in this study were more like to consume fruit and fruit juice, were more likely to have higher levels of self-efficacy to consume fruit and vegetables and were more likely to eat healthy foods compared to low-income women who were nonWIC participants. Future work should focus on the relationships between self-efficacy to 
consume fruit and vegetables with attitudes and beliefs toward fruit and vegetable consumption. Additionally, more research is needed to expand the role of the POB constructs and their influence on improving dietary behavior for low-income women participating in supplemental nutrition assistance programs. More research is also needed to further assess the relationship between fruit juice and fruit consumption and the services and supplemental nutrition assistance WIC participants receive. Future research assessing the relationship between these variables should consider logistic regression analysis to further predict the relationship between the variables. 


\section{REFERENCES}

AbuSabha, R., \& Achterberg, C. (1997). Review of self-efficacy and locus of control for nutrition- and health-related behavior. J Am Diet Assoc, 97(10), 1122-1132.

Ball, K., Crawford, D., \& Mishra, G. (2006). Socio-economic inequalities in women's fruit and vegetable intakes: a multilevel study of individual, social and environmental mediators. Public Health Nutr, 9(5), 623-630.

Bandura, A. (1994). Self-Efficacy. The Encyclopedia of Human Behavior, 4(06/1/2015), 71-81. Retrieved from http://www.uky.edu/ eushe2/Bandura/BanEncy.html

Bandura, A., Adams, N. E., \& Beyer, J. (1977). Cognitive processes mediating behavioral change. J Pers Soc Psychol, 35(3), 125-139. Retrieved from http://www.ncbi.nlm.nih.gov/pubmed/15093

Bazzano, L. A., He, J., Ogden, L. G., Loria, C. M., Vupputuri, S., Myers, L., \& Whelton, P. K. (2002). Fruit and vegetable intake and risk of cardiovascular disease in US adults: the first National Health and Nutrition Examination Survey Epidemiologic Follow-up Study. Am J Clin Nutr, 76(1), 93-99. Retrieved from http://www.ncbi.nlm.nih.gov/pubmed/12081821 http://ajcn.nutrition.org/content/76/1/93.full.pdf

Bensley, R. J. a. B.-F., J. (2009). Community Health Education Methods: A Practical Guide (3rd ed.): Jones and Bartlett Publishers.

Binkley, J., \& Golub, A. (2007). Comparison of grocery purchase patterns of diet soda buyers to those of regular soda buyers. Appetite, 49(3), 561-571.

Blitstein, J. L., Evans, W.D. (2006). Use of Nutrition Fact Panels among Adults Who make Household Food Purchasing Decisions. Journal of Nutrition Education and Behavior, 38(6), 360-364.

BRFSS. (2012). Behavioral Risk Factor Surveillance System Questionnaire. Retrieved from http://www.cdc.gov/brfss/questionnaires/pdf-ques/2012_BRFSS.pdf 
Brug, J., Kremers, S. P., Lenthe, F., Ball, K., \& Crawford, D. (2008). Environmental determinants of healthy eating: in need of theory and evidence. Proc Nutr Soc, 67(3), 307-316.

Brug, J., Lechner, L., \& De Vries, H. (1995). Psychosocial determinants of fruit and vegetable consumption. Appetite, 25(3), 285-296.

Campbell, M. K., DeVellis, B. M., Strecher, V. J., Ammerman, A. S., DeVellis, R. F., \& Sandler, R. S. (1994). Improving dietary behavior: the effectiveness of tailored messages in primary care settings. Am J Public Health, 84(5), 783-787. Retrieved from http://www.ncbi.nlm.nih.gov/pubmed/8179049

Campbell, M. K., Honess-Morreale, L., Farrell, D., Carbone, E., \& Brasure, M. (1999). A tailored multimedia nutrition education pilot program for low-income women receiving food assistance. Health Educ Res, 14(2), 257-267. Retrieved from http://www.ncbi.nlm.nih.gov/pubmed/10387505 http://her.oxfordjournals.org/content/14/2/257.full.pdf

Campbell, M. K., McLerran, D., Turner-McGrievy, G., Feng, Z., Havas, S., Sorensen, G., ... Nebeling, L. (2008). Mediation of adult fruit and vegetable consumption in the National 5 A Day for Better Health community studies. Ann Behav Med, $35(1), 49-60$.

Campbell, M. K., Symons, M., Demark-Wahnefried, W., Polhamus, B., Bernhardt, J. M., McClelland, J. W., \& Washington, C. (1998). Stages of change and psychosocial correlates of fruit and vegetable consumption among rural African-American church members. Am J Health Promot, 12(3), 185-191. Retrieved from http://www.ncbi.nlm.nih.gov/pubmed/10176093

CDC. (2012a). Adult Obesity Facts. Retrieved from http://www.cdc.gov/obesity/data/adult.html

CDC. (2012b). Adult Obesity Facts. Retrieved from http://www.cdc.gov/obesity/data/adult.html\#Prevalence

CDC. (2012c). Behavioral Risk Factor Surveillance System Questionnaire Retrieved from http://www.cdc.gov/brfss/questionnaires/pdf-ques/2012_BRFSS.pdf. 
CDC. (2015a). About BMI for Adults. Retrieved from http://www.cdc.gov/healthyweight/assessing/bmi/adult_bmi/index.html

CDC. (2015b). Obesity Prevalence Maps. Retrieved from http://www.cdc.gov/obesity/data/prevalence-maps.html

Census, U. (2008-2012). Selected Economic Characteristics 2008-2012. Retrieved from http://factfinder2.census.gov/faces/tableservices/jsf/pages/productview.xhtml?src $=\mathrm{bkmk}$

Census, U. (2010). US Census: State and County Quickfacts. Retrieved from http://quickfacts.census.gov/qfd/states/21/21059.html

Center, F. R. a. A. (2010). County-by-County Review of SNAP/Food Stamp Participation. Retrieved from http://frac.org/wpcontent/uploads/2010/07/ny_times_snap_poverty_formatted.pdf

Chen, D. Y., \& Gazmararian, J. A. (2014). Impact of personal preference and motivation on fruit and vegetable consumption of WIC-participating mothers and children in Atlanta, GA. J Nutr Educ Behav, 46(1), 62-67.

Cohen, J. (1998). Statistical Powere Analysis for Behavioral Sciences (2nd ed.). New Jersey: Lawrence Erlbaum Associates.

Cullen, K. W., Thompson, D. I., Scott, A. R., Lara-Smalling, A., Watson, K. B., \& Konzelmann, K. (2010). The impact of goal attainment on behavioral and mediating variables among low income women participating in an Expanded Food and Nutrition Education Program intervention study. Appetite, 55(2), 305310 .

Dharod, J. M., Drewette-Card, R., \& Crawford, D. (2011). Development of the Oxford Hills Healthy Moms Project using a social marketing process: a community-based physical activity and nutrition intervention for low-socioeconomic-status mothers in a rural area in Maine. Health Promot Pract, 12(2), 312-321.

DHHS. (2012). Healthy People 2020. Retrieved from http://www.healthypeople.gov/2020/topicsobjectives2020/overview.aspx?topicid $=29$ 
DHHS. (2013). Healthypeople.gov Nutrition, Physical Activity and Obesity. Retrieved from http://www.healthypeople.gov/2020/LHI/nutrition.aspx

Dickin, K. L., Dollahite, J.S., Habicht, J.P. (2005). Nutrition Behavior Change among EFNEP participants is Higher at Sites That are Well Managed and Whose FrontLine Nutrition Educators Value the Program. The Journal of Nutrition, 135(9), 2199-2205. Retrieved from http://jn.nutrition.org/content/135/9/2199.full.pdf

Dinour, L. M., Bergen, D., \& Yeh, M. C. (2007). The food insecurity-obesity paradox: a review of the literature and the role food stamps may play. J Am Diet Assoc, 107(11), 1952-1961.

Division of Nutrition, P. A. a. O. (2012). Overweight and Obesity: Kentucky State Nutrition, Physical Activity and Obesity Profile. Retrieved from http://www.cdc.gov/obesity/stateprograms/fundedstates/pdf/Kentucky-StateProfile.pdf

Do, M., Kattelmann, K., Boeckner, L., Greene, G., White, A., Hoerr, S., . . Nitzke, S. (2008). Low-income young adults report increased variety in fruit and vegetable intake after a stage-tailored intervention. Nutr Res, 28(8), 517-522.

Dollahite, J. S., Olson, C., Scott-Pierce, M. (2003). The Impact of Nutrition Education of Food Insecurity Among Low-Income Participants in EFNEP. Family and Consumer Sciences Research Journal, 32(2), 127-139.

Drewnowski, A., \& Specter, S. E. (2004). Poverty and obesity: the role of energy density and energy costs. American Journal of Clinical Nutrition, 79(1), 6-16.

Drewnowski, A., \& Specter, S. E. (2004). Poverty and obesity: the role of energy density and energy costs. Am J Clin Nutr, 79(1), 6-16. Retrieved from http://www.ncbi.nlm.nih.gov/pubmed/14684391

Dubois, L., Farmer, A., Girard, M., \& Porcherie, M. (2006). Family food insufficiency is related to overweight among preschoolers. Soc Sci Med, 63(6), 1503-1516.

Dubowitz, T., Heron, M., Bird, C. E., Lurie, N., Finch, B. K., Basurto-Davila, R., . . . Escarce, J. J. (2008). Neighborhood socioeconomic status and fruit and vegetable intake among whites, blacks, and Mexican Americans in the United States. Am J Clin Nutr, 87(6), 1883-1891. Retrieved from http://www.ncbi.nlm.nih.gov/pubmed/18541581 
Eicher-Miller, H. A., Mason, A. C., Abbott, A. R., McCabe, G. P., \& Boushey, C. J. (2009). The effect of Food Stamp Nutrition Education on the food insecurity of low-income women participants. J Nutr Educ Behav, 41(3), 161-168.

Erinosho, T., Oh, AY., Moser, RP., Davis, KL., Nebeling LC., Yaroch AL. . (2012). Association Between Perceived Food Environment and Self-Efficacy for Fruit and Vegetable Consumption Among US adults, 2007. Preveting Chronic Disease, 9.

Ettienne-Gittens, R., McKyer, E. L., Odum, M., Diep, C. S., Li, Y., Girimaji, A., \& Murano, P. S. (2013). Rural versus urban Texas WIC participants' fruit and vegetable consumption. Am J Health Behav, 37(1), 130-140.

Flegal, K. M., Carroll, M. D., Kit, B. K., \& Ogden, C. L. (2012). Prevalence of obesity and trends in the distribution of body mass index among US adults, 1999-2010. JAMA, 307(5), 491-497.

Flegal, K. M., Carroll, M. D., Ogden, C. L., \& Curtin, L. R. (2010). Prevalence and trends in obesity among US adults, 1999-2008. JAMA, 303(3), 235-241.

FNS. (2012). Supplemental Nutrition Assistance Program Education Guidance. USDA Retrieved from http://www.nal.usda.gov/fsn/Guidance/FY2013SNAPEdPlanGuidance.pdf.

FNS. (2013a). History of the FNS. Retrieved from http://www.fns.usda.gov/sites/default/files/HISTORY\%20OF\%20FNS.pdf

FNS. (2013b). WIC Annual Participation(By State). Retrieved from http://www.fns.usda.gov/pd/26wifypart.htm

FNS. (2013c). WIC Program Annual Summary. Retrieved from http://www.fns.usda.gov/pd/wisummary.htm

FNS. (2013d). WIC Program Nutrition Education Guidance. Retrieved from http://www.nal.usda.gov/wicworks/Learning_Center/ntredguidance.pdf.

Foundation, A. C. (2011). Women and Children receiving WIC in (Monthly participation). Retrieved from http://datacenter.kidscount.org/data/bystate/Rankings.aspx?state=KY\&ind=1299 
Foundation, A. E. C. (2012). Kids Count Data Center: Monthly (Average ) Kids and Infants recieving WIC Daviess County.

French, S. A., Story, M., \& Jeffery, R. W. (2001). Environmental influences on eating and physical activity. Annu Rev Public Health, 22, 309-335.

doi:10.1146/annurev.publhealth.22.1.309

Glanz, G., Rimer, B.K., and Lewis, F. M. (2002). Health Behavior and Health Education (3rd ed.). San Francisco: Jossey-Bass.

Greene, G. W., Fey-Yensan, N., Padula, C., Rossi, S., Rossi, J. S., \& Clark, P. G. (2004). Differences in psychosocial variables by stage of change for fruits and vegetables in older adults. J Am Diet Assoc, 104(8), 1236-1243.

Grutzmacher, S., \& Gross, S. (2011). Household food security and fruit and vegetable intake among low-income fourth-graders. Journal of Nutrition Education \& Behavior, 43(6), 455-463.

Guenther, P. M., Dodd, K. W., Reedy, J., \& Krebs-Smith, S. M. (2006). Most Americans eat much less than recommended amounts of fruits and vegetables. J Am Diet Assoc, 106(9), 1371-1379.

Guillaumie, L., Godin, G., \& Vezina-Im, L. A. (2010). Psychosocial determinants of fruit and vegetable intake in adult population: a systematic review. Int J Behav Nutr Phys Act, 7, 12.

Guthrie, J. F., Stommes, E., \& Voichick, J. (2006). Evaluating food stamp nutrition education: issues and opportunities. J Nutr Educ Behav, 38(1), 6-11.

Harnack, L., Stang, J., \& Story, M. (1999). Soft drink consumption among US children and adolescents: nutritional consequences. J Am Diet Assoc, 99(4), 436-441.

Havas, S., Anliker, J., Damron, D., Langenberg, P., Ballesteros, M., \& Feldman, R. (1998). Final results of the Maryland WIC 5-A-Day Promotion Program. Am J Public Health, 88(8), 1161-1167.

Havas, S., Anliker, J., Greenberg, D., Block, G., Block, T., Blik, C., . . DiClemente, C. (2003). Final results of the Maryland WIC Food for Life Program. Prev Med, 37(5), 406-416. 
Havas, S., Treiman, K., Langenberg, P., Ballesteros, M., Anliker, J., Damron, D., \& Feldman, R. (1998). Factors associated with fruit and vegetable consumption among women participating in WIC. J Am Diet Assoc, 98(10), 1141-1148.

Havens, E. K., Martin, K. S., Yan, J., Dauser-Forrest, D., \& Ferris, A. M. (2012). Federal nutrition program changes and healthy food availability. Am J Prev Med, 43(4), 419-422.

He, F. J., Nowson, C. A., Lucas, M., \& MacGregor, G. A. (2007). Increased consumption of fruit and vegetables is related to a reduced risk of coronary heart disease: metaanalysis of cohort studies. J Hum Hypertens, 21(9), 717-728.

Herman, D. R., Harrison, G. G., Afifi, A. A., \& Jenks, E. (2008). Effect of a targeted subsidy on intake of fruits and vegetables among low-income women in the Special Supplemental Nutrition Program for Women, Infants, and Children. American Journal of Public Health, 98(1), 98-105.

Herman, D. R., Harrison, G. G., Afifi, A. A., \& Jenks, E. (2008). Effect of a targeted subsidy on intake of fruits and vegetables among low-income women in the Special Supplemental Nutrition Program for Women, Infants, and Children. Am J Public Health, 98(1), 98-105.

Hersey, J., Anliker, J., Miller, C., Mullis, R. M., Daugherty, S., Das, S., . . Olivia, A. H. (2001). Food shopping practices are associated with dietary quality in low-income households. J Nutr Educ, 33 Suppl 1, S16-26.

Hildebrand, D. A., \& Betts, N. M. (2009). Assessment of stage of change, decisional balance, self-efficacy, and use of processes of change of low-income parents for increasing servings of fruits and vegetables to preschool-aged children. J Nutr Educ Behav, 41(2), 110-119.

Hsieh, F. Y., Bloch, D. A., \& Larsen, M. D. (1998). A simple method of sample size calculation for linear and logistic regression. Stat Med, 17(14), 1623-1634.

Hung, H. C., Joshipura, K. J., Jiang, R., Hu, F. B., Hunter, D., Smith-Warner, S. A., . . . Willett, W. C. (2004). Fruit and vegetable intake and risk of major chronic disease. J Natl Cancer Inst, 96(21), 1577-1584.

Inglis, V., Ball, K., \& Crawford, D. (2008). Socioeconomic variations in women's diets: what is the role of perceptions of the local food environment? J Epidemiol Community Health, 62(3), 191-197. 
Jackson, J. E., Doescher, M. P., Jerant, A. F., \& Hart, L. G. (2005). A national study of obesity prevalence and trends by type of rural county. J Rural Health, 21(2), 140148.

Jilcott, S. B., Keyserling, T., Crawford, T., McGuirt, J. T., \& Ammerman, A. S. (2011). Examining associations among obesity and per capita farmers' markets, grocery stores/supermarkets, and supercenters in US counties. Journal of the American Dietetic Association, 111(4), 567-572.

Kant, A. K. (2000). Consumption of energy-dense, nutrient-poor foods by adult Americans: nutritional and health implications. The third National Health and Nutrition Examination Survey, 1988-1994. Am J Clin Nutr, 72(4), 929-936.

Kim, H. S., Ahn, J., \& No, J. K. (2012). Applying the Health Belief Model to college students' health behavior. Nutr Res Pract, 6(6), 551-558.

King, T., Kavanagh, A. M., Jolley, D., Turrell, G., \& Crawford, D. (2006). Weight and place: a multilevel cross-sectional survey of area-level social disadvantage and overweight/obesity in Australia. Int J Obes (Lond), 30(2), 281-287.

Krebs-Smith, S. M., Heimendinger, J., Patterson, B. H., Subar, A. F., Kessler, R., \& Pivonka, E. (1995). Psychosocial factors associated with fruit and vegetable consumption. Am J Health Promot, 10(2), 98-104.

Kropf, M. L., Holben, D. H., Holcomb, J. P., Jr., \& Anderson, H. (2007). Food security status and produce intake and behaviors of Special Supplemental Nutrition Program for Women, Infants, and Children and Farmers' Market Nutrition Program participants. J Am Diet Assoc, 107(11), 1903-1908.

Landers, P. S. (2007). The Food Stamp Program: history, nutrition education, and impact. J Am Diet Assoc, 107(11), 1945-1951.

Larson, N. I., Perry, C. L., Story, M., \& Neumark-Sztainer, D. (2006). Food preparation by young adults is associated with better diet quality. J Am Diet Assoc, 106(12), 2001-2007.

Lorson, B. A., Melgar-Quinonez, H. R., \& Taylor, C. A. (2009). Correlates of fruit and vegetable intakes in US children. J Am Diet Assoc, 109(3), 474-478. 
Lucan, S. C., Barg, F. K., \& Long, J. A. (2010). Promoters and barriers to fruit, vegetable, and fast-food consumption among urban, low-income African Americans--a qualitative approach. Am J Public Health, 100(4), 631-635.

Maclellan, D. L., Gottschall-Pass, K., \& Larsen, R. (2004). Fruit and vegetable consumption: benefits and barriers. Can J Diet Pract Res, 65(3), 101-105.

Mainvil, L. A., Lawson, R., Horwath, C. C., McKenzie, J. E., \& Reeder, A. I. (2009). Validated scales to assess adult self-efficacy to eat fruits and vegetables. Am J Health Promot, 23(3), 210-217.

McLaughlin, C., Tarasuk, V., \& Kreiger, N. (2003). An examination of at-home food preparation activity among low-income, food-insecure women. J Am Diet Assoc, 103(11), 1506-1512.

Medicine, K. I. o. (2007). The Health of Kentucky: A county assessment. . Retrieved from Lexingtion, KY: http://www.kyiom.org/pdf/healthy2007a.pdf

Moore, L. V., Diez Roux, A. V., Nettleton, J. A., Jacobs, D. R., \& Franco, M. (2009). Fast-food consumption, diet quality, and neighborhood exposure to fast food: the multi-ethnic study of atherosclerosis. Am J Epidemiol, 170(1), 29-36.

NCHS. (2010). Obesity and Socioeconomic Status in Adults: United States 2005-2008. Retrieved from http://www.cdc.gov/nchs/data/databriefs/db50.pdf

Nord, M., Andrews, M., \& Carlson, S. (2009). Food Security in the U.S. 2008.

Nord, M., Coleman-Jensen, A., Andrews, M., \& Carlson, S. (2010). Household Food Secuirty in the United States, 2009.

Oberholser, C. A., \& Tuttle, C. R. (2004). Assessment of household food security among food stamp recipient families in Maryland. Am J Public Health, 94(5), 790-795.

Ogden, C. L., Carroll, M. D., Kit, B. K., \& Flegal, K. M. (2012). Prevalence of obesity and trends in body mass index among US children and adolescents, 1999-2010. JAMA, 307(5), 483-490.

Paeratakul, S., Lovejoy, J. C., Ryan, D. H., \& Bray, G. A. (2002). The relation of gender, race and socioeconomic status to obesity and obesity comorbidities in a sample of US adults. Int J Obes Relat Metab Disord, 26(9), 1205-1210. 
Patterson, P. D., Moore, C. G., Probst, J. C., \& Shinogle, J. A. (2004). Obesity and physical inactivity in rural America. J Rural Health, 20(2), 151-159.

Peterson, K. E., Sorensen, G., Pearson, M., Hebert, J. R., Gottlieb, B. R., \& McCormick, M. C. (2002). Design of an intervention addressing multiple levels of influence on dietary and activity patterns of low-income, postpartum women. Health Educ Res, 17(5), 531-540.

Powell, L. M., Han, E., Chaloupka, F.J. (2010). Economic Contextual Factors, Food Consumption and Obesity among U.S. Adolescents. The Journal of Nutrition, 140, 1175-1180.

Putnam, J., Allshouse, J., \& Kantor, S.L. (2002). U.S. Per Capita Food Supply Trends: More Calories, Refined Carbohydrates, and Fats. Food Review, 25(3).

Ruhm, W., \& Walsh, L. (2007). Current risk estimates based on the A-bomb survivors data - a discussion in terms of the ICRP recommendations on the neutron weighting factor. Radiat Prot Dosimetry, 126(1-4), 423-431.

Shaikh, A. R., Yaroch, A. L., Nebeling, L., Yeh, M. C., \& Resnicow, K. (2008). Psychosocial predictors of fruit and vegetable consumption in adults a review of the literature. Am J Prev Med, 34(6), 535-543.

Shankar, S., Klassen, A. C., Garrett-Mayer, E., Houts, P. S., Wang, T., McCarthy, M., . . . Zhang, L. (2007). Evaluation of a nutrition education intervention for women residents of Washington, DC, public housing communities. Health Educ Res, 22(3), 425-437.

Steptoe, A., Perkins-Porras, L., McKay, C., Rink, E., Hilton, S., \& Cappuccio, F. P. (2003). Behavioural counselling to increase consumption of fruit and vegetables in low income adults: randomised trial. BMJ, 326(7394), 855 .

Steptoe, A., Perkins-Porras, L., Rink, E., Hilton, S., \& Cappuccio, F. P. (2004). Psychological and social predictors of changes in fruit and vegetable consumption over 12 months following behavioral and nutrition education counseling. Health Psychol, 23(6), 574-581.

Stewart, H., \& Blisard, D. (2006). The Thrifty Food Plan and Low-Income Households in the United States: What food groups are being neglected. Food Policy, 31, 469482. 
Stewart, H., Hyman, J., Frazao, E., Buzby, J., \& Carlson, A. (2011). Can low-income americans afford to satisfy my pyramid fruit and vegetable guidelines? Journal of Nutrition Education and Behavior, 43(3), 173-179.

Stewart, H., Hyman, J., Frazao, E., Buzby, J. Carlson, A. (2011). Can Low-Income Americans Afford to Satisfy My Pyramid Fruit and Vegetable Guidelines? Journal of Nutrition Education and Behavior, 43(3).

Tarasuk, V., McIntyre, L., \& Li, J. (2007). Low-income women's dietary intakes are sensitive to the depletion of household resources in one month. J Nutr, 137(8), 1980-1987.

Taylor-Powell, E. (2006). Evaluating food stamp nutrition education: a view from the field of program evaluation. J Nutr Educ Behav, 38(1), 12-17.

Townsend, M. S., Johns, M., Shilts, M. K., \& Farfan-Ramirez, L. (2006). Evaluation of a USDA nutrition education program for low-income youth. J Nutr Educ Behav, $38(1), 30-41$.

Turrell, G., Hewitt, B., Patterson, C., \& Oldenburg, B. (2003). Measuring socioeconomic position in dietary research: is choice of socio-economic indicator important? Public Health Nutr, 6(2), 191-200.

USDA. (1983). Expanded Food and Nutrition Education Program Policies. Retrieved from http://www.nifa.usda.gov/nea/food/efnep/pdf/program-policy.pdf.

USDA. (2007). SNAP State Participation Data. Retrieved from http://www.ers.usda.gov/data-products/supplemental-nutrition-assistanceprogram-(snap)-data-system/time-series-data.aspx

USDA. (2010a). Dietary Guidelines for Americans, 2010. Retrieved from http://www.cnpp.usda.gov/publications/dietaryguidelines/2010/policydoc/execsu mm.pdf

USDA. (2010b). Nutrition Program Facts: Supplemental Nutrition Assistance Program Education (SNAP-Ed).

USDA. (2011a). Characteristics of SNAP Households. Washington, DC: Office of Research and Analysis Retrieved from http://www.fns.usda.gov/ora/SNAPCharacteristics/Kentucky/Kentucky.pdf. 
USDA. (2011b). Supplemental Nutrition Assistance Program. Retrieved from http://www.fns.usda.gov/snap/rules/Legislation/about.htm

USDA. (2012). Supplemental nutrition assistance program educational guidance. Retrieved from http://snap.nal.usda.gov/snap/Guidance/FinalFY2015SNAPEdGuidance.pdf.

Vail, A. (2012). EFNEP Kentucky 2012 Profile. Retrieved from http://www2.ca.uky.edu/HES/FCS/NEP/Profiles/EFNEP-profile-2012.pdf

Wardle, J., Waller, J., \& Jarvis, M. J. (2002). Sex differences in the association of socioeconomic status with obesity. Am J Public Health, 92(8), 1299-1304.

Webber, C. B., Sobal J., Dollahite, J.S. (2009). Shoping for fruits and vegetables. Food and retail qualitites of importance to low-income households at the grocery store. Appetite, 54(2), 297-303.

Whaley, S. E., Ritchie, L. D., Spector, P., \& Gomez, J. (2012). Revised WIC food package improves diets of WIC families. J Nutr Educ Behav, 44(3), 204-209.

Wiig, K., \& Smith, C. (2009). The art of grocery shopping on a food stamp budget: factors influencing the food choices of low-income women as they try to make ends meet. Public Health Nutr, 12(10), 1726-1734.

Williams, L., Ball, K., \& Crawford, D. (2010). Why do some socioeconomically disadvantaged women eat better than others? An investigation of the Personal, social and environmental correlates of fruit and vegetable consumption. Journal of Appetite, 55, 441-446.

Williams, L. K., Thornton, L., \& Crawford, D. (2012). Optimising women's diets. An examination of factors that promote healthy eating and reduce the likelihood of unhealthy eating. Appetite, 59(1), 41-46.

Yeh, M. C., Ickes, S. B., Lowenstein, L. M., Shuval, K., Ammerman, A. S., Farris, R., \& Katz, D. L. (2008). Understanding barriers and facilitators of fruit and vegetable consumption among a diverse multi-ethnic population in the USA. Health Promot Int, 23(1), 42-51. 
Zizza, C., Siega-Riz, A. M., \& Popkin, B. M. (2001). Significant increase in young adults' snacking between 1977-1978 and 1994-1996 represents a cause for concern! Prev Med, 32(4), 303-310. 


\section{Individuals Needed for Survey}

Researchers at the University of Louisville seek persons to take a survey on participation nutrition education programs and fruit and vegetable consumption. The survey will ask questions about your health, fruit and vegetable consumption and participation in nutrition education programs.

The survey can be completed on a convenient time for you. The survey will take about 30 minutes to complete. For taking the survey, you will be given a chance to win a $\$ 25$ gift card.

- To be eligible you must be :

○ Female

- a resident of Daviess County, KY

- 18 years of age or older

O able to read write and speak English

○ eligible for SNAP/Food Stamp or WIC program(you don't have to be currently receiving benefits)

To participate or learn more about the study, contact Dr. Muriel Harris, Principal Investigator 502-852-4061, muriel.harris@louisville.edu or CoInvestigator Lewatis McNeal at 270-313-6681, 1dmcne02@1ouisville.edu .

\begin{tabular}{|c|c|c|c|c|c|c|c|}
\hline 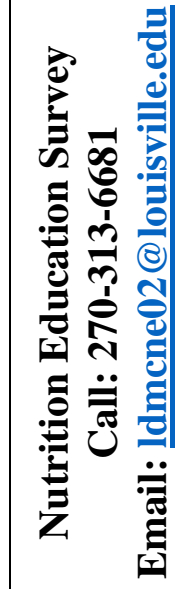 & 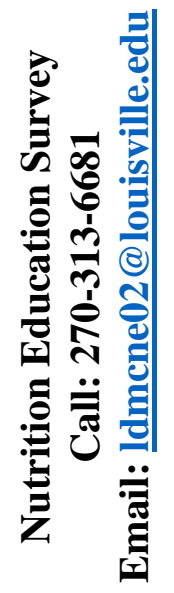 & 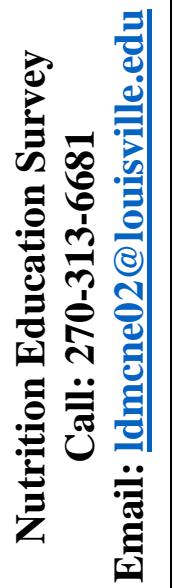 & 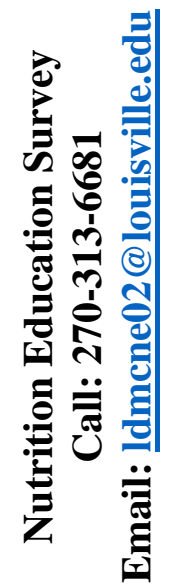 & 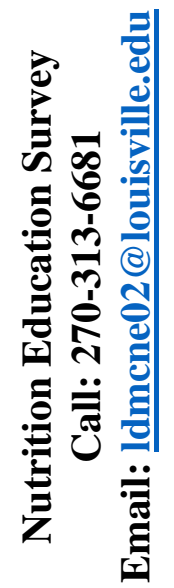 & 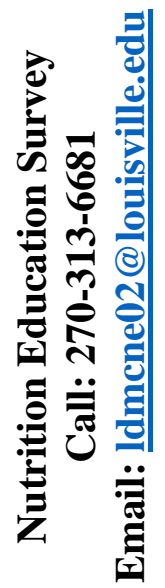 & 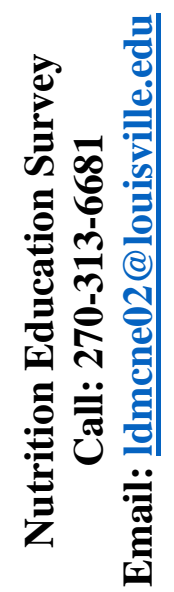 & 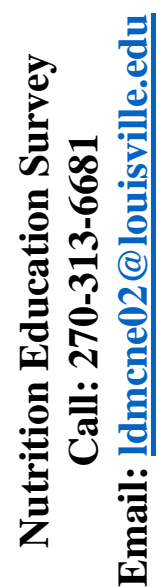 \\
\hline
\end{tabular}


APPENDIX - B

\section{Subject Informed Consent Document}

\section{THE INFLUENCE OF NUTRITION EDUCATION LLEVEL OF PERCEIVED SELF-EFFICACY ON FRUIT AND VEGETABLE CONSUMPTION FOR RURAL LOW-INCOME RESIDENTS IN WEST KENTUCKY}

IRB assigned number:

Investigator(s) name \& address: $\quad$ Muriel Harris, Ph.D.

School of Public Health and Information

Sciences, Room 213

485 East Gray Street, Louisville, KY 40202,

Lewatis D. McNeal, MPH

School of Public Health and Information

Sciences,

485 East Gray Street, Louisville, KY 40202

Sites Where Study is to be conducted: Daviess County Cooperative Extension

Service, Owensboro Community \&

Technical College, H.L. Neblett Community

Center and Green River District Health

Department all in Owensboro, Kentucky

Phone number for subjects to call for questions: $\quad$ 270-313-6681 or 502-852-4061

\section{Introduction and background Information}

You are invited to participate in a research study. The study is being conducted by Dr.

Muriel

Harris, and Lewatis D. McNeal, MPH. This study is sponsored by the University of

Louisville,

Department of Commissions. The study will take place at the University of Louisville

School of

Public Health and Information Sciences. Approximately 400 subjects will be invited to participate in this study.

\section{Purpose}

The purpose of this study to examine the relationship between participation in federal nutrition

education programs and fruit and vegetable consumption for low-income individuals. 
Specifically, how does fruit and vegetable consumption differ for individuals who do and don't participate in WIC program. In addition, how does self-efficacy influence fruit and vegetable consumption. The study will look at relationships between a person's intent to consume healthy foods, their participation in nutrition education programs and their belief in their ability to consume fruit and vegetables.

\section{Procedures}

In this research study, you will be asked to answer questions about your participation in federal supplemental nutrition assistance programs and your participation in federal nutrition education programs. You will also be ask questions about your consumption of fruits and vegetables and about your belief in your ability to consume fruit and vegetables in different situations. Lastly, you will be ask questions about your background. The survey consists of five pages and a total of 71 questions. The survey will take approximately 30 minutes to complete. You may decline to answer any questions that make you feel uncomfortable. This survey and your personal information will be protected, the surveys will be kept in a secured and locked location until the can be retrieved by the study investigator.

\section{Potential Risks}

There are no foreseeable risks other than possible discomfort in answering personal questions. There may also be unforeseen risks.

\section{Benefits}

The information collected for this study may not benefit you directly. The information learned in this study may be helpful to others. The possible benefits of this study include information that will help inform future nutrition education programs that affect fruit and vegetable consumption.

\section{Compensation}

You will be entered into a drawing to be given one of ten $\$ 25$ Wal-Mart gift cards as compensation for your time, inconvenience, or expenses while you are in this study.

Because you will be paid to be in this study the University of Louisville must collect your name, address, social security number, ask you to sign a W-9 form, and keep records of how much you are paid. You may or may not be sent a Form 1099 by the University. This will only happen if you are paid $\$ 600$ or more in one year by the University. We are required by the Internal Revenue Service to collect this information and you may need to report the payment as income on your taxes.

This information will be protected and kept secure in the same way that we protect your other private information. If you do not agree to give us this information, we can't pay 
you for being in this study. You can still be in the study even if you don't want to be paid.

\section{Confidentiality}

Total privacy cannot be guaranteed. Your privacy will be protected to the extent permitted by law. If the results from this study are published, your name will not be made public. While unlikely, the following may look at the study records:

The University of Louisville Institutional Review Board, Human Subjects Protection Program Office, and Privacy Office.

People who are responsible for research and HIPAA oversight at the institutions where the study is conducted Government agencies, such as:

Office for Human Research Protections (OHRP) and Office of Civil Rights.

We will do our best to keep your personal information private. Paper copies of the questionnaires will be kept in a locked file, and a code will be used instead of your name. The code connected to your name will be known only by the principle coordinator and the project coordinator

\section{Voluntary Participation}

Taking part in this study is voluntary. You may choose not to take part at all. If you decide to be in this study you may stop taking part at any time. If you decide not to be in this study or if you stop taking part at any time, you will not lose any benefits for which you may qualify.

\section{Research Subject's Rights, Questions, Concerns, and Complaints}

If you have any concerns or complaints about the study or the study staff, you have three options.

You may contact the principal investigator at 502-852-4061

If you have any questions about your rights as a study subject, questions, concerns or complaints, you may call the Human Subjects Protection Program Office (HSPPO) (502) 852-5188. You may discuss any questions about your rights as a subject, in secret, with a member of the Institutional Review Board (IRB) or the HSPPO staff. The IRB is an independent committee composed of members of the University community, staff of the institutions, as well as lay members of the community not connected with these institutions. The IRB has reviewed this study.

If you want to speak to a person outside the University, you may call 1-877-852-1167. You will be given the chance to talk about any questions, concerns or complaints in 
secret. This is a 24 hour hot line answered by people who do not work at the University of Louisville.

This paper tells you what will happen during the study if you choose to take part. Your signature means that this study has been discussed with you, that your questions have been answered, and that you will take part in the study. This informed consent document is not a contract. You are not giving up any legal rights by signing this informed consent document. You will be given a signed copy of this paper to keep for your records.

Signature of Subject/Legal Representative

Signature of Person Explaining the Consent Form (if other than the Investigator)

Signature of Investigator

LIST OF INVESTIGATORS

Muriel Harris, PhD

Lewatis McNeal, MPH

502-852-4061

270-313-6681
Date Signed

Date Signed

Date Signed

PHONE NUMBERS 


\section{APPENDIX - C}

\section{Questionnaire}

1. What is your age?

2. Is your Ethnicity Hispanic or Latino?

Yes

No

3. What Race do you identify with most?

White

African American/Black

Asian

American Indian/Alaskan Native

Native American/Pacific Islander

Bi-racial/Mixed Race

Other

4. Are you a resident of Daviess County, Kentucky?

Yes

No

5. What is your zip code?

6. How many people live in your household (including you)

7. How many children in your household are under the age of 18 ? 
8. What is your Annual Gross Household Income?

Less than 10,000 per year

$10,000-20,000$ per year

20,000-30,000 per year

Over 30,000 per year

9. What is your current relationship status?
a) Married
b) Divorced
c) Widowed
d) Separated
e) Never Married
f) Single
g) In a Relationship

11. What is your current employment status?
a. Employed for wages
b. Self-employed
c. Unemployed less than six months
d. Unemployed for six months to a year
e. Unemployed one year or longer
f. Homemaker
g. Student
h. Disabled
i. Retired

12. What is your highest level of education attained?
a. $8^{\text {th }}$ grade or less
b. Some high school
c. High School Graduate/GED
d. Some College or Technical School
e. College Graduate (Bachelor's Degree)
f. Graduate Degree

13. What is your current weight? 
14. What is your current height?

15. Are you currently or have you within the last six months received SNAP Benefits (Food Stamps) from the state of Kentucky?
A. Yes
B. No

16. Are you currently or have you within the last six months received WIC Benefits from the state of Kentucky?
A. Yes
B. No

17. Have you received or participated in EFNEP nutrition education programs within the last year?
A. Yes
B. No

18. Have you received or participated in SNAP-Ed nutrition education programs within the last year?
A. Yes
B. No

19. Have you received any nutrition education brochures/information from your local WIC program within the last year?
A. Yes
B. No

20. Have you ever received any nutrition education brochures/information about fruit and vegetables from participating in the SNAP -Ed (Food Stamp) program?
A. Yes
B. No

21. Have you ever received any nutrition education from sources other than SNAPEd, EFNEP or WIC about fruit and vegetables?
A. Yes
B. No 
22. During the past month, how many times per day, week or month did you drink $100 \%$ PURE fruit juices? Do not include fruit-flavored drinks with added sugar or fruit juice you made at home and added sugar to. Only include 100\% juice. (3 questions)

1 - Per day

$2-$ Per week

$3-$ Per month

$5 \overline{5} \overline{5}$ Never

777 Don't know / Not sure

999 Refused

23. During the past month, not counting juice, how many times per day, week, or month did you eat fruit? Count fresh, frozen, or canned fruit (3 questions)

1 _ Per day

$2-$ Per week

3 Per month

$5 \overline{5} \overline{5}$ Never

777 Don't know / Not sure

999 Refused

24. During the past month, how many times per day, week, or month did you eat cooked or canned beans, such as refried, baked, black, garbanzo beans, beans in soup, soybeans, edamame, tofu or lentils. Do NOT include long green beans. (3 questions)

1 _ Per day

2 - Per week

3

555 Never

777 Don't know / Not sure

999 Refused

25. During the past month, how many times per day, week, or month did you eat dark green vegetables for example broccoli or dark leafy greens including romaine, chard, collard greens or spinach?

(3 questions)

1 _ Per day

$2-$ Per week

3 Per month

$5 \overline{5} \overline{5}$ Never

777 Don't know / Not sure

999 Refused 
26. During the past month, how many times per day, week, or month did you eat orange- colored vegetables such as sweet potatoes, pumpkin, winter squash, or carrots?

(3 questions)

1 - Per day

2 - Per week

3 Per month

$5 \overline{5} \overline{5}$ Never

777 Don't know / Not sure

999 Refused

27. Not counting what you just told me about, during the past month, about how many times per day, week, or month did you eat OTHER vegetables? Examples of other vegetables include tomatoes, tomato juice or V-8 juice, corn, eggplant, peas, lettuce, cabbage, and white potatoes that are not fried such as baked or mashed potatoes.

(3 questions)

1 _ Per day

2 Per week

$3-$ Per month

$5 \overline{5} \overline{5}$ Never

777 Don't know / Not sure

999 Refused

The following questions ask about your intent to eat healthy. Please circle the answer that best describes you're your agreement or disagreement with the question asked. With a scale being " 1 " if you strongly disagree with the statement " 5 " is you strongly agree with the statement please choose the answer which best describes how you feel.

28. How worried are you about getting following diseases?
A. Obesity

1

2

3

4

5

Not at All

Not Really Neutral

Somewhat

Concerned

Very

Concerned

Concerned

Concerned 
B. Diabetes

$\begin{array}{lllll}1 & 2 & 3 & 4 & 5\end{array}$

Not at All

Not Really Neutral

Somewhat

Very

Concerned

Concerned

Concerned

Concerned

C. Cardiovascular Disease

1

2

3

4

5

Not at All

Not Really Neutral

Concerned

Somewhat Very

Concerned Concerned

Concerned

Concerned

D. Osteoporosis

1

2

3

4

5

Not at All

Not Really

Neutral

Somewhat

Concerned

Very

Concerned

Concerned

Concerned

29. I believe that vitamin supplements are good for my health

$\begin{array}{clccc}1 & 2 & 3 & 4 & 5 \\ \text { Strongly } & \text { Somewhat } & \text { Neither Agree or } & \text { Somewhat } & \text { Strongly } \\ \text { Disagree } & \text { Disagree } & \text { Disagree } & \text { Agree } & \text { Agree }\end{array}$

30. I believe that healthy food can prevent disease.

$\begin{array}{clccc}1 & 2 & 3 & 4 & 5 \\ \text { Strongly } & \text { Somewhat } & \text { Neither Agree or } & \text { Somewhat } & \text { Strongly } \\ \text { Disagree } & \text { Disagree } & \text { Disagree } & \text { Agree } & \text { Agree }\end{array}$


31. I believe the "My Plate Food Guide" helps me make healthy choices.

$\begin{array}{lllll}1 & 2 & 3 & 4 & 5\end{array}$

Strongly Somewhat Neither Agree or Somewhat Strongly

Disagree Disagree Disagree Agree Agree

32. I believe that nutrition facts food labels help me make healthy choices

$\begin{array}{lllll}1 & 2 & 3 & 4 & 5\end{array}$

Strongly Somewhat Neither Agree or Somewhat Strongly

Disagree Disagree Disagree Agree Agree

33. I believe that eating breakfast is important for my health.

$\begin{array}{llccr}1 & 2 & 3 & 4 & 5 \\ \text { Strongly } & \text { Somewhat } & \text { Neither Agree or } & \text { Somewhat } & \text { Strongly } \\ \text { Disagree } & \text { Disagree } & \text { Disagree } & \text { Agree } & \text { Agree }\end{array}$

34. What I eat is one of the most important things for my health.

$\begin{array}{lllll}1 & 2 & 3 & 4 & 5\end{array}$

Strongly Somewhat Neither Agree or Somewhat Strongly

Disagree Disagree Disagree Agree Agree

35. I have no control over the foods available at my home.

$\begin{array}{llccr}1 & 2 & 3 & 4 & 5 \\ \text { Strongly } & \text { Somewhat } & \text { Neither Agree or } & \text { Somewhat } & \text { Strongly } \\ \text { Disagree } & \text { Disagree } & \text { Disagree } & \text { Agree } & \text { Agree }\end{array}$

36. I have trouble knowing how much I should eat.

$1 \quad 2 \quad 3 \quad 4 \quad 4 \quad 5$

Strongly Somewhat Neither Agree or Somewhat Strongly

Disagree Disagree Disagree Agree Agree 
37. I know I should reduce fat and sugar in my diet but I don't know which foods are best to do this.

$\begin{array}{clccc}1 & 2 & 3 & 4 & 5 \\ \text { Strongly } & \text { Somewhat } & \text { Neither Agree or } & \text { Somewhat } & \text { Strongly } \\ \text { Disagree } & \text { Disagree } & \text { Disagree } & \text { Agree } & \text { Agree }\end{array}$

38. It is difficult to find time to plan healthy meals

$\begin{array}{llccr}1 & 2 & 3 & 4 & 5 \\ \text { Strongly } & \text { Somewhat } & \text { Neither Agree or } & \text { Somewhat } & \text { Strongly } \\ \text { Disagree } & \text { Disagree } & \text { Disagree } & \text { Agree } & \text { Agree }\end{array}$

39. I don't see any benefits from my efforts to eat a healthier diet.

$\begin{array}{llccc}1 & 2 & 3 & 4 & 5 \\ \text { Strongly } & \text { Somewhat } & \text { Neither Agree or } & \text { Somewhat } & \text { Strongly } \\ \text { Disagree } & \text { Disagree } & \text { Disagree } & \text { Agree } & \text { Agree }\end{array}$

40. I have trouble choosing healthy foods when I am out with family or friends.

$\begin{array}{lllrr}1 & 2 & 3 & 4\end{array}$

Strongly Somewhat Neither Agree or Somewhat Strongly

Disagree Disagree Agree Agree

41. The chance I will eat healthy food is high.

$\begin{array}{llccc}1 & 2 & 3 & 4 & 5 \\ \text { Strongly } & \text { Somewhat } & \text { Neither Agree or } & \text { Somewhat } & \text { Strongly } \\ \text { Disagree } & \text { Disagree } & \text { Disagree } & \text { Agree } & \text { Agree }\end{array}$

42. The likelihood that I would recommend the healthy food to a friend is high.

$\begin{array}{llccr}1 & 2 & 3 & 4 & 5 \\ \text { Strongly } & \text { Somewhat } & \text { Neither Agree or } & \text { Somewhat } & \text { Strongly } \\ \text { Disagree } & \text { Disagree } & \text { Disagree } & \text { Agree } & \text { Agree }\end{array}$


43. If I had to eat any type of meal, I would choose a healthy food.

$\begin{array}{llccr}1 & 2 & 3 & 4 & 5 \\ \text { Strongly } & \text { Somewhat } & \text { Neither Agree or } & \text { Somewhat } & \text { Strongly } \\ \text { Disagree } & \text { Disagree } & \text { Disagree } & \text { Agree } & \text { Agree }\end{array}$

The following questions are related to your self-efficacy to consume fruits and vegetables. Please circle the response that best describes how confident you feel about the identified behavior.

44. I can eat vegetables even when I have to prepare them myself.

$\begin{array}{ccccc}1 & 2 & 3 & 4 & 5 \\ \text { Not at All } & \text { Not Very } & \text { Neutral } & \text { Somewhat } & \text { Totally } \\ \text { Confident } & \text { Confident } & & \text { Confident } & \text { Confident }\end{array}$

45. I can eat at least two different vegetables during my main meal on most days.

$\begin{array}{ccccc}1 & 2 & 3 & 4 & 5 \\ \text { Not at All } & \text { Not Very } & \text { Neutral } & \text { Somewhat } & \text { Totally } \\ \text { Confident } & \text { Confident } & & \text { Confident } & \text { Confident }\end{array}$

46. I can eat vegetables even on days when I am in a rush.

$\begin{array}{ccccc}1 & 2 & 3 & 4 & 5 \\ \text { Not at All } & \text { Not Very } & \text { Neutral } & \text { Somewhat } & \text { Totally } \\ \text { Confident } & \text { Confident } & & \text { Confident } & \text { Confident }\end{array}$

47. I can eat vegetables when I am tired and have to prepare them.

1

Not at All

Confident
2

Not Very

Confident
3

Neutral
4

Somewhat

Confident
5

Totally

Confident 
48. I can eat vegetables when they are mixed with other foods, such as stir-fry, casserole, or stew.

$\begin{array}{ccccc}1 & 2 & 3 & 4 & 5 \\ \text { Not at All } & \text { Not Very } & \text { Neutral } & \text { Somewhat } & \text { Totally } \\ \text { Confident } & \text { Confident } & & \text { Confident } & \text { Confident }\end{array}$

49. I can eat vegetables as part of my lunch most days.

$\begin{array}{ccccc}1 & 2 & 3 & 4 & 5 \\ \text { Not at All } & \text { Not Very } & \text { Neutral } & \text { Somewhat } & \text { Totally } \\ \text { Confident } & \text { Confident } & & \text { Confident } & \text { Confident }\end{array}$

50. I can eat vegetables as a snack at least once a day.

$\begin{array}{ccccc}1 & 2 & 3 & 4 & 5 \\ \text { Not at All } & \text { Not Very } & \text { Neutral } & \text { Somewhat } & \text { Totally } \\ \text { Confident } & \text { Confident } & & \text { Confident } & \text { Confident }\end{array}$

51. I can eat fruit as a snack at least once a day.

$\begin{array}{ccccc}1 & 2 & 3 & 4 & 5 \\ \text { Not at All } & \text { Not Very } & \text { Neutral } & \text { Somewhat } & \text { Totally } \\ \text { Confident } & \text { Confident } & & \text { Confident } & \text { Confident }\end{array}$

52. I can eat fruit every day in the winter.

$\begin{array}{ccccc}1 & 2 & 3 & 4 & 5 \\ \text { Not at All } & \text { Not Very } & \text { Neutral } & \text { Somewhat } & \text { Totally } \\ \text { Confident } & \text { Confident } & & \text { Confident } & \text { Confident }\end{array}$

53. I can eat fruit as part of my lunch on most days.

$\begin{array}{ccccc}1 & 2 & 3 & 4 & 5 \\ \text { Not at All } & \text { Not Very } & \text { Neutral } & \text { Somewhat } & \text { Totally } \\ \text { Confident } & \text { Confident } & & \text { Confident } & \text { Confident }\end{array}$


54. I can eat fruit even on days when I am in a rush.

$\begin{array}{ccccc}1 & 2 & 3 & 4 & 5 \\ \text { Not at All } & \text { Not Very } & \text { Neutral } & \text { Somewhat } & \text { Totally } \\ \text { Confident } & \text { Confident } & & \text { Confident } & \text { Confident }\end{array}$

55. I can eat fruit even when the only type available needs to be peeled and cut.

$\begin{array}{ccccc}1 & 2 & 3 & 4 & 5 \\ \text { Not at All } & \text { Not Very } & \text { Neutral } & \text { Somewhat } & \text { Totally } \\ \text { Confident } & \text { Confident } & & \text { Confident } & \text { Confident }\end{array}$

56. I can eat fruit in the morning.

$\begin{array}{ccccc}1 & 2 & 3 & 4 & 5 \\ \text { Not at All } & \text { Not Very } & \text { Neutral } & \text { Somewhat } & \text { Totally } \\ \text { Confident } & \text { Confident } & & \text { Confident } & \text { Confident }\end{array}$

57. I can eat fruit and vegetables even when my favorite ones are of poor quality.

$\begin{array}{ccccc}1 & 2 & 3 & 4 & 5 \\ \text { Not at All } & \text { Not Very } & \text { Neutral } & \text { Somewhat } & \text { Totally } \\ \text { Confident } & \text { Confident } & & \text { Confident } & \text { Confident }\end{array}$

58. I can eat fruit and vegetables at least once a day.

$\begin{array}{ccccc}1 & 2 & 3 & 4 & 5 \\ \text { Not at All } & \text { Not Very } & \text { Neutral } & \text { Somewhat } & \text { Totally } \\ \text { Confident } & \text { Confident } & & \text { Confident } & \text { Confident }\end{array}$

59. I can eat fruit and vegetables when no else is eating them.

$\begin{array}{ccccc}1 & 2 & 3 & 4 & 5 \\ \text { Not at All } & \text { Not Very } & \text { Neutral } & \text { Somewhat } & \text { Totally } \\ \text { Confident } & \text { Confident } & & \text { Confident } & \text { Confident }\end{array}$


60. I can eat fruit and vegetables when I am unsure as to how they are grown.

$\begin{array}{ccccc}1 & 2 & 3 & 4 & 5 \\ \text { Not at All } & \text { Not Very } & \text { Neutral } & \text { Somewhat } & \text { Totally } \\ \text { Confident } & \text { Confident } & & \text { Confident } & \text { Confident }\end{array}$

61. I can eat fruit and vegetables when I am outside the home.

$\begin{array}{ccccc}1 & 2 & 3 & 4 & 5 \\ \text { Not at All } & \text { Not Very } & \text { Neutral } & \text { Somewhat } & \text { Totally } \\ \text { Confident } & \text { Confident } & & \text { Confident } & \text { Confident }\end{array}$

62. I can eat fruit and vegetables when I am eating out.

$\begin{array}{ccccc}1 & 2 & 3 & 4 & 5 \\ \text { Not at All } & \text { Not Very } & \text { Neutral } & \text { Somewhat } & \text { Totally } \\ \text { Confident } & \text { Confident } & & \text { Confident } & \text { Confident }\end{array}$

63. I can still eat fruit and vegetables when I do not have much money.

$\begin{array}{ccccc}1 & 2 & 3 & 4 & 5 \\ \text { Not at All } & \text { Not Very } & \text { Neutral } & \text { Somewhat } & \text { Totally } \\ \text { Confident } & \text { Confident } & & \text { Confident } & \text { Confident }\end{array}$

64. I can eat fruit and vegetables when I am down or depressed.

$\begin{array}{ccccc}1 & 2 & 3 & 4 & 5 \\ \text { Not at All } & \text { Not Very } & \text { Neutral } & \text { Somewhat } & \text { Totally } \\ \text { Confident } & \text { Confident } & & \text { Confident } & \text { Confident }\end{array}$

65. I can eat other fruit and vegetables when my favorite ones are expensive.

$\begin{array}{ccccc}1 & 2 & 3 & 4 & 5 \\ \text { Not at All } & \text { Not Very } & \text { Neutral } & \text { Somewhat } & \text { Totally } \\ \text { Confident } & \text { Confident } & & \text { Confident } & \text { Confident }\end{array}$


66. I can eat fruit and vegetables when I am feeling unwell.

$\begin{array}{ccccc}1 & 2 & 3 & 4 & 5 \\ \text { Not at All } & \text { Not Very } & \text { Neutral } & \text { Somewhat } & \text { Totally } \\ \text { Confident } & \text { Confident } & & \text { Confident } & \text { Confident }\end{array}$

67. I can eat fruit and vegetables when they are homegrown.

$\begin{array}{clccc}1 & 2 & 3 & 4 & 5 \\ \text { Not at All } & \text { Not Very } & \text { Neutral } & \text { Somewhat } & \text { Totally } \\ \text { Confident } & \text { Confident } & & \text { Confident } & \text { Confident }\end{array}$

Thank you for completing this survey. 
APPENDIX D

Approved Kentucky SNAP-Ed programs related nutrition

\begin{tabular}{|c|c|c|}
\hline Title & Author & Description \\
\hline My Plate & USDA & $\begin{array}{l}\text { New Food Guidance } \\
\text { System }\end{array}$ \\
\hline $\begin{array}{l}\text { Loving your Family, } \\
\text { Feeding Their Future }\end{array}$ & FNS & $\begin{array}{l}\text { Curriculum and support } \\
\text { materials foe SNAP } \\
\text { participants }\end{array}$ \\
\hline Money Wise Website & $\begin{array}{l}\text { University of Kentucky } \\
\text { Extension Specialist }\end{array}$ & $\begin{array}{l}\text { Resources on being food } \\
\text { resource wise }\end{array}$ \\
\hline $\begin{array}{l}\text { UK Nutrition Education } \\
\text { Curriculum }\end{array}$ & $\begin{array}{l}\text { UK Cooperative Extension } \\
\text { Service }\end{array}$ & $\begin{array}{l}\text { A Series of } 22 \text { nutrition } \\
\text { lessons for low literacy } \\
\text { audiences. Curriculum } \\
\text { includes teacher guides, } \\
\text { participant fact sheets, } \\
\text { Power point presentation, } \\
\text { scripts with interactive } \\
\text { learning experiences and } \\
\text { downloadable displays }\end{array}$ \\
\hline Weight the Reality Series & $\begin{array}{l}\text { UK Cooperative Extension } \\
\text { Service }\end{array}$ & $\begin{array}{l}\text { A series of } 10 \text { lessons } \\
\text { teaching basic nutrition and } \\
\text { encouraging physical } \\
\text { activity }\end{array}$ \\
\hline Dining with Diabetes & West Virginia Extension & $\begin{array}{l}\text { Curriculum, transparencies, } \\
\text { handouts and recipes }\end{array}$ \\
\hline Wildcat Way to Wellness & $\begin{array}{l}\text { UK Cooperative Extension } \\
\text { Service }\end{array}$ & $\begin{array}{l}\text { Series of lessons including } \\
\text { nutrition and physical } \\
\text { fitness }\end{array}$ \\
\hline Get Moving Kentucky & $\begin{array}{l}\text { UK Cooperative Extension } \\
\text { Service }\end{array}$ & $\begin{array}{l}\text { Series of lessons to } \\
\text { demonstrate and promote } \\
\text { being physically active } \\
\text { each day }\end{array}$ \\
\hline Super Star Chef & $\begin{array}{l}\text { UK Cooperative Extension } \\
\text { Service }\end{array}$ & $\begin{array}{l}\text { Teaches basic cooking and } \\
\text { food preparation skills with } \\
\text { an emphasis on fruits and } \\
\text { vegetables }\end{array}$ \\
\hline Food Safety Materials & $\begin{array}{l}\text { USDA Food Safety and } \\
\text { Inspection Service }\end{array}$ & $\begin{array}{l}\text { Posters, brochures and } \\
\text { magnets }\end{array}$ \\
\hline $\begin{array}{l}\text { Dr. Richter's Fresh } \\
\text { Produce }\end{array}$ & Henry Richter, MD & $\begin{array}{l}\text { In-depth resource book } \\
\text { with more than } 300 \\
\text { varieties of produce full of } \\
\text { color picture }\end{array}$ \\
\hline
\end{tabular}




\begin{tabular}{|l|l|l|}
\hline $\begin{array}{l}\text { Guide to KY Fresh } \\
\text { Vegetables }\end{array}$ & $\begin{array}{l}\text { UK Cooperative Extension } \\
\text { Service }\end{array}$ & $\begin{array}{l}\text { Pamphlet guide of } \\
\text { selecting, preparing and } \\
\text { storing fresh vegetables }\end{array}$ \\
\hline $\begin{array}{l}\text { We Can: Energizing Our } \\
\text { Community }\end{array}$ & $\begin{array}{l}\text { U.S. Health and Human } \\
\text { Services }\end{array}$ & $\begin{array}{l}\text { Curriculum to encourage } \\
\text { parents to get their children } \\
\text { more activity }\end{array}$ \\
\hline Downloadable Displays & NEP Coordinators & $\begin{array}{l}\text { Display on Hand washing, } \\
\text { food safety, food } \\
\text { preservation, dairy, whole } \\
\text { grains and budgeting }\end{array}$ \\
\hline $\begin{array}{l}\text { Taking Ownership of Your } \\
\text { Diabetes }\end{array}$ & $\begin{array}{l}\text { UK Cooperative Extension } \\
\text { Service }\end{array}$ & $\begin{array}{l}\text { Series of lessons helping } \\
\text { individuals manage their } \\
\text { diabetes and includes a } \\
\text { nutrition component, } \\
\text { altering recipes, food } \\
\text { selection and cooking } \\
\text { methods }\end{array}$ \\
\hline $\begin{array}{l}\text { Where Does Your Money } \\
\text { Go? }\end{array}$ & $\begin{array}{l}\text { UK Cooperative Extension } \\
\text { Service }\end{array}$ & $\begin{array}{l}\text { 1 \& 2 hours sessions to } \\
\text { help clients track expenses, } \\
\text { identify money leaks and } \\
\text { develop spending plan }\end{array}$ \\
\hline Making Your Money Work & $\begin{array}{l}\text { UK Cooperative Extension } \\
\text { Service }\end{array}$ & $\begin{array}{l}\text { Series of 6(90minute) } \\
\text { lessons to help become } \\
\text { aware of money } \\
\text { management practices and } \\
\text { take control of finances }\end{array}$ \\
\hline Information provided by Kentucky Cabinet for Families and Children: Vendor contract for SNAP-Ed programs for state of Kentucky \\
\hline
\end{tabular}

(2012) 


\section{APPENDIX E \\ Pre-Screening Questionnaire}

The following questions are related to a doctoral study regarding fruit and vegetable consumption. Please answer the following questions.

1. Do you currently live in Daviess County, Kentucky?
a. Yes
b. No

2. Are you at least 18 years age or older?
a. Yes
b. No

3. Can you complete this survey in English?
a. Yes
b. No

4. In the past 6 months have you received Supplemental Nutrition Assistance?
a. Yes
b. No

5. What is the current size of your household?

6. What is your gross monthly income to be? 


\section{APPENDIX F}

\section{Abbreviations}

\begin{tabular}{|c|c|}
\hline Abbreviation & Word/Phrase \\
\hline BMI & Body Mass Index \\
\hline BRFSS & Behavioral Risk Factor Surveillance System \\
\hline $\mathrm{CDC}$ & Centers for Disease Control and Prevention \\
\hline EFNEP & Expanded Food and Nutrition Education Program \\
\hline FNS & Food Nutrition Service \\
\hline HBM & Health Belief Model \\
\hline $\mathbf{N E}$ & Nutrition Education \\
\hline POB & Predictor of Behavior \\
\hline RNE & Required Nutrition Education \\
\hline SEFVAS & Self-Efficacy, Fruit and Vegetable Assessment Scale \\
\hline SE & Self-Efficacy \\
\hline SNAP & Supplemental Nutrition Assistance Program \\
\hline SNAP-ED & Supplemental Nutrition Assistance Program -Education \\
\hline USDA & United States Department of Agriculture \\
\hline VNE & Voluntary Nutrition Education \\
\hline WIC & $\begin{array}{c}\text { Women Infant and Children(The Special Supplemental } \\
\text { Nutrition Assistance Program) }\end{array}$ \\
\hline
\end{tabular}




\author{
CURRICULUM VITAE \\ Lewatis D. McNeal \\ 2543 Landing Terrace Owensboro, KY 42303 \\ E-Mail: Lewatis@yahoo.com
}

Summary:

Successful educator with experience in teaching public health and in higher education administration. Higher education expertise and experience include strategic enrollment management (SEM), diversity and inclusion, financial aid, academic advising, student retention, transfer student services, graduate advising and student services, budget management, facilities management, distance learning, continuing education and staff supervision.

\title{
Education:
}

University of Louisville

PhD in Public Health Sciences

Concentration: Health Promotion and Behavioral Science

Dissertation: The Influence of Nutrition Education and Self-Efficacy on Fruit and

Vegetable Consumption for Low-Income Women in West Kentucky.

Western Kentucky University

Master of Public Health

University of Arkansas at Pine Bluff B.S. Nutrition/Dietetics

\section{Teaching Experience:}

Adjunct Instructor, Department of Public Health, Western Kentucky University 
Courses lectured include the following undergraduate courses:

- Community Methods for Health Educators

- Health and Aging

- Human Sexuality

\section{Administrative Experience:}

Owensboro Community and Technical College

2012- Current

Associate Dean of Student Affairs

Provide leadership as the chief diversity administrator for the institution, which includes developing and implementing the college's diversity strategic plan as required by the KCTCS System and the state of Kentucky.

Provide Leadership and oversight for student services for multicultural students through the Office of Diversity and International Student Services.

Lead recruitment and retention efforts toward improving workforce diversity at all levels within the college and serve as the college's EEOC Officer.

Developed and implemented programs and services to increase and improve campus LGBT student services for campus community.

Provide leadership and oversight of the Transfer, Retention, Advising and Career Center (TRAC Central).

Provide leadership in strategic enrollment management of diverse student populations. Provide leadership in the retention of a diverse student population, including mentoring and official advising.

Assist the President in representing the college in diverse community settings and enhancing the college's role in global learning and international studies.

Assist Vice President with student grievance issues and violations of student code of conduct.

Implemented a college-wide program for faculty, staff, and students that promotes the critical need for diversity and a greater understanding of all individuals.

Serve as academic advisor for international students and minority/underserved students in academic distress.

Serve as member of numerous committees across departments and programs on campus. Coordinate/oversee international admissions and student services for the campus.

Serve as a school official (DSO) for the certification of international student visas. Advise and mentor underrepresented students at risk of academic or financial aid suspension.

Serve as advisor for Student Government Association (SGA). 
Serve as a member of the Student Affairs Leadership Team (Associate Deans and Directors).

Assist the financial aid department with the student financial aid appeals process (Current Committee Chair).

Working knowledge and experience with relevant student laws and regulations such as FERPA, Clery Act, Title IX, and HIPPA.

\section{Western Kentucky University}

2008-2012

Graduate Advisor/ Student Recruiter

Led community outreach and continuing education initiatives for the WKU-Owensboro campus.

Led advising and recruiting efforts for graduate programs at WKU-Owensboro.

Served as adviser to graduate students at the WKU-Owensboro campus.

Supervised and coordinated campus operations for evening and weekend hours.

Worked with academic departments to coordinate and facilitate academic programs and curriculum changes for undergraduate programs at the WKU Owensboro campus.

Assisted with coordination and implementation of student services for campus.

Assisted campus director with student disciplinary/conduct issues.

Recruited transfer students from area community colleges.

Assisted with marketing and promotion of degree programs for WKU-Owensboro campus. Supervised maintenance, custodial staff, campus facilitators and graduate assistants.

Served as a search committee chair and member for faculty and staff positions for regional campus.

Managed campus facilities and coordinated campus safety operations, OSHA and safety compliance for campus.

Worked with area businesses to create job placement and internship opportunities for WKU-O students.

Coordinated staff and professional development trainings for campus.

Chaired WKU-Owensboro academic scholarship awards committee.

Coordinated education outreach efforts for academic programs and services to regional businesses and industries. 
Coordinated Multiculturalism/diversity programs and services for the WKU-Owensboro campus

\section{University of Kentucky/ Trover Health System}

2007-2008

Coordinator, UK Center for Rural Health

(Job reduced/eliminated due to funding)

Facilitated the development of educational, research and service programs that were consistent with the centers mission of improving health for citizens in rural western Kentucky.

Developed community partnerships that enhanced health care services and promoted health education programs.

Managed Budget and Financial operations for the Madisonville Center for Rural Health. Assisted with physician recruitment and retention for rural and medically underserved areas.

Developed asset mapping for rural counties using GIS programs for rural health programming.

Assist health clinics, physicians and other health facilities in rural counties with development and implementation of an emergency operations plan for their facility.

Coordinated strategic planning for community health programs targeting rural communities. Assisted with grant writing projects for the Center for Rural Health and the Education Division of Trover Health System.

\section{Mississippi State University}

2005- 2006

Body Walk State Program Coordinator

Coordinated program and operation activities the Mississippi Body Walk program.

Designed and implemented in-service training programs for county extension personnel who participated in the Body Walk program.

Delivered mobile exhibit and body walk program to elementary schools across the state of Mississippi. 
Submitted necessary reports and documentation to funding groups and others, as appropriate.

Provided leadership in collecting, analyzing, summarizing and reporting evaluation data and handling all public relation activities associated with the Mississippi Body Walk program.

Designed marketing materials and promotional items associated with including newsletters, brochures, posters and development of website the Mississippi Body program.

\section{University of Kentucky}

Extension Agent for 4-H/Youth Development

Part of a 5 member professional staff operating Daviess County Extension Office.

Served as office fiscal budget coordinator managing a $\$ 700,000$ operating budget.

Coordinated 4-H extension programs for youth in Daviess County that focus on health and life skill development.

Collaborated with community agencies and organizations to provide extension programs.

Co-supervised office staff of seven, directly supervised 4-H program assistants and volunteers.

Recruited and trained volunteers for youth development programs.

Served as local representative for alumni and student recruitment for UK College of Agriculture.

Served as a member of the College of Agriculture's minority recruitment team recruiting students for graduate school, internships and entry-level positions. 